Portland State University

PDXScholar

Fall 11-16-2015

\title{
Fathers Caring for Children with Special Health Care Needs: Experiences of Work-Life Fit
}

Claudia Sellmaier

Portland State University

Follow this and additional works at: https://pdxscholar.library.pdx.edu/open_access_etds

Part of the Social Work Commons

Let us know how access to this document benefits you.

\section{Recommended Citation}

Sellmaier, Claudia, "Fathers Caring for Children with Special Health Care Needs: Experiences of Work-Life Fit" (2015). Dissertations and Theses. Paper 2636.

https://doi.org/10.15760/etd.2632

This Dissertation is brought to you for free and open access. It has been accepted for inclusion in Dissertations and Theses by an authorized administrator of PDXScholar. Please contact us if we can make this document more accessible: pdxscholar@pdx.edu. 
Fathers Caring for Children with Special Health Care Needs:

Experiences of Work-Life Fit

by

Claudia Sellmaier

A dissertation submitted in partial fulfillment of the requirements for the degree of

\author{
Doctor of Philosophy \\ in \\ Social Work and Social Research
}
Dissertation Committee:
Julie Rosenzweig, Chair
Eileen Brennan
Thomas Keller
Maura Kelly
Portland State University
2015


(C) 2015 Claudia Sellmaier 
ABSTRACT

Research about employed fathers of children with special health care needs (SHCN) is still limited, leaving fathers without the necessary workplace and community supports to better integrate work and life. Caregivers with exceptional caregiving responsibilities report greater levels of work-family conflict and considerable caregiver strain, as well as negative employment and financial consequences related to their caregiving responsibilities. These caregivers often struggle to access community supports such as childcare, afterschool care, and support from friends and neighbors.

This study provides insights into the types of job, home, and community resources that are relevant for fathers of children with SHCN in order to better integrate work and family. The exploratory cross-sectional design employed an online survey to collect the data, with 122 fathers meeting the study criteria of living at least part-time with a child with SHCN under the age of 18 and being employed at least part-time. The fathers had a mean age of 42 and most of them identified as Non-Hispanic White. The majority stated holding a college degree and over $90 \%$ reported being married or partnered. Fathers indicated having on average two children and Autism Spectrum Disorder was the most cited diagnosis for the child with SHCN. Regression analyses were conducted to analyze the study's research questions. Access and use of workplace flexibility were significant job resource measures predicting difficulty combining work and family, and spillover. Family flexibility to handle work issues was a significant predictor across all dimensions of positive and negative spillover. The availability of community services was found significantly related to negative 
family to work spillover and support from friends/neighbors was a significant predictor for both difficulty combining work and family, and spillover. Regression analyses with interaction terms of job and home resources showed buffering effects of resource ecologies on spillover.

The study's findings illustrate that, fathers of children with SHCN struggle to integrate work and family even if they are not considered primary caregivers. Community, home, and job resources were salient for these fathers to mitigate a lack of resources across ecologies. This lack of resources tended to reinforce traditional gender norms for both mother and father. Resources within and across the three different ecologies were found to have direct and compensatory effects. Community resources were identified as the most important resources for both positive and negative spillover. The study also highlights the positive spillover effects related to employment and family care for fathers of children with SHCN. Organizations are called to reduce flexibility stigma and decrease barriers to using workplace flexibility to improve work-life fit for fathers caring for children with SHCN. Social services like childcare, or after school care, and social support are of critical relevance and need to better support these fathers and families. Considerations for future research are presented. 


\section{ACKNOWLEDGEMENTS}

I want to say thank you to my family. This journey wouldn't have been possible without their endless support and patience!

I also want to thank my committee chair, Dr. Julie Rosenzweig for her tremendous support throughout this process. I have greatly appreciated her repeated readings of all the drafts. Her ability to ask the big questions and guide me through the finer art of editing has made all the difference.

Thank you also to committee member, Dr. Eileen Brennan, who helped me think and work through all the details of the dissertation methodology and analysis. Her feedback was invaluable in clarifying the dissertation analysis. Her tireless teachings of APA format were greatly appreciated. I also want to acknowledge all my committee members, Dr. Thomas Keller and Dr. Maura Kelly for their guidance in developing my dissertation proposal. Dr. Keller was always available to clarify any analysis questions providing additional support for developing my analysis plan.

Last but not least, I want to say thank you to all my friends pursuing their PhDs, your emotional support was instrumental in finishing this project. I also want to acknowledge all the mentors and great thinkers that influenced my academic development; there wouldn't be any dissertation without you. 


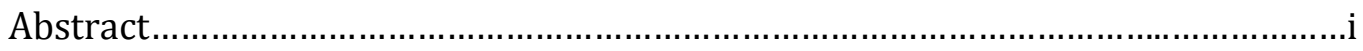

Acknowledgements ................................................................................ii

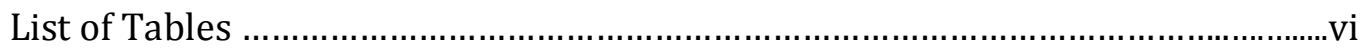

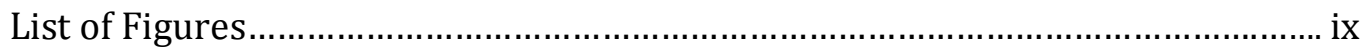

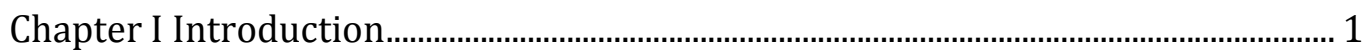

Definitions and prevalence of children with special health care needs................. 1

Need for knowledge about fathers ............................................................................... 3

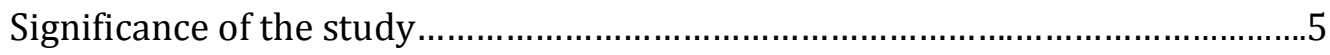

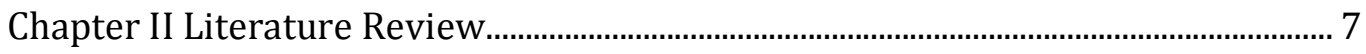

Historical perspective on work, family, and gender ................................................... 7

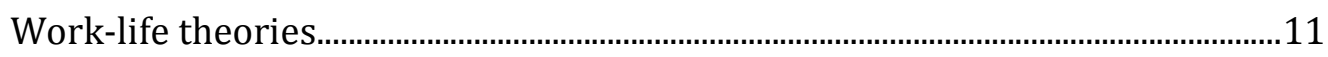

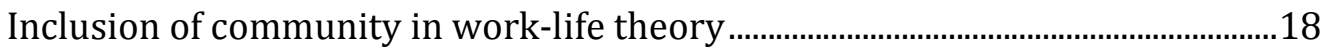

Positive spillover in work-life research .................................................................21

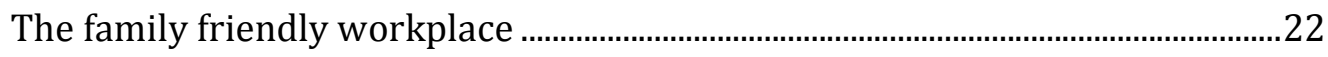

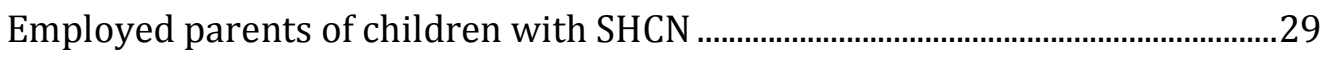

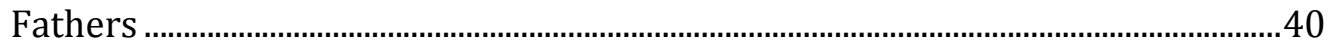

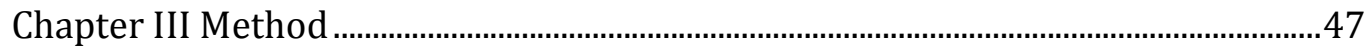

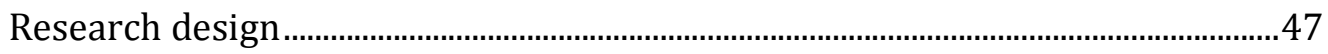

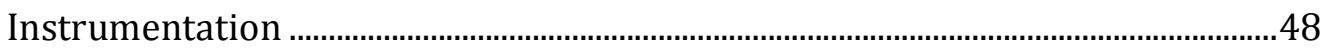

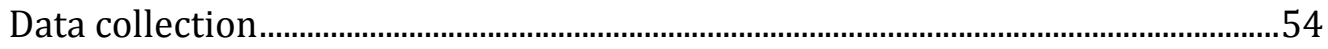

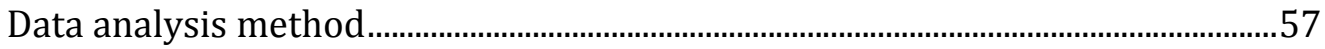

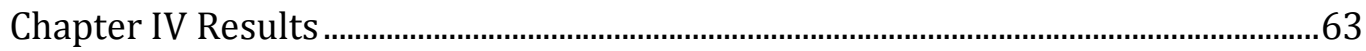


v

Descriptives: Children .........................................................................................63

Descriptives: Resource ecologies, difficulty combining work and family, and spillover

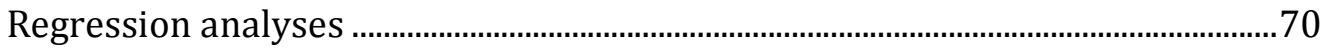

Regression analyses of job, home, community resource indices predicting

difficulty combining work and family and spillover ..................................................80

Regression analysis testing moderating relationships..............................................89

Summary

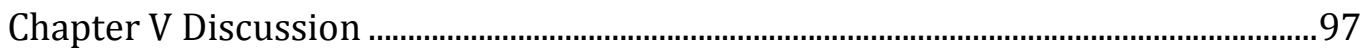

Importance of resources across ecologies for combining work and family

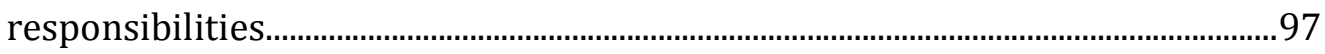

Interconnectedness of resource ecologies-the flexibility puzzle........................... 103

Intensity of exceptional caregiving responsibilities ............................................... 105

The work-family interface: Positive and negative spillover .................................... 105

Study limitations

Implications for theory and organizational policy-practice ................................ 108

Implications for social work practice.......................................................................... 112

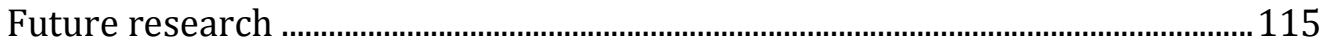

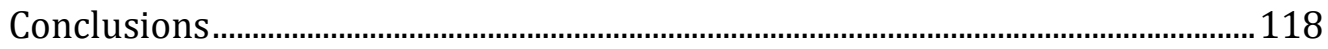

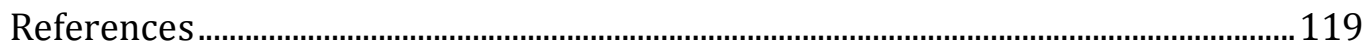

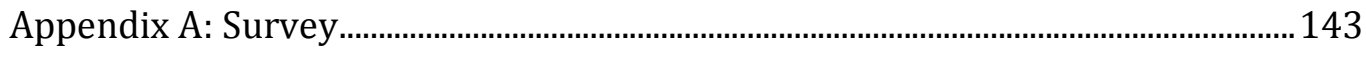

Appendix B: Codebook .............................................................................................. 157

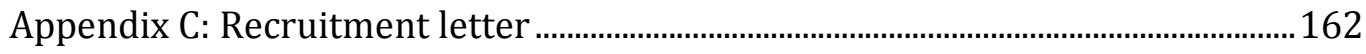




\section{LIST OF TABLES}

Table

1 Father Demographics Including Age, Relationship,

Employment, Education and Income $\quad 57$

$\begin{array}{lll}2 & \text { Index Descriptives } & 60\end{array}$

3 Child Age, Race, Gender, and Symptom Level 64

4 Descriptives: Job Resources, Flexibility, and

$\begin{array}{ll}\text { Career Impact } & 66\end{array}$

5 Descriptives: Home Resources, and Family Flexibility 67

6 Descriptives: Community Services, and

$\begin{array}{ll}\text { Friend/Neighbor Support } & 68\end{array}$

7 Descriptives: Difficulty Combining Work and Family,

$\begin{array}{ll}\text { and Spillover } & 70\end{array}$

8 Correlation of Job Resource Measures and Difficulty Combining

$\begin{array}{ll}\text { Work and Family and Spillover } & 72\end{array}$

9 Regression Job Resource Measures Predicting Difficulty

$\begin{array}{ll}\text { Combining Work and Family and Spillover } & 73\end{array}$

10 Correlations of Home Resource Measures and Difficulty

$\begin{array}{ll}\text { Combining Work and Family and Spillover } & 75\end{array}$

11 Regression Home Resource Measures Predicting Difficulty

Combining Work and Family and Negative Work to

$\begin{array}{ll}\text { Family Spillover } & 76\end{array}$

12 Regression Home Resource Measures Predicting Positive and Negative Family to Work Spillover 
13 Correlations of Community Resource Measures and Difficulty

Combing Work and Family and Spillover

14 Regression Community Resource Measures Predicting Difficulty

Combining Work and Family

15 Regression Community Resource Measures Predicting

Positive Work to Family and Family to Work Spillover

16 Regression Community Resource Measures Predicting Negative

Work to Family and Family to Work Spillover

17 Correlations of Job, Home, and Community Resources and

Demographics

82

18 Correlations of Job, Home, and Community Resources and Difficulty

Combining Work and Family and Spillover

19 Regression Predicting Difficulty Combining Work and Family

with Job, Home, and Community Resources

84

20 Regression Predicting Positive Work to Family Spillover with

Job, Home, and Community Resources

21 Stepwise Regression Predicting Positive Family to Work Spillover

with Job, Home, and Community Resources

22 Stepwise Regression Predicting Negative Work to Family Spillover with Job, Home, and Community Resources

23 Regression Predicting Negative Family to Work Spillover

with Job, Home, and Community Resources

24 Regression of Job, Home, Community Resources on Positive Work to Family Spillover including Job*Home Interaction 


\section{Regression of Job, Home, and Community Resources on Negative}

viii

Family to Work Spillover including Home*Community Interaction 


\section{LIST OF FIGURES}

\section{Figure}

1 Simple Slopes Interaction Job*Home on Positive Work

to Family Spillover

91

2 Simple Slopes Interaction Home*Community on Negative

Family to Work Spillover 


\section{Chapter I}

\section{Introduction}

Historically, work-family research has concentrated on maternal and child outcomes (Perry-Jenkins, Repetti, \& Crouter, 2000) often seeking a greater understanding of the effects of maternal employment on children's development and the experience of role strain for mothers. Contemporary social changes have broadened the research agenda from work-family to work-life (Bianchi \& Milkie, 2010), including a diversity of family structures, addressing socio-economic and racial/ethnic diversity, identifying both negative and positive effects of employment on individuals and gender issues across domains. The role of fathers in the workplace and their work-life issues are more frequently a part of the current work-life research agenda. However, research on fathers' work-life experiences continues to lag far behind that of mothers,' including a lack of specific focus on fathers of children with special health care needs (SHCN). This

dissertation is a response to this lack of empirical research and investigates the work-life fit experiences of fathers who have children with special health care needs.

\section{Definitions and prevalence of children with special health care needs}

There are three conceptualizations relevant for identifying children with health care requirements: (a) children with special health care needs, (b) children with special needs, and (c) children with a disability (Brennan \& Rosenzweig, 2008). According to McPherson, et al. (1998),

Children with special health care needs are those who have or are at increased risk for a chronic physical, developmental, behavioral, or 
FATHERS OF CHILDREN WITH SHCN 2 emotional condition and who also require health and related services of a type and amount beyond that required by children generally (p. 138). This is the most inclusive of the three conceptualizations, identifying broad categories of health and mental health concerns rather than specifying particular health issues. For example, the concept of special needs usually refers to children who have developmental delays or who have been diagnosed with a condition as set forth in the Individual with Disabilities Education Act (IDEA) (20 USC 1401, $\S 602$ 3a). Through this lens, some children with certain health conditions are eligible for special education. Disability as outlined in the American with Disabilities Act (ADA) uses a functional determination. A health condition is considered a disability when the impairment from the condition limits one or more major life activities (ADA, 1990, §12102).

Nearly 60,000 children in the United States have SHCN (National Survey of Children with Special Health Care Needs NSCSHCN, 2009/2010). Twenty-two percent of families in these 48,000 households reported financial difficulties and $15 \%$ reported that one family member had to stop working to take care of the child with SHCN (NS-CSHCN, 2009/2010). These families struggle to find and maintain employment, face the costs associated with their children's care, and suffer from the negative impact of work-family conflict on mental and physical health, and social relationships (Brennan, Rosenzweig, Ogilvie, Wuest, \& Shindo, 2007; Brown, 2014; Corrigan \& Miller, 2004; Earle \& Heymann, 2011; Powers, 2003; Stewart, 2013). 


\section{Need for knowledge about fathers}

The 2008 National Study of the Changing Workforce found in their nationally representative survey increasing levels of work-family conflict compared to 1977, especially for men (Aumann, Galinsky, \& Matos, 2011). This finding is due in part to fathers taking a more active role in household chores and childcare while maintaining full-time employment. Mothers' levels of workfamily conflict remained fairly stable over the last 30 years (Aumann et al., 2011). Fathers now report similar or greater levels of work-family conflict as mothers. Unfortunately, research focusing on fathers in general remains limited (Aumann et al., 2011; Barnett \& Gareis, 2009; Benzies, Harrison, \& Magill-Evans, 2004; Darling, Senatore, \& Strachan, 2012; Harrington, Van Deusen, \& Humberd, 2011; Hill, 2005; Nomaguchi, 2012). Research on caregivers of children with SHCN, for example, is often focused on the mother as primary caregiver (AlYogan, \& Cinamon, 2008; Lewis, Kagan, Heaton, \& Cranshaw, 1999; Powers, 2003; Porterfield, 2002); thus, excluding fathers from studies. Other studies do not identify participants' sex or gender, limiting gender specific conclusions (Brannan \& Heflinger, 2001; Brennan \& Brannan, 2005; Brennan, Rosenzweig, Ogilvie et al., 2007; Brown, 2014; Heiman, 2002; Kuhltau, Smith Hill, Yucel, \& Perrin, 2005). Learning more about fathers' experience of work-life fit is crucial to better support fathers as they face unique gender expectations at work and at home (Williams, 2010). Aumann et al. (2011) summarized these expectations with the concept of the new male mystique. Men are trying to be more active in childcare and household chores while at the same time trying to remain the breadwinners and ideal workers. These changing expectations influence their 
FATHERS OF CHILDREN WITH SHCN 4

experience of work-family conflict and have consequences for their physical and mental health as well as their jobs and personal relationships (Aumann et al., 2011; Towers, 2009; Williams, 2010).

The current study contributes to the knowledge base about the work-life fit of fathers whose children have SHCN. Using the life-course fit model (Moen, 2011) as the theoretical anchor, the primary research questions framing this study include:

1. What type of job ecology resources predicts difficulty combining work and family, and spillover effects for employed fathers of children with SHCN?

2. What type of home ecology resources predicts difficulty combining work and family, and spillover for employed fathers of children with SHCN?

3. What type of community ecology resources predicts difficulty combining work and family, and spillover for employed fathers of children with SHCN?

4. Do job, home, and community resources predict difficulty combining work and family, and positive and negative spillover for employed fathers of children with SHCN?

The second layer of questions addresses the potential interactions between different resource ecologies and potential moderating relationships:

5. Do home resources moderate the effects of job resources on difficulty combining work and family, and spillover for employed fathers of children with SHCN? 
6. Do community resources moderate the effects of home resources on difficulty combining work and family, and spillover for employed fathers of children with SHCN?

7. Do community resources moderate the effects of job resources on difficulty combining work and family, and spillover for employed fathers of children with SHCN?

\section{Significance of the study}

This study builds on existing research surrounding the work-life experiences of fathers in the general population and of parents with exceptional caregiving responsibilities and it extends the existing discourse both theoretically, and practically.

The findings of this dissertation illustrate what types of resources within the job, home, and community ecology are relevant for fathers of children with SHCN. They provide insights into the strategies employed by fathers of children with SHCN to better combine work and family demands and to solve the flexibility puzzle (Emlen, 2010). Knowledge about the type of resources within different ecologies of importance to fathers can be used to develop organizational policies, and strategies to meet the needs of employed fathers of children with SHCN. Learning more about the relevance of community services and friend/neighbor support for working fathers with children with SHCN is highly relevant for social work in order to improve services and better tailor them to the needs of this group of service users.

Looking at the influence of resources within the job, home, and community ecologies as well as at the influence of resource clusters measured as 
resource indices in these ecologies also advances theoretical concepts of worksocial system fit (Barnett, 1998) and life course fit (Moen, 2011). These theories assume that individuals live in different ecologies that are complex and comprised of different conditions, resources, and demands. Employing job, home, and community resource indices is one attempt to address the complexity of life in empirical research and to capture variables as resource patterns of cooccurring conditions "rather than as variables operating "net" of other variables" (Moen, Kelly, \& Huang, 2008a, p. 415). Including interaction terms to investigate moderating relationships provides insights into the complex interplay between resource clusters especially since the examination of these more complex relationships is still rare in empirical work-life research (Allen, 2001; Hill, 2005; Moen, Kelly, \& Huang 2008b; Voydanoff, 2005a) and has been regarded as critical for advancing the field of work-life research (Barnett, 1998).

Research on exceptional caregiving responsibilities is often focused on the challenges associated with these exceptional demands, including the financial costs, negative effects on employment, and work-family conflict (Brown, 2014; Kuhltau et al., 2005; Powers, 2003; Stewart, 2013). This study examines both the difficulty combining work and family, as well as the positive work to family and family to work spillover for fathers (MIDUS, 1995/1996) of children with SHCN. Using measures of negative and positive spillover deepens the understanding of how participation in different ecologies can be problematic and supportive at the same time (Grzywacz \& Marks, 2000; Heinrich, 2007; Kallenbach, 1997). 


\section{Chapter II}

\section{Literature Review}

\section{Historical perspective on work, family, and gender}

The separation of individuals based on gender has been present throughout history and has been significantly reflected in the organization of work life and family life in Western societies since the mid-1800s (Williams, 2000). Females have typically been primary in the role of child rearing and homemaking; and males typically assigned as holding the primary role of paid worker. The separation along gender and domains led to the conceptualization of the ideal worker norms (Williams, 2000, 2010). These norms assume that workers (males) can be totally committed to their work without distraction from family or community responsibilities. Blair-Loy (2001) described this phenomenon as family and work devotion schema. Williams (2010) emphasizes that this social and cultural notion of separate spheres is harmful to both men and women, especially if they cannot live up to these standards. Men who do not adhere to ideal worker norms and standards of masculinity might face discrimination. Fathers who take a leave of absence for family reasons might be less likely to be recommended for organizational promotions (Allen \& Russell, 1999). At the same time, men who adhere to the ideal worker norms might feel resentful of missing their own children's childhood or feel stressed about the burden of being the sole breadwinner (Williams, 2010).

Historic developments. Separate spheres have not always been the cultural norm (Margolis, 1984). During the 1800s production was tied more closely to the home and childrearing was a shared task between fathers, 
mothers, relatives, siblings, and neighbors. Childrearing was more integrated with the tasks of domestic production allowing family members to provide for material needs and supervise children at the same time. Based on religious beliefs women were not thought to be capable of the moral upbringing of the young, which therefore was part of the male dominion (Margolis, 1984; Williams, 2000). Overall, child rearing was a task shared by both parents. With increasing industrialization and urbanization, families moved to cities to pursue more work options leaving the small communities that supported child supervision. The nuclear family became more central than the extended family that included relatives, servants, and neighbors (Margolis, 1984). Industrialization also limited domestic and agricultural production, which resulted in more work outside the home, such as in factories and offices, primarily for men and unmarried women. Religious beliefs about childrearing and the role of parents changed as well. Children were seen as sweet angels who needed the constant nurturing presence of their mothers to develop and thrive, while fathers performed their work duties outside of the home (Margolis, 1984). These developments reified the gendered division of labor with women and mothers as homemakers, and men and fathers as breadwinners (Williams, 2000).

The notion of separate spheres has been a strong normative influence on how society organizes workplaces and values the family. This ideal might have been practiced only by a small number of families, mostly White middle-class families who could afford to live off one income and could not afford nannies for childrearing tasks (Hennessy, 2009; Margolis, 1984). African-American women for example have always had higher labor force participation and held the belief 
that being the provider and breadwinner is integral, not contradictory, to the mother role (Blair-Loy \& Dehart, 2003). Family and work devotion schemas are therefore not universal and may not even be practiced but they still have practical consequences today (Hennessy, 2009).

Practical consequences. Conceptualizing paid work and family as separate spheres and endorsing the associated gendered roles have implications for workplace practices and policies (Acker, 2006; Williams, 2010). Workplaces value face-time, and the flexibility to work overtime and travel at short notice, which are all based on the assumption of the unencumbered worker without any family responsibilities, or with someone at home to care for the children. The lack of policy solutions in the U.S. with regards to schedule flexibility, health insurance, parental leave, taxation, or childcare indicate that family issues are private issues that individuals need to deal with themselves (Palley \& Shdaimah, 2014). These workplace and policy conditions can have serious consequences for fathers raising children with SHCN. Health insurance in the U.S. is often employer-based. Employment is therefore critical to access health insurance and meet the medical needs of the children. The value of face-time and the schema of the committed worker might make fathers reluctant to ask for the flexibility needed to address health crises, as they fear negative career and employment consequences (Harrington et al., 2011).

Dual-earner couples and single parent families are significantly affected by the societal norms of work and family. According to the 2012 Current Population Survey, almost $60 \%$ of parents reported living in dual-earner households (Vespa, Lewis, \& Kreider, 2013). Single parent households accounted 
for $32 \%$ in the census, with $8 \%$ of these single households headed by fathers (PEW Research Center, 2013). Families with exceptional caregiving requirements often need two incomes to cover medical costs and other care costs (Kuhltau et al., 2005; Roundtree \& Lynch, 2011). Parents face significant challenges to find employment, which is suitable to mesh with often unpredictable care needs of their child (Rosenzweig, Barnett, Huffstutter, \& Stewart, 2008).

Childcare. Lack of adequate childcare resources presents a major barrier to finding and sustaining employment. In 2011, 33\% of preschool-aged children in the general population of the U. S. spent time in non-relative care and $19 \%$ of grade school aged children were enrolled in after-school care (Laughlin, 2013). Children spent more time alone at home with increasing age. Families also use relatives as a viable solution to address care needs during work hours; for example $24 \%$ of preschool-aged children in the U.S. were in the care of grandparents (Laughlin, 2013). Adjusting work schedules has been identified as a strategy that allows fathers and mothers to share care responsibilities (Laughlin, 2013). Only 23\% of fathers provided care for their preschool-aged child if mothers worked day-shifts compared to $42 \%$ of fathers providing childcare if mothers worked non-day shifts (Laughlin, 2013). Families caring for children with SHCN use similar strategies but securing adequate childcare is more difficult. One study found that school-aged children with emotional and behavioral issues were more likely to be cared for by immediate family members than extended family or professional childcare providers (Rosenzweig, Brennan, Huffstutter, \& Bradley, 2008). These findings are similar for preschool-aged 
children with SHCN. According to Booth-LaForce and Kelly (2004), preschoolaged children with SHCN started preschool later than peers with typical development, spent less time in preschool, and were more likely to be cared for in informal settings. Finding and keeping quality childcare can be challenging for parents of children with SHCN. Lack of information on available childcare options for children with SHCN or waiting lists for inclusive childcare services are barriers to access (Ceglowski, Logue, Ulrich, \& Gilbert, 2009). Lack of training for childcare providers in general, and specifically for working with children with SHCN, can be another barrier for accessing childcare services and a barrier for maintaining childcare services (Brennan, Bradley, \& Lieberman, 2008; Ceglowski et al., 2009; Knoche, Peterson, Pope Edwards, \& Jeon, 2006).

Parents report not only spending more time at work, they are also reporting to spend more time with their children on work days (Aumann et al., 2011) For example, young fathers (under the age of 29) spent 2.4 hours with their children in 1977 and 4.1 hours in 2008 (Aumann et al., 2011). Family life may have shifted away from the separate spheres model but workplaces have not necessarily adjusted, as suggested by the $49 \%$ of men in the general population reporting work-life conflict (Aumann et al., 2011). Recent surveys do not explicitly reflect the work-life challenges experienced by fathers of children with SHCN, which is likely to be higher because of the additional family demands and the lack of adequate resources and services.

\section{Work-life theories}

Role strain and conflict. The work-family interface has been studied across disciplines, such as occupational health, psychology, sociology, and social 
work. Different theories have emerged to explain the interactions within and across the domains and underlying mechanisms that produce an array of outcomes for individuals and families. Role strain theories initially dominated the work and family field. Greenhaus and Beutell (1985) developed a theory of work-family conflict that distinguished between time-based, strain-based, and behavior-based conflict. Characteristics of one role can influence an individual's time, strain, or behavior in this role, producing conflict with another role (Greenhaus \& Beutell, 1985). For example, time spent at work is time not available for childcare or household chores. This lack of time for childcare can produce conflict for individuals. These researchers proposed that pressures from work and family must be present to cause work-family conflict. Also, posited was the assumption that individuals' perceptions of the demands within a specific role contributed to work-family conflict. As such, conflict would increase if the role were salient for the person (Greenhaus \& Beutell, 1985). For example, men who are considered work-centric, meaning for whom the work role is very salient, reported more work-family conflict (Aumann et al., 2011). Greenhaus and Beutell (1985) also argued that role conflict would be greater for individuals who face negative repercussions for not meeting role demands. The extent to which work-family conflict would be experienced is related to the stage of the career in which people find themselves, to their drive for success, and the support systems available. These theoretical considerations illustrate that workfamily conflict might not only be due to the specific demands, but also to the characteristics of the individual. This theory explains how the demands of one role can influence the quality and performance in another role but does not 
specifically address positive spillover of one role to the other or the influence of resources on the experience of work-family conflict.

With mounting evidence to the contrary, the conflict model was expanded to include positive spillover and work-family enhancement acknowledging that experiences in one role can positively influence the experience in another role (Barnett 1998, Frone, 2003, Grzywacz \& Marks, 2000, Moen, 2011, Voydanoff, 2005d). Grzywacz and Marks (2000) developed measures of positive and negative work to family spillover and positive and negative family to work spillover. Job or family roles can have both negative and positive spillover simultaneously. For example, employment might involve long work hours and provide a high income at the same time.

The influence of ecological systems theory. As work-life researchers moved toward additional complexity, explanatory theories began to include Bronfenbrenner's ecological systems theory (Grzywacz \& Marks, 2000; Voydanoff, 2007; Moen et al., 2008a, b). Bronfenbrenner's theory $(1977,1986$, 1994) emphasizes the importance of situating the person within the environment. The environment or context influences the linkages between the individual and various systems such as family, work, and community. This model introduced the intricacies and transactional processes involved between work and family in context. Work-family spillover, for instance, may be experienced differently across persons based on environmental factors and individual level variables. Bronfenbrenner also included the significance of the passage of time, both in terms of the life course, as well as historical time, which can influence environments. 
Bronfenbrenner's paradigm identifies different levels within a system, specifically, micro, meso, exo, and chrono. The family is considered a microsystem. A mesosystem occurs when microsystems interact, such as the family and the workplace. An exosystem exerts influence without direct participation. The influence of parental workplaces on child outcomes is an example of exosystems. A community is conceptualized as one of the most influential exosystems. The influence of time, both as historical time and as time related to the life course, is included in the chrono system. Bronfenbrenner's ecological systems theory allows for situating individuals within their environments and accounting for the interactions between different system levels, personal characteristics, and time. For example, Edwards and Rothbart (1999) in their theory about psychological stress highlight the importance of individual appraisals of environmental factors. Individuals may respond to the same situation differently at different times. Person-environment interactions are dependent on objective, environmental aspects and subjective, individual characteristics and values.

Based on Bronfenbrenner's concept of ecological systems theory, Voydanoff $(2002,2005 d, 2005 e)$ proposed a theory of work demands/family resource fit, family demands/work resource fit and work-family balance. The core ideas of this theoretical framework included the assumption that work and family are microsystems that together build a mesosystem. Furthermore, each system provides individuals with certain demands and resources. The better the compatibility between work demands/resources and family demands/resources, the better the work-family fit. Individuals or families also employ boundary- 
spanning strategies to either reduce demands or increase resources to improve work-family balance. For example, in the absence of adequate after-school care the mother of a child with SHCN might reduce her work hours to care for her child after school. According to Voydanoff's model, this boundary-spanning strategy would reduce demands on her time, improve her work-family balance, and increase her family role performance and quality.

Voydanoff (2005a, 2005b, 2005c, 2007) later expanded the theory to include community as a significant microsystem of influence. Voydanoff identifies community as either a geographical location or as a social network. Together, the microsystems of family, work, and community create a mesosystem. Experiences of conflict or facilitation depend on whether or not resources and demands available across microsystems are additive/enhancing or diminishing to each other. Within-domain resources and demands, as opposed to boundary-spanning resources and demands, have different properties. For example, within-domain resources and demands can be attributed solely to the community system such as time spent with friends or support received from neighbors. Boundary-spanning demands and resources are related to two systems such as time spent at work, which influences the availability of time for community activities. Voydanoff also posits that individuals employ communitybased boundary-spanning strategies to either increase resources or decrease demands.

Work-life fit. The more specific concepts of work-social system fit (Barnett, 1998) and life-course fit (Moen, 2011; Moen et al., 2008a, 2008b) have allowed for a greater understanding of individuals' experiences of participating 
across the ecologies of work and family. Barnett (1998) developed her theory of work-social system fit based on a review and critique of previous empirical research. Barnett refuted the assumption long held in work-family research that participation in different domains was automatically problematic, suggesting that long work hours can have positive effects because they provide economic security or because they mean spending less time with tasks experienced as tedious. The quantity of work hours is not considered negative or positive per se, rather whether or not the schedule fits with an employee's needs and wants (Barnett, Gareis, \& Brennan, 1999).

Fit is a dynamic process of adjustment between work conditions and the characteristics of workers and their strategies to meet their own needs, as well as the needs of the other people or entities in their social system, and their interconnections. Accordingly, fit reflects the degree to which workers can realize the various dimensions of their work/social system adaptive strategies, given the options available in the workplace (Barnett, 1998, p. 154).

Fit is, in part, individually determined and can change over time as the needs of individuals and other members of their close social networks change. Fit is also interactive and interpersonal within families. Barnett (1998) distinguishes between distal and proximal conditions that affect adaptive strategies and fit. Distal conditions refer to factors outside the individual such as workplace conditions, policies, and economic factors. Distal conditions can occur on three levels: macroeconomic, social structural, and attitudinal factors; workplace policies and practices; and objective job conditions. Proximal 
conditions include individual characteristics such as age, gender, or race and the individual interpersonal context such as family composition. Proximal and distal conditions influence adaptive strategies and work/social system fit and lead to broader outcomes such as physical and mental health or quality of life. These larger outcomes in turn feed back into and change the distal and proximal conditions (Barnett, 1998).

Similarly, Moen's life course fit concept (2011) includes additional influencing and contextualizing systems (Moen et al., 2008a, 2008b). Life course fit refers to the level of match or mismatch between the demands and resources of relevant microsystems, or ecologies such as family, work, or community. Moen defines life-course fit as "the cognitive assessments by workers or family members of the congruence (or incongruence) between the claims on them and their needs and goals, on the one hand, and available resources on the other" (Moen, 2011, p. 91). Fit is also situated on a continuum depending on various appraisals of match and mismatch, between resources and demands. Similar to adaptive strategies, individuals select and are being selected into certain conditions. Social expectations around the nature of a good worker might lead men to opt out of a more flexible work arrangement to address family needs because of fear of career repercussions (Rudman \& Mescher, 2013; Williams, 2000). Racial and gender discrimination might restrict job mobility leaving individuals in less stable and rewarding employment conditions (Moen, 2011). Individuals therefore respond to certain workplace or family conditions trying to address work-family fit. 
Moen et al. (2008b) incorporate the concepts of home and job ecologies. Job and family conditions are socially structured systems or ecologies that exist in a number of specific clusters. Aspects of workplaces or family life are cooccurring, building specific patterns. The concept of ecologies maintains that multiple measures of resources and demands are necessary to understanding patterning of home and job ecologies, instead of using single variables such as time spent at work as a measure to determine fit. For example, working long hours needs to be evaluated in the context of greater income or having more children in the context of grandparents living in the same household. These different conditions work together to build a more or less demanding job or home ecology. People live and experience very specific home and workplace ecologies based on the existing resources and demands. These ecologies, and not only single variables, in turn influence levels of fit. The theory of life course fit also urges research to go beyond work and family ecologies and to integrate the influence of, for example, the community or larger social structures such as policies or cultural expectations (such as the career mystique) that place exclusive value on job commitments (Moen, 2011).

\section{Inclusion of community in work-life theory}

As illustrated in the previous sections, theoretical concepts expanded over the last 15 years, increasing in complexity by including community as another relevant microsystem. Bookman (2004) conducted an ethnographic study of 40 families working in biotech companies and interviewed them about their experience with community. Families in this study defined community as a geographical region and as a social, relational construct. For some community 
referred to their neighborhood, for others it meant a group of important people, and for others it was a sense of identity or virtual community. Besides these distinctions the concept of community could be summarized as a location and/or as relationships. Another important conclusion of her work is the emphasis on the individual's appraisal of community. For example, participants in the study chose longer commutes because of the high value they placed on their communities of living. Measuring objective demands or resources might therefore be less relevant than addressing the importance of community assets for individuals.

Families not only use services in their communities but successful community integration includes participation in communities (Kagan, Lewis, \& Brennan, 2008). The relationship between individuals and their communities is therefore reciprocal. Pitt-Catsouphes, MacDermid, Schwarz, and Matz (2006) illustrated the positive impact of community assessment, community satisfaction, and use of community strategies on work-family outcomes in their study. Their comprehensive concept of community included access and availability of services, relationships, community policies, and welcoming values. The more positive the overall community assessment, the greater the community satisfaction, and the more extensive the use of community strategies, the greater was family functioning, life satisfaction, and role balance, and the smaller workfamily role conflict.

Access to services in the community has been identified as crucial especially for parents (Sweet, Swisher, \& Moen, 2005). Based on telephone interviews with 17 parents and guardians, Gareis and Barnett (2008) developed 
a community resource fit measure covering services for parents with schoolaged children. The global community resource fit measure was positively correlated with family-work enhancement and the school resource subscale was positively correlated to both work-family and family-work enhancement. In a subsample of 53 married and employed fathers, school resource fit was found to positively influence job role quality and lessen psychological distress. Furthermore, good school resource fit balanced a lack of income and job flexibility (Barnett \& Gareis, 2009).

One study of 193 low-income workers living in a mid-sized city in the southeastern United States distinguished between the influence of partner, child, neighbor, extended family, community, supervisor, and coworker support on time-based and strain-based work-family and family-work conflict (Griggs, Casper, \& Eby, 2013). The results indicated that community support significantly reduced time-based and strain-based work-family conflict and strain-based family-work conflict even when controlling for the other sources of support. Neighbor support was also associated with time-based family-work conflict and extended family support reduced strain-based work-family conflict. Voydanoff (2005b) on the other hand reported in one study with a nationally representative sample that demands of friends positively influenced levels of family-work conflict but support from friends did not significantly reduce familywork conflict. Another study indicated that contact with neighbors and support from friends reduced job stress (Voydanoff, 2005a). It seems important to distinguish between different sources of support and to consider community engagement not only as a source of resources but potentially as producing 
additional demands on families. The relevance of services and social support specifically for caregivers with exceptional caregiving responsibilities will be discussed later in this chapter.

\section{Positive spillover in work-life research}

As mentioned above, theoretical considerations have been expanded over the last decades to include spillover which considers the beneficial effects of participating in multiple roles, such as work and family, in addition to the negative or problematic effects related to participation in multiple roles. This section highlights some of the empirical findings supporting this theoretical conceptualization. Grzywacz and Marks (2000) analyzed a subsample of 1,986 respondents from the nationally representative study of Midlife Development in the United States (MIDUS, 1995/1996). This analysis confirmed that positive and negative work to family, and family to work spillover were distinct aspects of the work-family interface. Work characteristics such as pressure on the job were especially relevant for the negative effects of work on family. Accordingly, workplace resources were a strong predictor of positive work to family spillover. Both family and workplace characteristics were relevant predictors for negative and positive family to work spillover. For example, less support from a partner or other family members, and less decision latitude at work were found to be negatively associated with positive family to work spillover. Additional analyses tried to identify the relationships between negative and positive spillover. For example, Grzywacz and Bass (2003) found that higher levels of negative work to family spillover and lower levels of positive spillover were associated with depression and problem drinking. Negative and positive spillover therefore had 
independent and direct effects on these health outcomes. In comparison, anxiety was better explained through a moderation model with positive spillover buffering the effects of negative spillover on rates of anxiety. Gareis, Barnett, Ertel, and Berkman (2009) showed that the relationships between work to family spillover and family to work spillover follow different models when looking at life satisfaction, mental health, and relationship quality. They found that both negative and positive work to family spillover had direct and independent effects on these outcomes, while positive and negative family to work spillover had buffering effects on these outcomes. The specific effects of positive and negative spillover therefore seem to depend on the outcome measured. Even if the simple additive model was used to predict life satisfaction, mental health, and relationship quality, both negative and positive spillover provided explanatory power, suggesting that positive and negative spillover make unique contributions to work-life fit.

\section{The family friendly workplace}

With increasing attention to work-family conflict and with the growing realization that work-family conflict was not only a women's issue or a private issue, the call for more workplace flexibility and childcare supports grew louder in the 1980s (Moen, 2011). This resulted in an increase in policy and organizational solutions such as the Family and Medical Leave Act (FMLA) of 1993 (PL 103-3; 2007a) or flextime options provided by employers. These organizational changes and policies are called family-friendly workplace supports. These supports are implemented to improve job satisfaction, as well as to reduce work-family conflict and turnover intentions (Hammer, Neal, Newsom, 
Brockwood, \& Colton, 2005). There are three types of family-friendly workplace supports including policies such as flexible work arrangements, services such as resources about childcare options, and benefits such as childcare subsidies (Neal, Chapman, Ingersoll-Dayton, \& Emlen, 1993).

Workplace flexibility. Workplace flexibility typically refers to the ability of individual employees to decide when, where, and how work is accomplished (Hill et al., 2008). Flexibility also encompasses flexibility about time, place, employment conditions, and benefits. Employees might be able to work a compressed work week with four 10-hour days or they might choose to telecommute one day a week. Flexibility solutions try to move away from notions of the ideal worker whose commitment is determined by constant availability and face-time instead of work outcomes and results. Flexibility allows the employee to choose when and where work gets done as long as the outcomes are accomplished. There appears to be an increasing uptake of flexibility policies by organizations and individuals (Kelly et al., 2008). One intervention study with 225 respondents illustrated that fathers significantly increased the days they worked off-site after the introduction of the Results Only Work Environment (ROWE) initiative which tried to change assumptions around where and when work has to take place in order to be considered an effective and committed employee. (Hill, Tranby, Kelly, \& Moen, 2013).

Findings on the effects of flexibility policies on work-family conflict are not conclusive (Eaton, 2003; Hammer et al., 2005; Lapierre \& Allen, 2006). Comparing different studies on availability and use of work-family initiatives resulted in mixed evidence of the positive effects of work-family initiatives on 
work-family conflict and enrichment (Kelly et al., 2008). In general, if studies looked at the use of flexibility they found more consistently positive effects than when looking at the availability of flexibility only. Another meta-analysis distinguished between availability and use as well as flextime and flexplace (Allen, Johnson, Kiburz, \& Shockley, 2013). They found that flextime was a stronger predictor of reducing work-family conflict than flexplace. The use of flexplace policies was a stronger predictor of reduced work-family conflict than availability only, but the availability of flextime policies was a stronger predictor of reduced work-family conflict than use of flextime.

Employees' perceptions of flexibility and schedule control can have overall positive effects on work-family conflict and work-family balance (Kelly et al., 2008). Interestingly, a sense of job control might be even more important for well-being and work-family fit than the actual use of flexibility (Kossek, Lautsch, \& Eaton, 2006). This finding suggests that flexibility needs to mesh with an individual's adaptive strategy to be experienced as beneficial, otherwise an individual may experience work as encroaching on family life as boundaries are too permeable, often exacerbated by the use of modern technologies (Kossek \& Lautsch, 2008).

Similar findings regarding the relevance of workplace flexibility have been reported for families with exceptional caregiving responsibilities. Stewart (2013) reported a positive influence of schedule control on decreasing workfamily conflict for employees with exceptional caregiving responsibilities and that flexibility usage lowered family-work conflict. Brennan, Rosenzweig, Ogilvie et al. (2007) used a general workplace flexibility measure with 60 employed 
caregivers of children with mental health disorders and found greater levels of workplace flexibility predicted greater job satisfaction. One nationally representative study found that access to paid leave for family health needs, and paid sick leave was beneficial for fathers' mental health (Earle \& Heymann, 2011). Additionally, the latitude to decide how tasks get done, work hours, and a sense of having enough time to get work done, have been reported to be beneficial for fathers' mental and overall health in this study.

Several qualitative studies highlight the importance of workplace flexibility for caregivers of children with SHCN (Lewis, Kagan, \& Heaton, 2000b; Rosenzweig, Brennan, \& Ogilvie, 2002). This can involve a variety of strategies such as reducing work hours, switching to a part-time schedule, taking sick or emergency leave, and being able to answer family related phone calls at the workplace. In Lewis et al.'s study both fathers and mothers reported about using flexibility solutions. The 40 participating families talked about the importance of formal flexibility policies and having an organizational climate that promoted the use of flexibility policies. The norms of the ideal worker and associated values appeared deeply ingrained in workplace practices, leaving both managers and parents reluctant to use leave time. Fearing the negative consequences of job loss or burdening co-workers was found to be a barrier to accessing flexibility initiatives (Rosenzweig, Roundtree, \& Huffstutter, 2008).

Supervisor and co-worker support. Existing literature distinguishes between the effects of supportive supervisors, co-workers, and the overall work environment. Favorable perceptions about the supportiveness of supervisors and the overall family-friendly climate of an organization have been found to 
have positive effects on work-family conflict and enrichment, job satisfaction, and turnover intentions (Kelly et al., 2008). Similar to perceptions about flexibility and schedule control, there is less clarity on what constitutes supportive behaviors and how an organization or a supervisor could influence employees' perceptions of a family-friendly work environment. Hammer, Kossek, Anger, Bodner, and Zimmerman (2011) distinguished between four dimensions of supervisor support: emotional, instrumental, role-model behavior, and creative solution seeking to work-family issues. Allen (2001) developed a scale consisting of 14 items to evaluate family-supportive organization perceptions, which determines whether employees experience their organizations as reenforcing ideal worker norms or as supportive of family needs. Allen conceptualized the organizational climate as distinctive from supervisor support. Perceptions of a more family-friendly organization were associated with lower levels of work-family conflict. Supervisor support mediated this relationship, suggesting that supervisor support influences the appraisal of the overall work environment.

Perceptions of supportive workplaces may be different for males and females. Hill (2005) reported in his secondary analysis of data from the National Study of the Changing Workforce that fathers experienced their workplaces as less family supportive than mothers, and fathers experienced lower levels of family-to-work facilitation in more supportive work environments. For mothers the effect worked in the opposite direction. In another study (Nomaguchi, 2012) comparing work-family conflict for single and married mothers and fathers, a family supportive work culture reduced single and especially married fathers' 
levels of home to job conflict, which did not hold true for mothers. These studies indicate the need to develop more knowledge regarding gendered effects of supervisor and workplace support.

Qualitative studies underscore the importance of supportive workplaces for parents caring for a child with special health care needs (Lewis et al., 2000b, Rosenzweig et al., 2002). "Flexibility in terms of latitude to change hours or place of work to fit in with family needs, together with supportive management, were crucial for all the families interviewed" (Lewis et al., 2000b, p. 420). Supervisors that accommodated family needs had a positive impact on fathers' mental health (Earle \& Heymann, 2011) and supervisor support, coworker support, and a family-supportive workplace were associated with reduced work to family conflict for employed family caregivers (Brown, 2014; Stewart, 2013). Workplace culture is of additional importance for caregivers with exceptional care needs. Rosenzweig, Roundtree et al. (2008) found in their study of female caregivers raising children with mental health issues that the level of organizational family friendliness influenced participants' willingness to disclose their child's condition. Fear of stigmatization and negative workplace consequences leads parents to conceal their child's special health care needs which makes it more difficult to access flexibility benefits and adds to the overall strain of raising a child with SHCN.

Flexibility policies and supportive workplaces seem to have a positive effect on work-family conflict for fathers and mothers with and without exceptional caregiving responsibilities but there are also a number of studies that illustrate negative consequences if flexibility is accessed. 
Flexibility stigma. Despite the importance of workplace flexibility and a supportive environment for work-life fit, research suggests that parents face negative consequences or flexibility stigma (Coltrane, Miller, DeHaan, \& Stewart, 2013; Williams, Blair-Loy, \& Berdahl, 2013), when workplace supports are accessed. Fathers who did not follow traditional gender expectations, as exemplified by engaging in family caregiving and domestic chores, reported experiencing more harassment at their workplace than fathers who followed more traditional gender norm expressions (Berdahl \& Moon, 2013). Cech and Blair-Loy (2014) found in their study of 266 faculty members that both fathers and mothers working in disciplines of science, technology, engineering, and mathematics (STEM-sciences) who did not adhere to the ideal worker norms reported flexibility stigma in their academic departments. The experience of flexibility stigma might not only reduce the likelihood of employees accessing flexibility options, but also reduce their level of work-life fit and job satisfaction.

Fathers in the general population reported valuing workplaces that allowed conversations about family matters, although they did not adjust their work schedules after the birth or adoption of a child (Harrington et al., 2011), suggesting that fathers are challenged to blend historical and contemporary expectations of what it means to be a good father.

Workplace resources of flexibility, supervisor and co-worker support, as well as family-friendly work environments are significant contributors to worklife fit. Because of gender stereotypes, accessing these supportive resources might be more difficult for fathers than mothers in general, and exceedingly difficult for fathers with exceptional caregiving responsibilities in particular. 


\section{Employed parents of children with SHCN}

Exceptional caregiving responsibilities. Exceptional caregiving

responsibilities were initially conceptualized to describe the level and type of activities that extend beyond the traditional scope of dependent care for children (Roundtree \& Lynch, 2006). The notion of exceptional caregiving responsibilities now extends beyond care requirements for a child with SHCN to encompass caregiving engagement with adult family members as well, such as an aging parent or a chronically ill partner (Stewart, 2013). Some aspects of exceptional caregiving responsibilities have been identified as being more time intensive, more expensive, and often emergency-driven (Roundtree \& Lynch, 2006). Unlike care for children with typical development, exceptional caregiving responsibilities for children with SHCN often extends across later developmental stages, as youth and young adults often do not gain independence and selfsufficiency, and care can become more demanding. Exceptional caregiving responsibilities are associated with work-family conflict, negative employment outcomes, stress and strain, and stigmatization, which will be described in more detail in the following sections.

Work-family conflict, flexibility, and fit. Exceptional caregiving responsibilities have been reported to increase levels of work-family conflict (Brown, 2014; Stewart, 2013). Stewart (2013) reported in her secondary analysis using data from the National Study of the Changing Workforce that employees with exceptional caregiving responsibilities indicated higher levels of work-family and family-work conflict, and lower levels of family support than parents of children with typical development. The severity of child symptoms 
and the number of children with exceptional care needs in a family were found to influence the level of work-family conflict (Brown, 2014). Similarly, Moen et al. (2008b) reported that families with children experiencing chronic health conditions scored high on home demands and low on home control. Parents within this high demand/low control home ecology reported higher levels of conflict and negative spillover than participants with fewer home demands.

Emlen (2010) compared the achievement of work-family fit to solving a puzzle and flexibility in the work, family, and childcare ecologies as the key variables in finding a solution. Emlen (2010) measured workplace, family, and childcare flexibility in a sample of 862 parents and found that the different sources of flexibility interact. Parents who reported low workplace flexibility tried to compensate for this through family or childcare flexibility. A subsample of 56 parents of children with emotional or behavioral problems reported low levels of workplace and family flexibility, which could not be ameliorated adequately with high childcare flexibility. These caregivers tried to access flexible childcare services but the children's emotional and behavioral challenges made this difficult. The children with emotional and behavioral issues in this sample were 20 times more likely to be expelled from childcare than the children without emotional or behavioral issues in this sample (Emlen, 2010), making it difficult for parents to compensate for low levels of workplace and family flexibility. Caregivers tried to solve the flexibility puzzle and improve fit by accessing resources within job, home, and community ecologies while caregivers of children with SHCN faced additional barriers to a satisfactory solution within all three ecologies. Brennan, Rosenzweig, Ogilvie et al.'s (2007) research also 
found that family flexibility was positively associated with work-family fit and job satisfaction for employed parents of children with mental health conditions.

Employment and financial burden. The majority of studies examining employment find consistently negative effects of exceptional care on the mothers' paid work status and engagement (Baker \& Drapela, 2010; Becker, 2006; Brennan \& Brannan, 2005; Porterfield, 2002; Powers, 2003). BusseWidmann (2005) found that of 580 parents caring for a child with diabetes under the age of 6 years old, $4 \%$ of fathers reduced their work hours and $2 \%$ quit their jobs, compared to $33 \%$ of the mothers making job schedule changes and 21\% quitting employment. Heckmann (2007) and Kallenbach's (2002) findings are similar, reporting that fathers of children with disabilities tend to remain fully employed and less engaged in the day-to-day caretaking. In general, mothers and fathers who provide exceptional care reported in one qualitative study that full-time employment was challenging because of the lack of flexibility and the lack of understanding and support in the workplace, paired with caregiving demands that included unplanned trips to the emergency room or frequent doctor's appointments scheduled during working hours (George, Vickers, Wilkes, \& Barron, 2008).

Reduction of work hours or quitting employment can have significant negative financial consequences for families caring for a child with SHCN (Earle \& Heymann, 2012). The loss of income is especially difficult for families with exceptional caregiving responsibilities who must meet additional expenses, such as out-of-pocket costs for treatment and equipment (Kuhltau et al., 2005; Lukemeyer, Meyers, \& Smeeding, 2000; Lynch \& Dickerson, 2012). According to 
the National Survey on Children with Special Health Care Needs (2009/2010), $21 \%$ of caregivers reported annual out-of-pocket costs between $\$ 250$ and $\$ 500$, and $22 \%$ reported having expenses greater than $\$ 1000$.

Although exceptional caregiving responsibilities and the lack of workplace and community supports make employment and work-life integration more challenging, employed parents also report the positive effects of employment (Becker, 2006; George, Vickers, Wilkes, \& Barron, 2008; Lewis et al., 1999). In these qualitative studies the employed caregivers referred to the emotional, social, and financial benefits of their employment that often go hand in hand. For example, one mother reported that:

Originally [I worked for] financial reasons but I do enjoy going to work now. I wouldn' t like to stay at home all the time. I just enjoy what I do. I do enjoy going to work. I like to get out and it's a change of scenery and to just talk to different people (Lewis et al., 1999, p. 566).

Financial considerations were found to be the primary reason for a parent (often the mother) to seek employment, but these financial benefits were accompanied by emotional benefits as well. Several parents mentioned that they experience their time at work as a time of respite, away from the worries and struggles at home (George et al., 2008; Lewis et al., 1999).

Stress and caregiver strain. Work-family conflict affects psychological and physical well-being, contributing to depression, burn-out and other workrelated stresses, increasing marital and parental stress, and decreasing the quality of family life (Allen, Herst, Bruck, \& Sutton, 2000). 
There is also a growing body of research demonstrating that caregivers of children with emotional and behavioral issues experience greater levels of caregiver strain (Brannan, Heflinger, \& Bickman, 1997). Three types of caregiver strain have been conceptualized: (a) objective caregiver strain, negative effects on the caregiver due to the child's condition; (b) subjective internalizing strain, challenging emotional experiences such as sadness; and (c) subjective externalizing strain, which includes negative feelings directed towards the child, such as anger. Caregivers reporting more strain also reported lower quality of family life and greater general distress (Brannan et al., 1997). Caregivers of children with a diagnosis of Attention Deficit Hyperactivity Disorder (ADHD) also tend to report greater parenting stress and lower family functioning compared to parents of children without an ADHD diagnosis (Kendall, 1998; Schilling, Petermann, \& Hampel, 2006). Earle and Heymann (2011) found that fathers' functional health scores were negatively associated with the number of children with SHCN in their family. Similarly, Darling et al. (2012) reported in their study of 206 participants from an urban center in the middle of the U. S., that fathers caring for children with disabilities had higher levels of parenting and health stress, and lower levels of family coping and life satisfaction compared to fathers of children without disabilities.

Severity of child symptoms and the type of health care needs appear to contribute differentially to the experience of stress. Schuh (2008) found in her study of 100 families that parents of children with mental health difficulties reported higher levels of stress compared to parents of children with a chronic health condition such as arthritis. 
Courtesy stigmatization. Caregivers with exceptional caregiving responsibilities need flexibility solutions that facilitate work-life integration, but frequently face barriers accessing the necessary supports (Stewart, 2013). Without supports, caregivers involuntarily reduce work hours, quit employment, or work in low demand jobs (Brennan \& Brannan, 2005; George et al., 2008; Kuhltau et al., 2005). Employed parents of children with SHCN are reluctant to ask for flexible solutions or emergency leave, because they are concerned about repercussions.

The parents were often overly grateful for any flexibility or "concessions" at work. They were often reluctant to ask for the flexibility they needed, especially if this was regarded as a favour rather than an entitlement, and particularly if jobs were insecure (Lewis et al., 2000b, p. 423).

Parents of children with SHCN often experience courtesy stigmatization (Corrigan \& Miller, 2004). Courtesy stigmatization is a concept describing discrimination and prejudice based on the association with someone from a stigmatized group. Caregivers of children with SHCN have reported experiencing courtesy stigmatization because of their relationship to their child (Ali, Hassiotis, Strydom, \& King, 2012; Corrigan \& Miller, 2004). Negative responses can come from friends, family members, co-workers, supervisors, and community service providers including health and mental health workers (Ali et al., 2012; Angermeyer, Schulze, \& Dietrich, 2003; Larson \& Corrigan, 2008; Corrigan \& Miller, 2004; Power, 2008). Parents of children with SHCN are often blamed by others, including family members or health care providers, for their children's 
behaviors due to poor parenting decisions (Corrigan \& Miller, 2004; Harden, 2005; Ryan, 2005).

Courtesy stigmatization also extends to the workplace leaving caregivers reluctant to seek emotional or instrumental support from supervisors or coworkers (Brennan, Rosenzweig, Malsch, Stewart, \& Conley, 2007). Disclosure of a child's health status within the workplace has been identified as a strategy used by employed caregivers, which can result in both favorable benefits and negative consequences (Brohan, et al., 2012; Munir, Leka, \& Griffiths, 2005; Rosenzweig, Brennan, \& Malsch, 2009). For example, Brohan et al. (2012) reported in their systematic review that disclosure allowed employees with mental health issues to adjust their work schedule or get time off for medical appointments. Disclosure was also experienced as relief for some, because they did not have to invent "cover stories" (Brohan et al., 2012, p. 8) to conceal their difficulties. Another example illustrates the potential negative effects of disclosure, which always have to be considered and negotiated. In disclosing the health status of her son diagnosed with schizophrenia, this mother shares her experience: "My boss showed little understanding for the loss of working hours. My colleagues reacted reserved and could not imagine the burden I had to carry and the experiences I had" (Angermeyer et al., 2003, p. 598). Courtesy stigmatization can contribute to increased levels of stress and strain, adding to the strain associated with exceptional caregiving responsibilities (Ali et al., 2012).

Accessing community-based services. According to the 2009/2010 National Survey of Children with Special Health Care Needs $94 \%$ of children with SHCN used between 2 and 7 health-related services or pieces of equipment, such 
as preventive care, specialty care, mental health services, physical, occupational and speech therapy, hearing aids, or mobility devices. Most parents reported that their child did not have any unmet needs at the time of the survey, however, 34\% indicated experiencing difficulties or delays in accessing services. The primary reasons cited for the delays included costs associated with specific services and the lack of available appointments. Access to services was also less satisfactory for families caring for a child with functional limitations at or above routine needs. Of the participating caregivers, 38\% reported some level of frustration when trying to access services (NS-CSHCN 2009/2010). Bethell et al. (2013) found in their analysis of a nationally representative sample that less than $20 \%$ of children with SHCN received high levels of quality health care, with significant socio-economic disparities in access to quality care. One literature review including studies about a variety of chronic health issues found that children of color had higher rates of chronic health conditions and lower rates of accessing adequate medical care than White children (Berry, Bloom, Foley, \& Palfrey, 2010). Maintaining health insurance is crucial for meeting children's medical needs; $34 \%$ of families reported having inadequate health insurance and 18\% reported avoiding changing jobs in order to maintain health care coverage (NSCSHCN, 2009/2010). Navigating the health care system and dealing with insurance companies is one of the many challenges that make up exceptional caregiving responsibilities (Heiman, 2002; Roundtree \& Lynch, 2006).

Employed parents also face challenges in accessing childcare services. Caregivers of children with mental health difficulties reported using on average two childcare arrangements every day, which have to be changed and adjusted 
regularly (Rosenzweig, Brennan et al., 2008). These children were more likely to be cared for by another parent than by extended family or community childcare settings compared to children with typical development. Booth-LaForce and Kelly (2004) had similar findings when comparing childcare arrangements for children with developmental disabilities and typical development. The 89 children with developmental disabilities entered childcare at a later age and with fewer care hours compared to children with typical development.

Qualitative studies with caregivers of preschool and school-aged children with disabilities illustrate the struggles of parents to find quality childcare or any childcare at all (Brennan, Bradley, \& Ackerman Lieberman, 2008; Ceglowski, et al., 2009; Gopalan, Burton, McKay, \& Rosenzweig, 2008; Jinnah \& Stoneman, 2007). For example, one father describes his family's experience: "[this child care situation] was our only option basically. It's hard to find someone that will take a special needs child and you can't pay them enough to make it worth their while." (Ceglowski et al., 2009, p. 501). Families therefore often have to settle for lower quality childcare in order to secure any care at all. Parents cited providers' reluctance to accept children with SHCN as one barrier, in addition to a lack of information and resources on available childcare options such as Head Start programs. If parents find quality childcare they face challenges of maintaining the care once accepted, despite the entitlements under the American with Disabilities Act that protect them from discrimination based on the child's disability status (Jinnah \& Stoneman, 2007).

Children with SHCN often need childcare in later developmental stages compared to children with typical development, however available care is often 
geared towards younger children. Parents in one qualitative study commented that it is especially difficult to find after-school or summer care for their children with SHCN once they moved on to middle or high school (Jinnah \& Stoneman, 2007). Transportation was cited as another barrier to accessing childcare services. Services might not be close to home resulting in long commutes during the workday with parents being often the only option for transportation (Jinnah \& Stoneman, 2007; Rosenzweig et al., 2002).

Parents also reported that childcare and school personnel and administrators often lacked an understanding of their children's health issues and needs (Rosenzweig et al., 2002) and care providers were found to lack training to effectively care for children with SHCN (Ceglowski et al., 2009). Research comparing inclusive and non-inclusive care support these accounts. Inclusive care settings have been found to be of higher quality (Grisham-Brown, Cox, Gravil, \& Missall, 2010) and personnel were more likely to have specific child development training with more training hours (Knoche et al., 2006).

These challenges to secure adequate childcare had a variety of consequences. Some parents reported that they often received calls from school during the workday to pick up their child or to come to school and deal with the child's disruptive behavior (Rosenzweig et al., 2002). Parents were willing to accept lower quality care in order to secure any care at all (Ceglowski et al., 2009). Other parents had terminated childcare arrangements out of fear for the child's safety (Jinnah \& Stoneman, 2007). Childcare services adequate for children with SHCN can also be more expensive resulting in additional costs for families (Ceglowski et al., 2009). Difficulties securing adequate care 
arrangements for children with SHCN were found to negatively impact parental employment (Brennan \& Brannan, 2005; Rosenzweig, Brennan et al., 2008) and work-family fit (Brennan, Rosenzweig, Ogilvie et al., 2007; Rosenzweig, Brennan et al., 2008; Rosenzweig et al., 2002).

Social support. Research identifying the effect of social support on workfamily fit for parents of children with SHCN is still limited. Brennan, Rosenzweig, Ogilvie et al. (2007) found positive correlations between family support sources and work-family fit and work-family strategies. Single parents reported significantly fewer family-support sources than partnered caregivers. Another study that did not distinguish between family and friend support showed that social support is effective in addressing work-family and family-work conflict for caregivers with exceptional care responsibilities (Stewart, 2013).

Raising a child with SHCN has been identified as increasing parental stress and strain and social support was found helpful in that regard. Several studies reported both direct and indirect positive effects of social support on parental well-being and caregiver strain across disability groups and racial identities (Brannan \& Heflinger, 2001; Ha, Greenberg, \& Mailick Seltzer, 2011; McCabe, Yeh, Lau, Garland, \& Hough, 2005; Schoeder \& Remer, 2007; Skok, Harvey, \& Reddihough, 2006).

Studies found a variety of positive effects of informal and formal support for caregivers of children with SHCN. For example, in one national study parents identified emotional support as the most significant contribution from spouses, friends, and neighbors (Friesen, 1989). Furthermore, peer support in parent-toparent support groups was found to provide a sense of belonging and 
empowerment; in addition peer support allowed them to access much needed information and resources (Shilling, Morris, Thompson-Coon, Ukoumunne, Rogers, \& Logan, 2013). Sharing experiences with other parents of children with SHCN can be reassuring: "It really did help to know that some of these things we were thinking and feeling were perfectly normal; that there wasn't anything wrong with it." (Ainbinder et al., 1998, p. 103). This shared experience often allowed for a connection not possible with family members or friends who did not care for a child with SHCN (Kerr \& McIntosh, 2000).

Caregivers also report struggling with social isolation and a lack of social support (Becker, 2006; Kerr \& McIntosh, 2000) with fathers potentially being even less likely to reach out for support (Kallenbach, 2002). In one study of 966 parents caring for a child with emotional difficulties $63 \%$ of parents indicated that their child's difficulties had worsened the family's relationship with extended family, friends, and neighbors and had made it more challenging to participate in social activities as a family (Friesen, 1989). Type of disability matters: Heiman and Berger (2007) found that parents of children with Asperger Syndrome reported less social support from family and friends than parents of children with learning disabilities or parents of children with typical development.

\section{Fathers}

Some aspects of work-life fit and exceptional caregiving responsibilities specific to fathers have been included throughout the preceding discussions. The majority of the findings cited were from comparative studies of mothers and 
fathers. Presented here are work-life studies that specifically focused on fathers (see e.g., Aumann et al., 2011; Harrington et al., 2011; Towers, 2009).

Findings from a study of 963 fathers employed full-time in white-collar jobs indicated that the participating fathers valued both their careers and their family lives equally (Harrington et al., 2011). The fathers were primarily White, well educated and working in management positions. Almost all of them reported being married or in a relationship and 69\% were living in dual-earner households. They indicated that the responsibilities of a good father included both earning money and taking care of the children. Respondents rated job security highly and for most of these middle-aged fathers, flexibility was more important than income. Fathers in this study reported placing a high value on the importance of showing love and involvement with their children, however they rated their actual engagement in the daily tasks of childcare as very low. Similarly, fathers agreed that both partners should share work and childcare equally but indicated that in most cases their partners were doing the greater share of childcare-related tasks.

While there appears to be an ideological or attitudinal shifting away from the stereotypical male worker role, this may not be related to behavioral changes. Fathers for example did not often take more than one week off after birth or adoption of their child, and $98 \%$ returned to the same job conditions without any adjustments (Harrington et al., 2011). The majority reported that work was interfering more with family life than family life interfering with work; and that family life was more enriching for their work life than the other way 
around. The study's findings also indicated that partner support positively influenced work-life conflict, enrichment, and job satisfaction.

In their 2008 National Study of the Changing Workforce, Aumann et al. (2011) coined the term new male mystique.

We use the term new male mystique to describe how traditional views about men's role as breadwinners in combination with emerging gender role values that encourage men to participate in family life and a workplace that does not fully support these new roles have created pressure for men to, essentially, do it all in order to have it all. (Aumann et al., 2011, p. 2)

The men surveyed reported higher levels of work-family conflict in 2008 than in 1977, marked with a rise of 15\%, which also exceeded women's reported levels of work-family conflict. Men indicated spending more time engaged in household and childcare with an increase from 1.8 hours in 1977 to 3 hours in 2008 for childcare and an increase from 1.2 hours in 1977 to 2.3 hours in 2008 for household chores. However, the study found that these increased family demands were less important predictors of work-family conflict than the amount of time spent at work. The study found that men are dealing with greater demands in the workplace, including working longer hours, blurred boundaries between work and non-work, job insecurity, and flat earnings. These increased work demands were found to be important predictors of work-family conflict for men (Aumann et al., 2011). Access to workplace flexibility, and supervisor and workplace support was found to reduce work-family conflict. 
Additionally, the study found that men with more traditional gender role expectations and who prioritized work over family reported more work-family conflict. The study also found that fathers with children under the age of 18 reported more work-family conflict and that the way childcare and household chores were shared between partners did not affect work-family conflict. Fathers worked significantly more hours than men without children despite fathers' preference to work fewer hours.

Men who were married or partnered reported more work-family conflict than single men indicating that: "the traditional gendered divisions of labor are not currently as successful at reducing family pressures on married/partnered men as might be assumed" (Aumann et al., 2011, p. 9). This is in line with findings from Grzywacz and Marks (2000) who reported more negative work to family spillover for married men compared to unmarried men; however, married men also reported more positive family to work spillover than unmarried men. Additionally, men who reported less spousal emotional support and more spousal disagreement reported lower levels of positive family-work spillover (Grzywacz \& Marks, 2000). In another study fathers directly commented about their wife's employer support and workplace flexibility when asked about how they manage to integrate work and their child's needs (Lewis et al., 2000b). Being married or partnered therefore seems to be associated with more negative spillover or conflict for men when compared to unmarried men, however, spousal support within the couple dyad seems to be associated with more positive spillover and less negative spillover. 
In Recognising Fathers, a national survey of 251 fathers who have children with learning disabilities in the United Kingdom (Towers, 2009), fathers reported their spouses as the greatest source of support followed by support from extended family and friends. More than half of the participating fathers reported that members of the wider family had difficulty dealing with the child's diagnosis and $50.8 \%$ reported losing friendships since having a child with a disability, however, $47.8 \%$ reported having made new friends because of the child's disability (Towers, 2009). This study also reported about fathers' workplace adjustments. Most fathers in the study were employed $(62.3 \%$ fulltime, $8.1 \%$ part-time, and $10.5 \%$ self employed) while only half of the mothers were employed (12.1\% full-time, and $31.6 \%$ part-time). When reporting workplace adjustments, fathers cited most often that they changed their pattern of work such as changing shift work or becoming self-employed, followed by a reduction in hours, a change in the type of work they were doing, and a change in their roles or responsibilities at work including forgoing promotions or other career opportunities. Fathers indicated being often equally engaged as their wives in caring for their children, especially for evening and bedtime routines and on weekends. Most fathers also identified as being stressed some of the time (52\%) or all of the time (41\%) and half of the fathers reported that their physical health had been negatively impacted by the pressures of caring for their child with a disability. Worrying about the child's future, the demands associated with the care tasks, a lack of sleep, the difficulty finding services, and the lack of respite services were cited by more than half of the fathers as sources of stress (Towers, 2009). 
Existing research illustrates the demands and challenges associated with exceptional caregiving responsibilities such as increased work-family conflict, stress and strain, loss of employment or income, and stigmatization. Services such as health care services, childcare, and after-school care, and support from family and friends are important resources for parents of children with SHCN, however, these services and supports are not always adequate. Similarly, workplace supports such as workplace flexibility, and support from supervisors and coworkers have been found to alleviate work-family conflict if available to families, but there is still a gap related to research about fathers' work-life fit. Fathers face the dilemma of trying to engage at home and trying to keep up with ideal worker norms in the workplace, potentially leading to increased levels of work-family conflict. Research specifically about fathers of children with SHCN is marginal, limiting the possibilities to better support fathers in their roles as workers and as caregivers. This study provides first insights into the relevance of different resources within the job, home, and community ecologies and their relationships with work family integration for employed fathers of children with SHCN by investigating the following questions:

1. What type of job ecology resources predicts difficulty combining work and family, and spillover effects for employed fathers of children with SHCN?

2. What type of home ecology resources predicts difficulty combining work and family, and spillover for employed fathers of children with SHCN?

3. What type of community ecology resources predicts difficulty combining work and family, and spillover for employed fathers of children with SHCN? 
4. Do job, home, and community resources predict difficulty combining work and family, and positive and negative spillover for employed fathers of children with SHCN?

5. Do home resources moderate the effects of job resources on difficulty combining work and family, and spillover for employed fathers of children with SHCN?

6. Do community resources moderate the effects of home resources on difficulty combining work and family, and spillover for employed fathers of children with SHCN?

7. Do community resources moderate the effects of job resources on difficulty combining work and family, and spillover for employed fathers of children with SHCN? 


\section{Chapter III}

\section{Method}

As established with the literature review, scholarship in the work-life field is expanding to include a greater diversity of influencing contexts and family structures; however, research on fathers' experiences of integrating work and family is limited and nearly absent for fathers of children with SCHN. The current study addresses this limitation by exploring the work-life experiences of fathers with children challenged by SHCN. This chapter describes the research design for the present study, the measurement instruments used, and the recruitment strategy and selection of the sample. A description of the data analysis plan is also provided.

\section{Research design}

The lack of research on employed fathers with child-related exceptional caregiving responsibilities indicates the need to take an exploratory approach to the current study (Singleton \& Straits, 2010). Exploratory designs are indicated if little is known about a topic, in this case employed fathers of children with SHCN. The aim of exploratory studies is to gain a general report of the phenomenon without being able to rely on pre-existing categories of analysis. The primary purpose of this exploratory research was to gain an initial description of employed fathers of children with SHCN and their difficulties combining work and family.

Quantitative data was collected through an online cross sectional survey. Cross-sectional designs are conducted at one point in time with a sample considered representative of the population under investigation (Singleton \& 
Straits, 2010). Cross-sectional designs are commonly used in social science research. This design is a cost-effective method to collect data in a short period of time without attrition of participants. Bourque (2004) describes the objective of cross-sectional designs: "to get a "snapshot" or picture of a group" (p. 3), which is in line with the purpose of this exploratory study about employed fathers of children with SHCN. Distributing the survey online was a cost effective and time efficient method for data collection (Singleton \& Straits, 2010). The university provided access to the online survey software Qualtrics ${ }^{\odot}$ allowing for cost-free set up of the survey. The use of an online survey provided an ideal method to recruit the sample of interest. Accessing fathers with child-related exceptional caregiving responsibilities can be challenging. Fathers, compared with mothers, tend to be less active in social support organizations (Heckmann, 2007; Kallenbach, 2002). Like employed mothers, employed fathers are juggling work and family responsibilities and may have limited time and interest in completing surveys. Using the internet to disseminate the survey to the sample of interest through relevant websites enhanced recruitment.

Fathers completing the survey were also asked to participate in a telephone interview about work-life resources and barriers. An analysis of these qualitative data is not included in the current study.

\section{Instrumentation}

The survey was constructed to measure key variables from the theoretical model of life course fit (Moen et al., 2008a, b) and related empirical research (Barnett \& Gareis, 2008; Brennan, Rosenzweig, Ogilvie et al., 2007; Brown, 2014; Emlen, 2010; Griggs et al., 2013; Kelly et al., 2008; Rosenzweig, Brennan et al., 
2008; Rosenzweig et al., 2002; Stewart, 2013) as these apply to fathers of children with SHCN. To date, there are no existing measures specific to employed fathers of children with SHCN. All the selected key variables have been identified in the literature as relevant for achieving work-life fit for either employees in general, fathers specifically, or caregivers with exceptional caregiving responsibilities specifically.

The survey consisted of 65 questions divided into seven sections including eligibility criteria, job resources, home resources, community resources, difficulty combining work and family, spillover, child demographics, and father demographics. The following sections provide a detailed description of the measurements included for job, home, and community resources, difficulty combining work and family, spillover, and participant demographics. The complete survey can be reviewed in Appendix A and the codebook in Appendix B.

Job ecology resources measures. Descriptive information was collected on the hours worked in the last full work week, the time spent commuting to and from work, and the type of work schedule including standard full-time, flexible work hours, compressed work week, job sharing, and other part-time. These questions were based on the Support for Working Caregivers Interview Schedule (Brennan, Rosenzweig, Ogilvie, Zimmerman, \& Ward, 1999). Questions on fathers' workplace flexibility, and supervisor and coworker support were based on and adapted from the National Study of the Changing Workforce 2008 (Aumann et al., 2011). Possible flexibility options included, flexibility to make short-notice schedule changes, work from somewhere else than the workplace, 
and access to sick days. Respondents answered yes or no indicating the availability of these options in their workplace. A 3-point Likert scale 1 (low), 2 (moderate), and 3 (high) was used to measure participant's overall access to workplace flexibility, use of workplace flexibility, and coworker and supervisor support. Difficulty taking time off was measured with a 4-point Likert scale 1 (not at all difficult) to 4 (very difficult). The impact of using flexibility on career advancement was measured with two 4-point Likert scale questions taken from the Support for Working Caregivers Interview Schedule (Brennan et al., 1999). One item asked: "Do you believe that employees in your organization are less likely to advance if they are using flexible work options such as telecommuting or compressed work week?" Fathers could select items from 1 (strongly agree) to 4 (strongly disagree). The other item asked: "Do you think that caring for your child or children with special health care needs has negatively impacted your career?" and was measured from 1 (not at all) to 4 (definitely).

Home ecology resource measures. Data on resources within the family ecology were collected with questions about the father's partner status including married, partners living together, partners not living together, single, widowed, divorced, and legal separation, employment status of partner, and the number of hours worked by partner, if applicable. Questions from Emlen's (2010) Quality of Care from a Parent's Perspective research and the Support for Working Caregivers Interview Schedule (Brennan et al., 1999) were used to determine if there was someone with whom fathers were sharing family responsibilities. Two questions asked about how responsibility for childcare and care coordination was shared within the family using 5-point Likert scales 1 (I do completely), 2 
(mostly I do), 3 (equally shared), 4 (mostly spouse/partner or other does), and 5 (spouse/partner or other does completely). The level of flexibility fathers have in their family schedule to address either work or childcare issues was measured on two 4-point Likert scales from 1 (no flexibility at all) to 4 (a lot of flexibility).

Community ecology resource measures. Participants rated the helpfulness of specific community resources including, childcare, school, afterschool care, public transportation, and health services, on a 10-point scale from 10 (almost always helpful) to 0 (not at all helpful). Participants assessed on a 3point Likert scale with 1 (high), 2 (moderate), and 3 (low) the overall availability of services and resources to better integrate work and family. Using a measure of social support from the National Study of the Changing Workforce (2008), respondents rated their level of social support from friends and neighbors on a positively worded 4-point Likert scale with 1 (strongly agree), 2 (agree), 3 (disagree), and 4 (strongly disagree).

Difficulty combining work and family and spillover measures. The measure of difficulty combining work and family employed in the current study was originally developed by Neal et al. (1993) and was used in the Support for Working Caregivers Interview Schedule (Brennan, Rosenzweig, Ogilvie, Zimmerman, \& Ward, 1999, p. 22): “Circumstances differ and some people find it easier than others to combine working with family responsibilities. In general, how easy or difficult is it for you?" Fathers rated their level of difficulty combining work demands and family responsibilities on a 6-point scale 1 (very easy) to 6 (very difficult). 
Spillover was measured using four subscales (positive and negative family to work and work to family spillover) developed for the National Survey of Midlife Development in the United States (MIDUS, 1995/1996) and employed in previous work-life studies (Grzywacz, 2000; Grzywacz \& Marks, 2000). The subscales positive work to family spillover and negative work to family and family to work spillover consisted of four questions each. The subscale of positive family to work spillover consisted of three questions. Measurement examining positive work to family spillover included: "Have the things you do at work helped you deal with personal and practical issues?" and negative work to family spillover: "Has your job reduced the effort you can give to activities at home?" Negative family to work spillover was measured with a question such as: "Have responsibilities at home reduced the effort you can devote to your job?" Positive family to work spillover included the question: "Has your home life helped you relax and feel ready for the next day's work?" All questions were rated on 5-point Likert scales with the options 1 (never), 2 (rarely), 3 (sometimes), 4 (most of the time), and 5 (all of the time). Similar to other studies (Grzywacz \& Marks, 2000, Moen et al., 2008a, 2008b) the scale had acceptable levels of reliability for the current study with Cronbach's $\alpha$ of .68 for positive work to family spillover, of .86 for negative work to family spillover, of .68 for positive family to work spillover, and of .71 for negative family to work spillover. Overall scores have been calculated by adding the scores on the single items resulting in total subscale scores from 4-20 for positive and negative work to family spillover and negative family to work spillover scales, and from 3-15 on 
the positive family to work spillover scale with higher scores indicating more positive and/or negative spillover.

Additional variables of job security and income adequacy were measured. The job security scale (Siegrist et al., 2004) asked if participants experienced or expected to experience undesirable work changes ranging from 1 (very likely) to 4 (not likely at all). Finally, on a scale of 0 (very inadequate) to 10 (more than adequate) fathers indicated how adequate their income was to meet their financial needs (National Study of the Changing Workforce, 2005).

Demographics. The final section of the survey focused on demographic descriptives. Questions regarding the father's children included number, age, gender, race/ethnicity, SHCN status, and diagnosis if applicable. Two questions of the National Survey of Children with Special Health Care Needs 2009/2010 were used to discern severity of the child's health issue. If families had more than one child with SCHN fathers were asked to respond about the child with the more severe condition, or if that was not applicable, about the younger child. Fathers were asked to indicate how often the child's health issue had affected the child's ability to do the things other children the same age could do using a 4point Likert scale 1 (never), 2 (sometimes), 3 (usually), and 4 (always) and how much the child's ability to do things was affected by the health condition on a 3point Likert scale 1 (very little), 2 (some), and 3 (a great deal). The survey concluded with questions for the respondent about his education, age, race/ethnicity, annual household income, zip code, and how he had learned about the study. 


\section{Data collection}

Sample recruitment. Quantitative data were collected with a convenience, non-probability sample (Singleton \& Straits, 2010) using mailing lists, websites, and direct recruitment through several statewide and national parent support groups, health and mental health agencies, schools, social media sites, and blogs. The Oregon Family Support Network, Parent 2 Parent USA, Washington State Fathers Network, Harper's Playground, and Family Voices emailed the recruitment flyer (see Appendix C) to the members on their listservs in mid-January, 2015 and a second reminder was sent in mid-February, 2015. The study was also advertised through the Autism Speaks Families Participate in Research page (http://www.kintera.org/site/c.cdJGKONnFmG/b.3976705/k.5180/Participate_ in_Research/apps/nl/newsletter2.asp), the National Down Syndrome Society (http://www.ndss.org), a guest blog post on Dads of Disability (http://blog.dadsofdisability.com), and My Special Needs Network (http://www.myspecialneedsnetwork.com). Postings on disability-related Facebook pages included Children with Special Needs, National Autism Association, Seattle Children's Hospital, and the Special Needs Network. A Facebook page Survey: Working fathers caring for children with special health care needs was established and the study was promoted upon invitation at a meeting of the local Washington Dads chapter. The list of organizations, social network sites, and blogs was the result of an extensive internet search and professional recommendations to locate national and local support groups that were geared either towards caregivers of children with special needs in general, 
specific disability groups such as Autism or Down Syndrome, or fathers of children with SHCN. Fathers were recruited from different states throughout the United States resulting in a more nationally representative sample.

The data were collected through an anonymous online survey using Qualtrics $^{\oplus}$. Qualtrics ${ }^{\circledR}$ is a software tool that allows researchers to create online surveys. The software program also provides a link for distribution of the survey, storage of the online surveys, and export into statistical analysis software (www.qualtrics.com). Participating fathers could choose at the end of the survey to enter their e-mail address for a drawing of two $\$ 25$ gift certificates. These email addresses were not connected to their online surveys keeping the surveys anonymous.

Sample selection. Fathers $(N=90)$ indicated that they most frequently learned about the study through social media, or general searches on the web $(N$ =43). Additional sources included: wife/friend/school $(N=29)$, or through email including support group listserv e-mails $(N=18)$. Respondents who selfidentified as: (a) fathers of at least one child under 18 years old with SHCN, (b) either lived with the child full-time or provided at least part-time care for the child, and (c) was employed at least part-time, which was defined as working between 15 and 30 hours/week were included in the final sample. These criteria were met by $83 \%(N=122)$ of the total respondents $(N=147)$. The non-eligible 25 fathers either did not have a child under the age of 18 , or did not live at least part-time with the child with SHCN, or were not employed at least part-time.

Sample descriptives. The mean age of the fathers sampled was 42.49 years old $(S D=7.76)$ with an age range from 28 years to 61 years (see Table 1$)$. 
FATHERS OF CHILDREN WITH SHCN 56

Most of these fathers (85.7\%) self-identified racially as Non-Hispanic White, with less than $11 \%$ self-identifying as Hispanic/Latino. The majority of the fathers had college degrees, with slightly over one-third reporting a bachelors level and $28 \%$ reporting a graduate level degree.

Nearly all of the fathers (97\%) reported living full-time with their children who had SHCN and working full-time (84\%), an average of 42.74 (SD = 11.10) hours per week. The majority of fathers (92\%) were also partnered (married or living with a partner). Over half of the partners $(56.65 \%)$ were employed an average of $37.33(S D=13.89)$ hours per week. Slightly over half of the fathers reported an annual household income of between $\$ 60,000$ and $\$ 119,000$; nearly $15 \%$ indicated an income over $\$ 150,000$, and $7 \%$ indicated income under $\$ 30,000$ (see Table 1). When asked to rate how well their income met their financial needs on a scale ranging from $0-10$, fathers reported an average score of $5.70(S D=2.50)$ with a score of 5 indicating (sometimes adequate). 
Table 1

Father Demographics including Age, Relationship, Employment, Race, Education, and Income

\begin{tabular}{|c|c|}
\hline Characteristics & Percent/Mean $(S D)$ \\
\hline Fathers' mean age & $42.49(7.76)$ \\
\hline \multicolumn{2}{|l|}{ Fathers' relationship status } \\
\hline Married & $90.5 \%$ \\
\hline Partners and living together & $1.9 \%$ \\
\hline Single & $1.9 \%$ \\
\hline Widowed & $1.0 \%$ \\
\hline Divorced & $3.8 \%$ \\
\hline Legal separation & $1.0 \%$ \\
\hline \multicolumn{2}{|l|}{ Fathers' employment } \\
\hline Full-time & $83.8 \%$ \\
\hline Part-time & $6.0 \%$ \\
\hline Self-employed & $10.3 \%$ \\
\hline \multicolumn{2}{|l|}{ Fathers' race } \\
\hline Non-Hispanic White & $85.7 \%$ \\
\hline Hispanic/Latino & $10.7 \%$ \\
\hline Asian/Pacific Islander & $2.4 \%$ \\
\hline Biracial/mixed & $1.2 \%$ \\
\hline \multicolumn{2}{|l|}{ Fathers' education } \\
\hline Grade school or less & $1.1 \%$ \\
\hline Some high school & $2.2 \%$ \\
\hline Graduated from high school & $11.0 \%$ \\
\hline Some college & $17.6 \%$ \\
\hline Graduated from college & $34.1 \%$ \\
\hline Some graduate study & $6.6 \%$ \\
\hline Graduate degree & $27.5 \%$ \\
\hline Father's weekly work hours & $42.74(11.10)$ \\
\hline \multicolumn{2}{|l|}{ Annual household income } \\
\hline Under $\$ 30,000$ & $6.7 \%$ \\
\hline$\$ 30,000-\$ 59,000$ & $20.2 \%$ \\
\hline$\$ 60,000-\$ 89,000$ & $24.7 \%$ \\
\hline$\$ 90,000-\$ 119,000$ & $26.9 \%$ \\
\hline$\$ 120,000-\$ 149,000$ & $6.7 \%$ \\
\hline More than $\$ 150,000$ & $14.6 \%$ \\
\hline Income adequacy & $5.70(2.50)$ \\
\hline
\end{tabular}

Note. $N=105$.

\section{Data analysis method}

Data cleaning and variable modification. All the data collected with the online survey program Qualtrics ${ }^{\circledR}$ were directly imported into the statistical analysis program SPSS $22^{\odot}$ (Pallant, 2010). The data were visually inspected by 
this researcher for any data entry errors. All cases were checked for eligibility, only including eligible fathers in the final sample for analysis.

A codebook was developed by this researcher (see Appendix B). The variables of access and use of flexibility, supervisor and coworker support, and service availability were recoded so higher values indicated higher levels of flexibility. Schedule flexibility, workplace flexibility, and access to sick days were recoded as well resulting in (no) answers being coded as 1 and (yes) answers being coded as 2 . This helped interpret directions of relationships in bivariate correlations and multivariate regressions with a higher score indicating more flexibility. The scores on the single items of the positive and negative work to family and family to work spillover subscales were summed resulting in subscale scores ranging from $4-20$ and 3 - 15 (MIDUS, 1995/1996). Summed scores of these subscales were used for regression analyses. Mean scores of these subscales were used in $t$-test analyses.

Information on gender, race/ethnicity, and child diagnosis was collected in text boxes filled in by participating fathers. After inspecting the individual responses, categories were developed capturing repeating answers. Gender was categorized as male or female. Race included Non-Hispanic White, Hispanic/Latino, African American/Black, Asian/Pacific Islander, and Biracial/mixed race. A dichotomous race/ethnicity variable with 0 (Non-Hispanic White) and 1 (Not Non-Hispanic White) was produced for inclusion in regression analysis. Diagnoses types were summarized as 1 (Autism Spectrum Disorder primary diagnosis, 2 (Cerebral Palsy CP primary diagnosis), 3 (mental health), 4 (developmental disability), 5 (chronic physical disease), and 6 (other), which was 
included for diagnoses appearing only once that couldn't be summarized with other categories. Based on the reports of participating fathers variables for number of children with SHCN in the family, age of the youngest child in the family, and total number of children in the family were computed.

Indices development. Indices were developed for job, home, and community resources to assess overall levels of resources. Resources included in the analyses were based on previous empirical research (Barnett \& Gareis, 2008; Brennan, Rosenzweig, Ogilvie et al., 2007; Brown, 2014; Emlen, 2010; Griggs et al., 2013, Kelly et al. 2008; Rosenzweig, Brennan et al., 2008; Rosenzweig et al., 2002; Stewart, 2013) and theoretical considerations (Moen, 2011; Voydanoff, 2007). Indices are compositions of individual measures addressing the same underlying concept and offer the possibility to measure complex concepts by summarizing a variety of single indicators (Carmines \& Woods, 2004). Using indices in addition to single indicators supports the theoretical assumptions of this study that resources and demands in different ecologies form a complex system (Barnett, 1998; Moen et al., 2008b). The variables used to create the job, home, and community resource indices can be seen in Table 2: 
Table 2

Variables Included in Resource Indices

\begin{tabular}{ll}
\hline Index & Variables \\
\hline Job resources & Access to flexibility \\
& Use of flexibility \\
& Access to sick days \\
& Flexibility to make schedule changes \\
& Workplace flexibility \\
& Supervisor support \\
& Coworker support \\
& Employment status partner \\
Home resources & Responsibility for childcare \\
& Responsibility for care coordination \\
& Flexibility at home for work issues \\
& Flexibility at home for childcare \\
& Service availability \\
Community resources & Support from friends and neighbors \\
\hline
\end{tabular}

These variables were first standardized to avoid biased influence of variables with more answer categories on the overall index score. This linear transformation of the individual scores allowed comparability across different levels of measurements without affecting the distribution or its correlations (Cohen, Cohen, West, \& Aiken, 2003). The mean scores of these standardized variables formed the indices for job, home, and community resources. Higher scores reflected higher levels of flexibility and resources within these three ecologies.

Preliminary analyses. All variables used in the final regression analyses were subjected to preliminary analyses. Histograms, skewness and kurtosis statistics, normal q-q plots, and boxplots were employed to assess normality of continuous variables (Pallant, 2010). These analyses included individual variables and the indices of job, home, and community resources. Histograms 
were inspected visually and appeared reasonably normal especially after considering the normal q-q plots. Skewness and kurtosis values were evaluated and the ratio of skewness/kurtosis values and the respective standard errors were assessed. Most ratios fell within the recommended +/-3 range (Coleman, 2012). Some negative skewness was observed for the variables responsibility for childcare (skewness $=-1.08, S E=.24$ ), and responsibility for care coordination (skewness $=-.86, S E=.24$ ). But all q-q plots appeared reasonably normal. Boxplots indicated some outliers but comparing mean and 5\% trimmed mean for these variables did not show any difference, so outliers did not seem to influence the overall mean statistics. Scatterplots were utilized to assess linearity and equal variance on a bivariate level across the continuous variables. Variables appeared adequately linear with equal variance based on the inspection of the scatterplots.

Analysis plan. Descriptive statistics were used to better determine the composition and characteristics of the sample including demographics, type and level of resources in each ecology, and levels of difficulty combining work and family, and spillover. A correlation table was used to represent bivariate correlations of relevant independent and dependent variables used in the regression analyses.

The influence of job, home, and community resources was analyzed using a set of five regression analyses predicting difficulty combining work and family, negative work to family and family to work spillover, and positive work to family and family to work spillover. Regression analysis was appropriate for the sample 
size in this study based on the requirement of a minimum of 10 cases per variable included (Peduzzi, Concato, Kemper, Holford, \& Feinstein, 1996). Job, home, and community resource indices were used in a set of regression analyses. Regression analyses of these indices was chosen over categorizing fathers into high and low resource groups because of the potential impact on effect size and statistical power (MacCallum, Zhang, Preacher, \& Rucker, 2002). This loss of power could be critical with a smaller sample size especially since the use of categorical variables in ANOVA did not provide any advantage over using continuous variables in regression analysis. The analyses were used to determine the influence of job, home, and community resources on difficulty combining work and family, and spillover.

The final analyses included interaction terms of job and community resources, home and community resources, and job and home resources to identify the potential moderating effects of resource ecologies (Cohen et al., 2003). Simple slopes models were developed for significant interaction terms to visualize the moderating relationships between resources (Dawson, 2014). 


\section{Chapter IV}

\section{Results}

Subsequent to the preliminary analyses, descriptive statistics were generated on the sample. Bivariate correlations and multivariate regression analyses were employed to analyze which job, home, and community resources predicted difficulty combining work and family, and positive and negative spillover for employed fathers of children with SHCN. Regression analyses were also conducted using the job, home, and community resource indices. The final analyses reported in this chapter examined the potential of moderating relationships between resource ecologies through the inclusion of variable product terms in regression analyses and the development of simple slopes models for significant interaction terms.

\section{Descriptives: Children}

Fathers reported having an average of 2 children, with one of those having SHCN (see Table 3). Children with SHCN and their siblings ranged in age from 1 year to 22 years old with a mean age of 7 years $(7.47 ; S D=4.14)$. Slightly more than half (57\%) of the children were identified as male, and $43 \%$ of the children identified as female. Similar to the racial self-identification of the fathers, children were identified by the fathers as $74 \%$ Non-Hispanic White, $8 \%$ as mixed race, and $13 \%$ as Hispanic/Latino.

Autism Spectrum Disorder was the most frequently reported (31\%) child's primary SHCN diagnosis, and the second most frequent primary diagnosis reported was Cerebral Palsy (18\%). Other child diagnoses included mental health-related concerns of Attention Deficit Hyperactivity Disorder, Obsessive 
Compulsive Disorder, anxiety or a developmental disability of Down Syndrome, or Fragile X; or chronic physical illnesses including diabetes and cancer (see Table 3). When asked "How often has your child's medical, behavioral, emotional, developmental or other health conditions affected his/her ability to do things other children the same age would do?" $56 \%$ of the fathers reported that the child's health care needs always affected his/her ability to do things other children the same age would do; and when asked, "How much do your child's medical, behavioral, emotional, developmental or other health conditions affect his/her ability to do things?," 71\% reported feeling that the child's condition affected his/her ability to do things a great deal.

Table 3

Child Age, Race, Gender, and Symptom Levels

\begin{tabular}{|c|c|}
\hline Characteristics & Percent/Mean $(S D)$ \\
\hline Child mean age & $7.47(4.14)$ \\
\hline \multicolumn{2}{|l|}{ Child race } \\
\hline Non-Hispanic White & $74.2 \%$ \\
\hline Hispanic/Latino & $12.9 \%$ \\
\hline Asian/Pacific Islander & $4.5 \%$ \\
\hline Biracial/mixed & $7.9 \%$ \\
\hline \multicolumn{2}{|l|}{ Child gender } \\
\hline Female & $42.8 \%$ \\
\hline Male & $57.2 \%$ \\
\hline Number of children in the household & $2.13(1.12)$ \\
\hline \multicolumn{2}{|l|}{ Child diagnosis } \\
\hline $\begin{array}{l}\text { Autism Spectrum Disorder (ASD) primary } \\
\text { diagnosis }\end{array}$ & $31.0 \%$ \\
\hline Cerebral Palsy (CP) primary diagnosis & $18.0 \%$ \\
\hline Mental health & $7.0 \%$ \\
\hline Developmental disability & $8.0 \%$ \\
\hline Chronic physical disease & $5.0 \%$ \\
\hline Other & $32.0 \%$ \\
\hline \multicolumn{2}{|l|}{ How often child symptoms affect activities } \\
\hline Sometimes & $13.6 \%$ \\
\hline Usually & $30.7 \%$ \\
\hline Always & $55.7 \%$ \\
\hline \multicolumn{2}{|l|}{ How much child symptoms affect activities } \\
\hline Very little & $5.6 \%$ \\
\hline Some & $23.6 \%$ \\
\hline A great deal & $70.8 \%$ \\
\hline
\end{tabular}

Note. $N=89$. 


\section{Descriptives: Resource ecologies, difficulty combining work and family, and spillover}

Another set of descriptive analyses produced information on the type and level of resources within the three ecologies of job, home, and community, as well as the father's levels of difficulty combining work and family, and positive and negative spillover.

Job resources. As shown in Table 4, nearly three quarters of fathers indicated access to at least five paid sick days per year and the flexibility to make short-notice schedule changes. Although fewer than half of the fathers (43\%) reported that they had the flexibility available to work from somewhere else than their workplace, about half of the fathers indicated that it was not at all difficult or not too difficult to take time off during the workday. Eighty-six percent of the fathers rated their access to flexibility as moderate or high; however, only $71 \%$ rated their use of flexibility as moderate or high. More than $80 \%$ rated their levels of supervisor and coworker support as moderate or high. Despite these positive ratings regarding workplace flexibility and support, more than $50 \%$ of fathers indicated that caring for a child with SCHN had somewhat (27.9\%) or definitely (26\%) negatively impacted their career. Similarly, $60 \%$ of the sample, either strongly agreed (25.7\%) or somewhat agreed (34.7\%), that taking flexibility had a negative career impact. More than $50 \%$ of fathers reported that a negative job change was not very likely or not likely at all. 
Table 4

\begin{tabular}{lll} 
Descriptives: Job Resources, Flexibility, & and Career Impact & \\
\hline Variable & Response & Percent \\
\hline Access to sick leave & Yes & $73.5 \%$ \\
Flexibility short-notice schedule changes & Yes & $73.8 \%$ \\
Flexibility work from somewhere else & Yes & $42.7 \%$ \\
Difficulty taking time off & Not at all difficult & $12.6 \%$ \\
& Not too difficult & $41.7 \%$ \\
& Somewhat difficult & $32.0 \%$ \\
Access to flexibility & Very difficult & $13.6 \%$ \\
& High & $38.8 \%$ \\
Use of flexibility & Moderate & $61.2 \%$ \\
& Low & $12.6 \%$ \\
Coworker support & High & $21.2 \%$ \\
& Moderate & $50.0 \%$ \\
Supervisor support & Low & $28.8 \%$ \\
& High & $43.7 \%$ \\
Job security & Moderate & $41.7 \%$ \\
& Low & $14.6 \%$ \\
& High & $52.4 \%$ \\
Career impact use flexibility & Moderate & $36.9 \%$ \\
& Low & $10.7 \%$ \\
& Very likely & $13.7 \%$ \\
Career impact exceptional care & Somewhat likely & $30.5 \%$ \\
& Not very likely & $38.9 \%$ \\
& Not likely at all & $16.8 \%$ \\
& Strongly disagree & $9.8 \%$ \\
& Somewhat disagree & $29.4 \%$ \\
& Somewhat agree & $35.3 \%$ \\
& Strongly agree & $25.5 \%$ \\
& Not at all & $24.8 \%$ \\
& A little & $21.0 \%$ \\
& Somewhat & $27.6 \%$ \\
& Definitely & $26.7 \%$ \\
\hline & &
\end{tabular}

Note. $N=104$.

Home resources. In the context of the current study, father's partner status and partner's participation in household and parenting responsibilities were explored as home resources (Emlen, 2010). The vast majority of fathers in this sample were married or partnered (92.3\%) and 56.6\% of fathers indicated that their partners were employed outside the home (see Table 5). A high percentage of the fathers $(82.5 \%)$ reported having someone with whom they could share home and care responsibilities and half indicated that their spouse/partner was mostly or completely responsible for childcare and care 
coordination. Given this significant level of participation in childcare from partner/spouse it is not surprising that $85 \%$ reported that they had flexibility in their family schedule to handle work responsibilities $(61.5 \%$ some flexibility and $24 \%$ a lot of flexibility) or childcare responsibilities (64.4\% some flexibility and 23.1\% a lot of flexibility).

Table 5

Descriptives: Home Resources, and Family Flexibility

\begin{tabular}{lll}
\hline Variable & Response & Percent \\
\hline Employment status partner & Yes & $56.6 \%$ \\
Responsibility for childcare & No & $43.4 \%$ \\
& I do completely & $5.8 \%$ \\
& Mostly I do & $6.7 \%$ \\
& Equally shared & $37.5 \%$ \\
Responsibility for care coordination & Mostly spouse/partner/other & $48.1 \%$ \\
& Spouse/partner/other completely & $1.9 \%$ \\
& I do completely & $8.7 \%$ \\
& Mostly I do & $6.8 \%$ \\
& Equally shared & $25.2 \%$ \\
Family flexibility to handle work issues & Mostly spouse/partner/other & $46.6 \%$ \\
& Spouse/partner/other completely & $12.6 \%$ \\
& No flexibility at all & $1.0 \%$ \\
& Hardly any flexibility & $13.5 \%$ \\
Family flexibility to handle childcare issues & Some flexibility & $61.5 \%$ \\
& A lot of flexibility & $24.0 \%$ \\
& No flexibility at all & $1.9 \%$ \\
& Hardly any flexibility & $10.6 \%$ \\
& Some flexibility & $64.4 \%$ \\
\hline
\end{tabular}

Note. $N=104$.

Community resources. A similar number of fathers indicated that the availability of resources and services to better integrate work and family life was low (44.4\%) or moderate (43.4\%) in their communities (see Table 6). Five questions asked fathers to rate the usefulness of specific services to meet work and family demands on a scale of 0-10. The services included childcare, child's school and after-school care, public transportation, and health care services. The mean score for childcare services was $5.15(S D=3.39)$, for school services 6.08 
$(S D=2.87)$, for after-school services $4.25(S D=3.52)$, for public transportation $2.89(S D=3.04)$, and $6.12(S D=3.04)$ for health care services. School and health care services were higher than midpoint and after-school care and public transportation had especially low ratings. Almost half of the participating fathers strongly disagreed or disagreed with the statement that they had the support they needed from friends and neighbors.

Table 6

Descriptives: Community Services, and Friend/Neighbor Support

\begin{tabular}{llr}
\hline Variable & Response & Percent/Mean $(S D)$ \\
\hline Service availability & High & $12.1 \%$ \\
& Moderate & $43.3 \%$ \\
& Low & $44.4 \%$ \\
Service ratings & & \\
Childcare & Mean (SD) & $5.15(3.39)$ \\
School & Mean (SD) & $6.08(2.87)$ \\
After-school care & Mean (SD) & $4.25(3.52)$ \\
Public transportation & Mean (SD) & $2.89(3.04)$ \\
Health care & Mean (SD) & $6.12(3.04)$ \\
Support from friends and neighbors & Strongly disagree & $16.2 \%$ \\
& Disagree & $31.3 \%$ \\
& Agree & $41.4 \%$ \\
& Strongly agree & $11.1 \%$ \\
\hline
\end{tabular}

Note. $N=99$.

Difficulty combining work and family, and spillover. In this sample of employed fathers of children with SHCN, 78\% indicated experiencing difficulty combining work and family responsibilities (36.1\% somewhat difficult, $28.9 \%$ difficult, and $13.4 \%$ very difficult) (see Table 7). Fewer than a quarter of fathers indicated any level of easiness combining the responsibilities, with most of those (18.6\%) only reporting it to be somewhat easy.

Positive and negative work to family spillover and family to work spillover scores were in mid-range for the sample, most fathers reporting moderate levels of positive and negative spillover. The mean score for positive 
work to family spillover was $11.63(S D=2.60)$, with a range of scores from 4 to 19 and the mean score for positive family to work spillover was $9.06(S D=2.24)$ ranging from 3 to 14 . The mean score for negative work to family spillover was $12.44(S D=2.78)$ with a range from 5 to 20 , and the mean score for negative family to work spillover was $12.49(S D=2.39)$, ranging from 6 to 19 . Fathers reported higher levels of both negative work to family spillover and family to work spillover than both positive work to family and family to work spillover. Mean scores of the four spillover subscales were used in $t$-tests to compare mean differences. The mean difference between positive work to family and negative work to family spillover was significant $(t(95)=-3.49, p=.00)$. The mean difference between positive family to work spillover and negative family to work spillover scores was not significant $(t(95)=-1.30, p=.20)$. Scores on the four spillover scales in this sample were compared to scores drawn from a nationally representative sample used in the MIDUS 1995/1996. Grzywacz and Marks (2000) reported mean scores for a subsample of fathers as follows: negative work to family spillover 2.66 , positive work to family spillover 2.59 , negative family to work spillover 2.11 , and positive family to work spillover 3.44 . The fathers with exceptional caregiving responsibilities scored significantly lower on the positive family to work spillover subscale $(t(95)=-5.05, p=.00)$, significantly higher on the positive work to family subscale $(t(93)=3.68, p=.00)$, and significantly higher on the negative spillover subscales $\left(t_{f w}(95)=16.61, p_{f w}=.00\right.$ and $\left.t_{w f}(93)=6.28, p_{w f}=.00\right)$. 
Table 7

\begin{tabular}{llr} 
Descriptives: Difficulty Combining Work and Family, and Spillover \\
\hline \multicolumn{1}{l}{ Variable } & Response & Percent/Mean (SD) \\
\hline Difficulty combining work and family & Very easy & $1.0 \%$ \\
& Easy & $2.1 \%$ \\
& Somewhat easy & $18.6 \%$ \\
& Somewhat difficult & $36.1 \%$ \\
& Difficult & $28.9 \%$ \\
& Very Difficult & $13.4 \%$ \\
Summed scores & Mean (SD) & \\
Positive work to family spillover & Mean (SD) & $11.63(2.60)$ \\
Positive family to work spillover & Mean (SD) & $9.06(2.24)$ \\
Negative work to family-spillover & Mean (SD) & $12.49(2.39)$ \\
Negative family to work spillover & & $12.44(2.78)$ \\
Mean scores & Mean (SD) & \\
Positive work to family spillover & Mean (SD) & $2.91(.65)$ \\
Positive family to work spillover & Mean (SD) & $3.02(.75)$ \\
Negative work to family-spillover & Mean (SD) & $3.11(.69)$ \\
Negative family to work spillover & & $3.12(.60)$ \\
\hline
\end{tabular}

Note. $N=97$.

\section{Regression analyses}

The theoretical underpinnings of the current study suggest that the type and availability of resources within the job, home, and community ecologies would be associated with father's difficulty combining work and family, and positive and negative spillover. Multiple hierarchical regression analyses were used to analyze the relationships between job, home, and community resources and difficulty combining work and family, and spillover. A correlation table reports the bivariate relationships of the resource measures with the outcome variables preceding each regression analysis. Research questions 1,2 , and 3 are addressed by the regression analyses reported in this section. 
FATHERS OF CHILDREN WITH SHCN

\section{Research question 1: What type of job ecology resources predicts} difficulty combining work and family, and spillover effects for employed

\section{fathers of children with SHCN?}

Job ecology between variable correlations. As shown in Table 8, nearly all the job resource variables were positively correlated. Schedule flexibility was positively associated with workplace flexibility, access to sick days, access and use of flexibility, and supervisor and coworker support.

The outcome variable of difficulty combining work and family was negatively correlated with having the flexibility to make short-notice schedule ( $p$ $=.03$ ), supervisor support ( $p=.01)$, and coworker support ( $p=.01$ ) (see Table 8). The outcome variable of positive family to work spillover was positively correlated with supervisor and coworker support $(p=.03$, and $p=.05$, respectively). Lower ratings of supervisor support were associated with higher levels of negative family to work spillover $(p=.05)$. Access to workplace flexibility $(p=.00$, and $p=.02)$ but not use of workplace flexibility $(p=.60$, and $p$ $=.65$ ) was negatively correlated with difficulty combining work and family, and positively related to positive work to family spillover. 
Table 8

Correlation of Job Resource Measures and Difficulty Combining Work and Family and Spillover

\begin{tabular}{|c|c|c|c|c|c|c|c|}
\hline Job resources & 1 & 2 & 3 & 4 & 5 & 6 & 7 \\
\hline \multicolumn{8}{|l|}{$\begin{array}{l}\text { 1. Schedule } \\
\text { flexibility }\end{array}$} \\
\hline $\begin{array}{l}\text { 2. Workplace } \\
\text { flexibility }\end{array}$ & $.336^{* *}$ & & & & & & \\
\hline 3. Sick days & $.261^{* *}$ & $.253^{* *}$ & & & & & \\
\hline $\begin{array}{l}\text { 4. Access work } \\
\text { flexibility }\end{array}$ & $.532^{* *}$ & $.425^{* *}$ & $.296^{* *}$ & & & & \\
\hline $\begin{array}{l}\text { 5. Use work } \\
\text { flexibility }\end{array}$ & $.336^{* *}$ & $.277^{* *}$ & $.220 * *$ & $.494^{* *}$ & & & \\
\hline $\begin{array}{l}\text { 6. Supervisor } \\
\text { support }\end{array}$ & $.398^{* *}$ & $.201^{*}$ & $.286^{* *}$ & $.463^{* *}$ & $.232^{*}$ & & \\
\hline $\begin{array}{l}\text { 7. Coworker } \\
\text { support }\end{array}$ & $.363^{* *}$ & $.210^{*}$ & .088 & $.373^{* *}$ & $.204^{*}$ & $.606^{* *}$ & \\
\hline 8. Diff. comb & $-.224^{*}$ & $-.178^{\dagger}$ & -.066 & $-.365^{* *}$ & -.054 & $-.250^{*}$ & $-.251^{*}$ \\
\hline $\begin{array}{l}\text { 9. Pos. w-f } \\
\text { spillover }\end{array}$ & .151 & .118 & $.181 \dagger$ & $.238^{*}$ & .047 & .159 & $.201^{*}$ \\
\hline $\begin{array}{l}\text { 10. Pos. f-w } \\
\text { spillover }\end{array}$ & .102 & .115 & 100 & .154 & .016 & $.229^{*}$ & $.206^{*}$ \\
\hline $\begin{array}{l}11 \text { Neg. w-f } \\
\text { spillover }\end{array}$ & .121 & .006 & .004 & .028 & .061 & -.031 & -.112 \\
\hline $\begin{array}{l}\text { 12. Neg. f-w } \\
\text { spillover }\end{array}$ & .025 & .054 & -.054 & -.133 & -174 & $-.202^{*}$ & -.152 \\
\hline
\end{tabular}

Job ecology regression analyses. Regression analyses were conducted to determine the effect of job resources on predicting difficulty combining work and family, and negative and positive spillover for fathers of children with SHCN. Job resources only explained $18 \%$ of variance $(F=2.60, p=.02)$ in difficulty combining work and family. As reported in Table 9, only the job resource of access to workplace flexibility was a significant predictor of difficulty combining work and family when controlling for all the job resources. 
Table 9

Regression Job Resource Measures Predicting Difficulty Combining Work and Family and Negative Family to Work Spillover

\begin{tabular}{lllllll}
\hline & \multicolumn{3}{l}{$\begin{array}{l}\text { Model 1 Difficulty combining } \\
\text { work and family }\end{array}$} & \multicolumn{3}{l}{$\begin{array}{l}\text { Model 2 Negative family to work } \\
\text { spillover }\end{array}$} \\
\hline & $B$ & $S E B$ & $\beta$ & $B$ & $S E B$ & $\beta$ \\
\hline Schedule flexibility & -.14 & .30 & -.06 & .75 & .69 & .13 \\
Workplace flexibility & -.03 & .23 & -.02 & .74 & .53 & .16 \\
Sick days & .05 & .25 & .02 & -.55 & .59 & -.10 \\
Access work flexibility &.- .51 & .23 & $-.33^{*}$ & -1.32 & .53 & $-.37^{*}$ \\
Use work flexibility & .23 & .17 & .16 & 1.13 & .40 & $.33^{* *}$ \\
Coworker support & -.12 & .21 & -.08 & -.24 & .48 & -.07 \\
Supervisor support & -.16 & .19 & -.11 & -.28 & .43 & -.08 \\
$\mathrm{R}^{2}$ & & .18 & & & & .16 \\
\hline
\end{tabular}

Note. $N=91$.

${ }^{*} p<.05 .{ }^{* *} p<.01$.

The regression on negative family to work spillover found that fathers who reported more access to workplace flexibility reported less interference of family issues with work and fathers who reported more use of workplace flexibility reported more interference of family issues with work. The job resources of access to workplace flexibility and use of workplace flexibility were both significant predictors of negative family to work spillover $(F=2.25, p=.04)$. The job resource of access to flexibility was negatively associated and the job resource of use of flexibility was positively associated with negative family to work spillover. Job resources explained $16 \%$ of variance in negative family to work spillover (see Table 9). None of the job resources were significant predictors of positive work to family spillover $(F=1.45, p=.20)$, positive family to work spillover $(F=.96, p=.47)$, or negative work to family spillover $(F=.61, p$ $=.74)$. 
FATHERS OF CHILDREN WITH SHCN

Research question 2: What type of home ecology resources predicts difficulty combining work and family, and spillover for employed fathers of children with SHCN?

Home ecology between variable correlations. Bivariate correlations were explored as a first step to learn more about the relationships between home resources and the outcome variables of difficulty combining work and family, and spillover (see Table 10). Employment status of spouse/partner was positively associated with responsibility for childcare and care coordination $(p=$ .00 , and $p=.02$, respectively). Responsibility for childcare was positively associated with responsibility for care coordination. There was a trend level association between responsibility for care coordination and family flexibility to deal with work issues $(p=.07)$. Family flexibility to deal with work issues was positively correlated with family flexibility to deal with childcare issues $(p=.00)$. Examining correlations among outcome variables, family flexibility for managing work or childcare issues was negatively associated with difficulty combining work and family $(p=.00)$ and negative family to work spillover $(p=$ $.00)$, and positively correlated with positive family to work spillover $(p=.00)$ (Table 10). Responsibility for childcare was positively associated with positive and negative work to family spillover ( $p=.03$, and $p=.02$, respectively) and negatively associated with negative family to work spillover $(p=.01)$. A positive correlation was found between responsibility for care coordination and positive family to work spillover and a negative correlation with negative family to work spillover ( $p=.02$, and $p=.02$ respectively). 
Table 10

Correlations of Home Resource Measures and Difficulty Combining Work and Family and Spillover

\begin{tabular}{|c|c|c|c|c|c|}
\hline Home resources & 1 & 2 & 3 & 4 & 5 \\
\hline $\begin{array}{l}\text { 1. Employment } \\
\text { partner } \\
\text { 2. Resp. childcare }\end{array}$ & $.333^{* *}$ & & & & \\
\hline $\begin{array}{l}\text { 3. Resp. care } \\
\text { coordination }\end{array}$ & $.238^{*}$ & $.774^{* *}$ & & & \\
\hline $\begin{array}{l}\text { 4. Flexibility work } \\
\text { issues }\end{array}$ & .151 & .157 & $.179+$ & & \\
\hline $\begin{array}{l}\text { 5. Flexibility childcare } \\
\text { issues }\end{array}$ & .131 & -.018 & -.018 & $.621^{* *}$ & \\
\hline 6. Diff. comb & .035 & -.037 & -.160 & $-.413^{* *}$ & $-.424^{* *}$ \\
\hline 7. Pos. w-f spillover & -.045 & -.050 & -.073 & .127 & .157 \\
\hline 8. Pos. f-w spillover & .009 & $.223^{*}$ & $.280^{* *}$ & $.361^{* *}$ & $.255^{*}$ \\
\hline 9. Neg. w-f spillover & .148 & $.247^{*}$ & .156 & -.043 & .040 \\
\hline 10. Neg. f-w spillover & -.138 & $-.244^{*}$ & $-.249 *$ & $-.382^{* *}$ & $-.259 *$ \\
\hline
\end{tabular}

Home ecology regression analyses. Regression analyses were conducted to examine the multivariate influence of home resources on fathers' difficulty combining work and family, and spillover (see Tables 11 and 12). The results show that family flexibility to handle work issues was a significant resource for fathers in relationship to both the positive and negative family to work spillover. Employment status of spouse or partner was not a significant predictor for any of the dependent variables.

Responsibility for childcare was positively and significantly associated with difficulty combining work and family $(F=6.74, p=.00)$ and negative work to family spillover $(F=1.55, p=.18)$ at trend level. Partner/spousal 
responsibility for childcare was positively related with difficulty combining work and family, and negative work to family spillover.

Family flexibility to handle both work and childcare issues was negatively and significantly associated with difficulty combining work and family therefore higher family flexibility was associated with lower difficulty combining work and family. Family flexibility to manage work responsibilities was also a significant predictor of positive family to work spillover $(F=3.35, p=.01)$ and negative family to work spillover $(F=3.01, p=.02)$.

None of the home resources was significantly related to positive work to family spillover $(F=.72, p=.61)$. Home resources explained the most variance in difficulty combining work and family $\left(R^{2}=.28\right)$, but they were of smaller predictive power for spillover.

Table 11

Regression Home Resource Measures Predicting Difficulty Combining Work and Family and Negative Work to Family Spillover

\begin{tabular}{lccccccc}
\hline & $\begin{array}{l}\text { Model 1 Difficulty } \\
\text { combining work and } \\
\text { family }\end{array}$ & \multicolumn{5}{c}{$\begin{array}{c}\text { Model 2 Negative work to } \\
\text { family spillover b }\end{array}$} \\
\hline \multicolumn{1}{c}{ Variables } & $B$ & $S E B$ & $\beta$ & $B$ & $S E B$ & $\beta$ \\
\hline Employment partner & .13 & .21 & .06 & .42 & .64 & .08 \\
Resp. childcare & .43 & .18 & $.31^{*}$ & .99 & .56 & $.27 \dagger$ \\
Resp. care coordination & -.24 & .13 & $-.23+$ & -.14 & .42 & -.05 \\
Flexibility work issues & -.42 & .19 & $-.26^{*}$ & -.89 & .60 & -.20 \\
$\begin{array}{l}\text { Flexibility childcare } \\
\text { issues }\end{array}$ & -.44 & .19 & $-.27^{*}$ & .73 & .60 & .17 \\
$\mathrm{R}^{2}$ & & .28 & & & .09 & \\
\hline
\end{tabular}

\footnotetext{
${ }^{\mathrm{a}} n=90 .{ }^{\mathrm{b}} n=87$.
}

$+p<.1{ }^{*} p<.05$. 
Table 12

Regression Home Resource Measures Predicting Positive and Negative Family to Work Spillover

\begin{tabular}{lcccccc}
\hline & \multicolumn{3}{c}{$\begin{array}{c}\text { Model 1 Positive family } \\
\text { to work spillover }\end{array}$} & \multicolumn{4}{c}{$\begin{array}{c}\text { Model 2 Negative family to } \\
\text { work spillover }\end{array}$} \\
\hline \multicolumn{1}{c}{ Variables } & $B$ & $S E B$ & $\beta$ & $B$ & $S E B$ & $\beta$ \\
\hline Employment partner & -.40 & .48 & -.09 & -.17 & .51 & -.04 \\
Resp. childcare & -.06 & .43 & -.02 & -.15 & .45 & -.05 \\
Resp. care coordination & .43 & .31 & .19 & -.18 & .33 & -.08 \\
Flexibility work issues & .96 & .45 & $.28^{*}$ & -1.12 & .48 & $-.31^{*}$ \\
$\begin{array}{l}\text { Flexibility childcare } \\
\text { issues }\end{array}$ & .42 & .45 & .12 & -.22 & .48 & -.06 \\
$\mathrm{R}^{2}$ & & .17 & & & .15 & \\
\hline
\end{tabular}

Note. $N=89$.

$* p<.05$.

Research question 3: What type of community ecology resources predicts difficulty combining work and family, and spillover for employed

\section{fathers of children with SHCN?}

Community ecology between variable correlations. As can be seen in

Table 13, the helpfulness of services was positively associated with support from friends and neighbors $(p=.00)$. Higher ratings of services and resources were also associated with reduced difficulty combining work and family $(p=.01)$, less negative family to work spillover $(p=.00)$, and increased positive family to work spillover $(p=.03)$. Support from friends and neighbors was negatively correlated with difficulty combining work and family $(p=.00)$ and negative work-family and family work spillover $(p=.01$, and $p=.00)$. Support from friends and neighbors was positively associated with positive work to family and family to work spillover ( $p=.02$, and $p=.00$, respectively). 
Table 13

Correlations of Community Resource Measures and Difficulty Combing Work and Family and Spillover

\begin{tabular}{|c|c|c|c|c|c|c|}
\hline $\begin{array}{l}\text { Community } \\
\text { resources }\end{array}$ & 1 & 2 & 3 & 4 & 5 & 6 \\
\hline 1. Services & - & & & & & \\
\hline $\begin{array}{l}\text { 2. Friend/neighbor } \\
\text { support }\end{array}$ & $.337^{* *}$ & & & & & \\
\hline 3. Diff. comb & $-.271^{*}$ & $-.428^{* *}$ & & & & \\
\hline 4. Pos. w-f spillover & -.089 & $.251^{*}$ & $-.208^{*}$ & & & \\
\hline 5. Pos. f-w spillover & $.218^{*}$ & $.473^{* *}$ & $-.457^{* *}$ & $.379^{* *}$ & & \\
\hline 6. Neg. w-f spillover & -.148 & $-.260 *$ & $.361^{* *}$ & -.033 & $-.243^{*}$ & \\
\hline 7. Neg. f-w spillover & $-.319^{* *}$ & $-.421^{* *}$ & $.488^{* *}$ & -.079 & $-.614^{* *}$ & $-.399 * *$ \\
\hline
\end{tabular}

Community ecology regression analyses. Regression analyses confirmed initial bivariate findings illustrating the significant association between community supports and work-family integration. Support from friends and neighbors was a significant predictor of all five outcome variables (see Tables 14, 15, and 16). Service helpfulness was a significant predictor of negative family to work spillover (Table 16) and was negatively related at trend level to positive work to family spillover (Table 15). Fathers who reported more friend and neighbor support, reported lower levels of both work and family interfering, and greater levels of both work and family enhancing each other. All five models predicting difficulty combining work and family, positive work to family and family to work spillover, and negative work to family and family to work spillover were significant $(F=11.85, p=.00, F=4.99, p=.01, F=13.73, p=.00$, $\mathrm{F}=3.53, \mathrm{p}=.03$, and $\mathrm{F}=12.57, \mathrm{p}=.00$ respectively). Community resources explained 
considerable variance in difficulty combining work and family $\left(R^{2}=.20\right)$, positive family to work spillover $\left(R^{2}=.23\right)$, and negative family to work spillover $\left(R^{2}=\right.$ $.21)$.

Table 14

Regression Community Resource Measures Predicting Difficulty Combining Work and Family

\begin{tabular}{lccc}
\hline & \multicolumn{4}{c}{ Model 1 Difficulty combining work and } \\
family & & \multicolumn{1}{c}{$\beta$} \\
\hline \multicolumn{1}{c}{ Variables } & $B$ & $S E B$ & -.14 \\
\hline Services & -.22 & .15 & $-.38^{* * *}$ \\
$\begin{array}{l}\text { Friend/neighbor } \\
\text { support }\end{array}$ & -.44 & .11 & \\
$\mathrm{R}^{2}$ & & .20 & \\
\hline
\end{tabular}

Note. $N=96$.

*** $p<.001$.

Table 15

Regression Community Resource Measures Predicting Positive Work to Family and Family to Work Spillover

\begin{tabular}{lcccccc}
\hline & \multicolumn{3}{c}{$\begin{array}{l}\text { Model 2 Positive work to } \\
\text { family spillover }\end{array}$} & \multicolumn{3}{c}{$\begin{array}{c}\text { Model 3 Positive family to } \\
\text { work spillover }\end{array}$} \\
\hline \multicolumn{1}{c}{ Variables } & $B$ & $S E B$ & $\beta$ & $B$ & $S E B$ & $\beta$ \\
\hline Services & -.77 & .40 & $-.20+$ & .22 & .31 & .07 \\
$\begin{array}{l}\text { Friend/neighbor } \\
\text { support } \\
\mathrm{R}^{2}\end{array}$ & .92 & .30 & $.32^{* *}$ & 1.11 & .24 & $.45^{* * *}$ \\
& & .10 & & & .23 & \\
\hline
\end{tabular}

Note. $N=93$.

$+\mathrm{p}<.1{ }^{* *} p<.01 .{ }^{* * *} p<.001$. 
Table 16

Regression Community Resource Measures Predicting Negative Work to Family and Family to Work Spillover

\begin{tabular}{lccccccc}
\hline & \multicolumn{3}{c}{$\begin{array}{l}\text { Model 4 Negative work to } \\
\text { family spillover }\end{array}$} & \multicolumn{4}{c}{ Model 5 Negative family to } \\
work spillover & \\
\hline \multicolumn{1}{c}{ Variables } & $B$ & $S E B$ & $\beta$ & $B$ & $S E B$ & $\beta$ \\
\hline Services & -.27 & .43 & -.07 & -.70 & .34 & $-.20^{*}$ \\
$\begin{array}{l}\text { Friend/neighbor } \\
\text { support }\end{array}$ & -.72 & .33 & $-.24^{*}$ & -.93 & .26 & $-.35^{* * *}$ \\
$\mathrm{R}^{2}$ & & .07 & & & .21 & \\
\hline
\end{tabular}

Note. $N=93$.

${ }^{*} p<.05{ }^{* * *} p<.001$.

The findings demonstrate significant relationships between several types of job, home, and community resources with fathers' ability to integrate work and family demands. Fathers of children challenged by SHCN have complex lives that take place in different constellations of job, home, and community ecologies, replete with varying resources. The next set of analyses focused on a closer investigation of the effects of resources within and across job, home, and community ecologies on fathers' reports of difficulties combining the demands of work and family.

\section{Regression analyses of job, home, community resource indices predicting difficulty combining work and family and spillover}

Measuring resources within the job, home, and community ecologies is complex (Moen, 2011) and indices provided one opportunity to address this complexity through using composite measures instead of single indicators (Carmines \& Woods, 2004, Mc Lennan, Moyle, Ruhanen, \& Ritchie, 2013). Bivariate correlations of the single resource measures presented in the previous 
sections demonstrate that individual resources were correlated empirically, supporting the theoretical considerations of resource ecologies (Moen et al., 2008a). Bivariate correlations were produced to better understand the spread and relationships of resources in this sample of employed fathers caring for children with SHCN. The indices were then used in a set of regression analyses to examine the influence of resource levels in the job, the home, and the community on difficulty combining work and family, and negative and positive spillover. Job resources for fathers in this sample were slightly skewed to the right, with more fathers reporting above average job resources. Community resources were slightly skewed to the left, with more fathers reporting below average community resources. Home resources were distributed fairly evenly. Skewness of these indices was found acceptable for regression analysis.

Between variable correlations. One set of bivariate correlations investigated the differences in resource levels based on fathers and children's demographics (see Table 17). Income $(p=.00)$ and education was positively correlated with job resources $(p=.01)$, with fathers reporting higher incomes and educational attainments reporting more job resources.

The levels of job, home, or community resources were not significantly correlated with any of the child descriptives (Table 17). Even if not significant, fathers who reported more demanding family ecologies, with more or younger children and higher symptom levels, reported lower levels of home and community resources. In contrast, fathers reporting more and younger children, reported more job resources. 
Table 17

Correlations of Job, Home and Community Resources, and Demographics

\begin{tabular}{|c|c|c|c|c|c|c|c|c|}
\hline Child variable & 1 & 2 & 3 & 4 & 5 & 6 & 7 & 8 \\
\hline 1. Father's age & 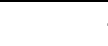 & & & & & & & \\
\hline 2. Income & .014 & & & & & & & \\
\hline 3. Education & .047 & $.352^{* *}$ & & & & & & \\
\hline 4. Race & $-.213+$ & -.064 & -.157 & & & & & \\
\hline $\begin{array}{l}5 . \text { Age of the } \\
\text { youngest child }\end{array}$ & $.465^{* *}$ & -.125 & .022 & -.099 & & & & \\
\hline $\begin{array}{l}\text { 6. Number of } \\
\text { children }\end{array}$ & -.074 & -.068 & -.097 & .129 & $-.259 *$ & & & \\
\hline $\begin{array}{l}\text { 7. How often child } \\
\text { symptoms affect } \\
\text { activities }\end{array}$ & -.009 & -.010 & -.108 & .033 & -.038 & .058 & & \\
\hline $\begin{array}{l}\text { 8. How much child } \\
\text { symptoms affect } \\
\text { activities }\end{array}$ & -.005 & .047 & $-.181 \dagger$ & .051 & -.020 & -.120 & $.650^{* *}$ & \\
\hline $\begin{array}{l}\text { 9. Job resource } \\
\text { index }\end{array}$ & .095 & $.379^{* *}$ & $.271^{*}$ & .062 & .017 & .065 & -.006 & -.099 \\
\hline $\begin{array}{l}10 . \text { Home } \\
\text { resource index }\end{array}$ & .062 & .027 & -.067 & .021 & -.075 & -.017 & -.039 & .005 \\
\hline $\begin{array}{l}\text { 11. Community } \\
\text { resource index }\end{array}$ & -.111 & .077 & .053 & .030 & -.035 & -.043 & -.124 & -.156 \\
\hline
\end{tabular}

Another set of bivariate correlations was developed to examine the relationships between job, home, and community resources and the dependent variables (see Table 18). 
Table 18

Correlations of Job, Home, and Community Resources and Difficulty Combining Work and Family and Spillover

\begin{tabular}{lccc}
\multicolumn{1}{c}{ Resource indices } & 1 & 2 & 3 \\
\hline 1. Job resource index & - & & \\
2. Home resource index & .013 & & \\
3. Community resource index & $.293^{* *}$ & $.226^{*}$ & \\
4. Difficulty combining & $-.335^{* *}$ & $-.231^{*}$ & $-.427^{* *}$ \\
5. Pos. w-f spillover & $.278^{* *}$ & .015 & .099 \\
7. Pos. f-w spillover & $.195^{\dagger}$ & $.304^{* *}$ & $.423^{* *}$ \\
8. Neg. w-f spillover & -.011 & .137 & $-.250^{*}$ \\
9. Neg. f-w spillover & -.076 & $-.342^{* *}$ & $-.453^{* *}$ \\
\hline
\end{tabular}

Note. $N=93$.

$\dagger \mathrm{p}<.1{ }^{*} p<.05 .{ }^{* *} p<.01$.

Job resources were significantly and positively correlated with community resources $(p=.00)$ and home resources were significantly and positively associated with community resources $(p=.03)$. Job and home resources were not significantly associated. Resources in all three ecologies were negatively correlated with difficulty combining work and family $(p=.00, p=.03$, and $p=.00$ respectively). More resources within the job ecology were associated with more positive work to family spillover $(p=.01)$. Home and community resources were positively and significantly correlated with positive family to work spillover $(p=.00)$ and negatively with negative family to work spillover ( $p$ $=.00$ ). More support within the community ecology was significantly associated with less negative work to family spillover on a bivariate level $(p=.02)$. 
Research question 4: Do job, home, or community resources predict difficulty combining work and family, and positive and negative spillover for employed fathers of children with SHCN? The job, home, and community resource indices were used in regression analyses to predict all five outcome variables: difficulty combining work and family, and positive and negative work to family, and family to work spillover. The most parsimonious model for each outcome variable was chosen and demographic control variables were included if appropriate.

Difficulty combining work and family. As shown in Table 19, resources in the job, home, and community ecologies were associated negatively with difficulty combining work and family with all three indices reaching a significant level. Job, home, and community resources explained $29 \%$ of the variance of difficulty combining work and family $\left(R^{2}=.29, F=11.30, p=.00\right)$. Community resources were the strongest predictor of difficulty combining work and family $(\beta=-.36)$, followed by job $(\beta=-.21)$, and home $(\beta=-.20)$ resources at a similar level.

Table 19

Regression Predicting Difficulty Combining Work and Family with Job, Home, and Community Resources

\begin{tabular}{|c|c|c|c|c|}
\hline Predictor & $R^{2}$ & $B$ & $S E B$ & $\beta$ \\
\hline & .29 & & & \\
\hline Job resource index & & $-.34^{*}$ & .16 & $-.21^{*}$ \\
\hline Home resource index & & $-.36^{*}$ & .17 & $-.20 *$ \\
\hline Community resource index & & $-.45^{* * *}$ & .12 & $-.36^{* * *}$ \\
\hline
\end{tabular}


Including child variables such as age of the youngest child, number of children, and symptom severity or additional job variables such as job security did not improve the overall fit of the model $(F=4.02, p=.00)$ with similar variance explained $\left(R^{2}=.30\right)$ and smaller adjusted $R^{2}$.

Positive work to family spillover. The second regression model (Table 20) predicting positive work to family spillover explained $11 \%$ of variance $\left(R^{2}=\right.$ .11) in positive work to family spillover. The model was significant $(F=3.28, p=$ .03 ) and the job resource index was a significant independent predictor of positive work to family spillover when controlling for home and community resources. Fathers who reported more job resources reported greater facilitation between their work and family. Community and home resources were not significant independent predictors of positive work to family spillover. Child demographics or job security measures were not significant and did not improve overall model fit $(F=1.24, p=.29)$ and reduced levels of adjusted $R^{2}$ from .08 to .02 .

Table 20

Regression Predicting Positive Work to Family Spillover with Job, Home, and Community Resources

\begin{tabular}{lcccc}
\hline Predictor & $R^{2}$ & $B$ & $S E B$ & $\beta$ \\
\hline Job resource index & .11 & & & \\
Home resource index & & .85 & .43 & $.22^{*}$ \\
Community resource index & & .12 & .45 & .03 \\
\hline
\end{tabular}

Note. $N=85$.

${ }^{*} p<.05$.

Positive family to work spillover. Both regression models employed for predicting positive family to work spillover were significant $\left(F_{1}=8.35, p_{1}=.00\right.$ 
and $F_{2}=8.99, p_{2}=.00$, adjusted $R^{2}=.29$ ). As can be seen in Table 21 , job, home, and community resources explained $25 \%$ of variance in positive family to work spillover. Including the child symptomology variable of how often child symptoms affected activities increased variance explained by $8 \%\left(R^{2}{ }_{1}=.25\right.$ and $R^{2}{ }_{2}=.33$ ). Home and community resources positively predicted positive family to work spillover. Job related resources also increased positive family to work spillover but they were not significant. The symptom measure of how often the child's SHCN affected his/her activities was negatively associated with positive family to work spillover. Age of the youngest child, number of children, and how much the child's activity levels were impaired were not significant predictors of positive family to work spillover and did not improve overall model fit $(F=4.07$, $p=.00$, adjusted $R^{2}=.23$ ). Community resources were the strongest predictor of positive family to work spillover $(\beta=.32)$ followed by child symptoms $(\beta=-.28)$. Table 21

Stepwise Regression Predicting Positive Family to Work Spillover with Job, Home, and Community Resources

\begin{tabular}{|c|c|c|c|c|c|}
\hline Step & Predictor & $R^{2}$ & $B$ & $S E B$ & $\beta$ \\
\hline \multirow[t]{4}{*}{1} & & .25 & & & \\
\hline & Job resource index & & .22 & .38 & .06 \\
\hline & Home resource index & & .97 & .38 & $.26^{*}$ \\
\hline & Community resource index & & .93 & .28 & $.35^{* *}$ \\
\hline \multirow[t]{5}{*}{2} & & .33 & & & \\
\hline & Job resource index & & .24 & .36 & .07 \\
\hline & Home resource index & & .92 & .36 & $.25^{*}$ \\
\hline & Community resource index & & .83 & .27 & $.32^{* *}$ \\
\hline & $\begin{array}{l}\text { How often child symptoms affect } \\
\text { activities }\end{array}$ & & -.82 & .28 & $-.28^{*}$ \\
\hline
\end{tabular}

Note. $N=77$.

${ }^{*} p<.05 .{ }^{* *} p<.01$. 
Negative work to family spillover. Two models were developed for predicting negative work to family spillover $\left(F_{1}=4.27, p_{1}=.01\right.$ and $F_{2}=5.77, p_{2}=$ $.00)$. Community resources were negatively associated with negative work to family spillover, when controlling for work and family resources, see Table 22 . Therefore, fathers who reported more community resources, reported less conflict between work and family roles. Job and home resources were not significant predictors of negative work to family spillover. Income adequacy was negatively and significantly associated with negative work to family spillover. The age of the youngest child was also a significant predictor of negative work to family spillover for fathers in this study. The full model explained $30 \%$ of variance in negative work to family spillover $\left(R^{2}=.30\right)$. Community resources $(\beta$ $=-.33$ ) were again the strongest predictor similar to the findings in the other dimensions of work-life fit.

Table 22

Stepwise Regression Predicting Negative Work to Family Spillover with Job, Home, and Community Resources

\begin{tabular}{|c|c|c|c|c|c|}
\hline Step & Predictor & $R^{2}$ & $B$ & $S E B$ & $\beta$ \\
\hline \multirow[t]{4}{*}{1} & & .15 & & & \\
\hline & Job resource index & & .33 & .47 & .08 \\
\hline & Home resource index & & .10 & .52 & .02 \\
\hline & Community resource index & & $-1.25^{* *}$ & .36 & $-.41^{* *}$ \\
\hline \multirow[t]{6}{*}{2} & & .30 & & & \\
\hline & Job resource index & & .65 & .45 & .16 \\
\hline & Home resource index & & .10 & .49 & .02 \\
\hline & Community resource index & & -1.12 & .33 & $-.37^{* *}$ \\
\hline & Income adequacy & & -.34 & .11 & $-.33^{* *}$ \\
\hline & Age youngest child in family & & -.15 & .06 & $-.26^{*}$ \\
\hline
\end{tabular}

Note. $N=73$.

$* p<.05$. ${ }^{* *} p<.01$. 
Negative family to work spillover. According to Table 23, home and community resources were significantly and negatively related to negative family to work spillover. Higher levels of both community and home resources were therefore associated with less conflict between family and work. The model was significant $(F=13.66, p=.00)$ and explained $29 \%$ of variance. Including child and income variables did not improve overall model fit $(F=5.59, p=.00)$. The community resource index $(\beta=-.45)$ was the strongest predictor of negative family to work spillover followed by home resources $(\beta=-.26)$

Table 23

Regression Predicting Negative Family to Work Spillover with Job, Home, and Community Resources

\begin{tabular}{|c|c|c|c|c|c|}
\hline Step & Predictor & $R^{2}$ & $B$ & $S E B$ & $\beta$ \\
\hline \multirow[t]{4}{*}{1} & & .29 & & & \\
\hline & Job resource index & & .56 & .36 & .16 \\
\hline & Home resource index & & -1.05 & .37 & $-.26^{* * *}$ \\
\hline & Community resource index & & -1.25 & .28 & $-.45^{* * *}$ \\
\hline
\end{tabular}

Note. $N=86$.

${ }^{* * *} p<.001$

Job, home, and community resource indices were found to be significant predictors of difficulty combining work and family, and positive and negative spillover. Community resources was the strongest predictor of difficulty combining work and family, positive family to work spillover, and negative work to family spillover and family to work spillover. Symptom levels and the age of the youngest child were significant predictors of positive family to work spillover and negative work to family spillover. The final set of regression analyses included variable product terms to take a look at potential moderating relationships between job, home, and community resources. 


\section{Regression analysis testing moderating relationships}

The second set of research questions focused on possible moderating relationships of job, home, and community resources:

5. Do home resources moderate the effects of job resources on difficulty combining work and family, and spillover for employed fathers of children with SHCN?

6. Do community resources moderate the effects of home resources on difficulty combining work and family, and spillover for employed fathers of children with SHCN?

7. Do community resources moderate the effects of job resources on difficulty combining work and family, and spillover for employed fathers of children with SHCN?

As shown in the prior analyses, there was a simple effect of job, home, and community resources on fathers' difficulty combining work and family, and spillover, suggesting that the effect of job, home, and community resources on the dependent variables was additive. If there is an interaction or moderating relationship between job, home, or community resources, then the effects of job, home, and community resources depend on each other and are more than the sum of the separate effects (Cohen et al., 2003). Moderating relationships can be synergistic, therefore the effect of the combination of two variables is greater than the effect of both variables separately. Moderating relationships can also be compensatory, with one variable compensating for the other variable. Moderating relationships of continuous variables can be explored with regression analysis using variable product terms. The three interaction 
questions were analyzed using the product of job resource index*home resource index, home resource index*community resource index, and job resource index* community resource index in regression analyses predicting all five outcome variables. Simple slopes models were developed for significant interactions to better understand the nature of the moderating relationships (Cohen et al., 2003; Dawson, 2014).

Research question 5: Do home resources moderate the effects of job resources on difficulty combining work and family, and spillover for employed fathers of children with SHCN? The regression analyses including the job*home resource index product term found one significant interaction between job and home resources on positive work to family spillover (see Table 24). Both models were significant $(F=3.28, p=.03$ and $F=3.75, p=.01$ respectively). The second model explained $16 \%$ of variance in positive work to family spillover. The interaction between job and home resources accounted for $5 \%$ of variance in this sample. Job resources positively and significantly predicted positive work to family spillover. The interaction term of job and home resources was negatively correlated with positive work to family spillover. 
Table 24

Regression of Job, Home, Community Resources on Positive Work to Family Spillover including Job*Home Interaction

\begin{tabular}{|c|c|c|c|c|c|}
\hline Step & Predictor & $\mathrm{R}^{2}$ & $B$ & $S E B$ & $\beta$ \\
\hline \multirow[t]{4}{*}{1} & & .11 & & & \\
\hline & Job resource index & & .85 & .43 & $.22^{*}$ \\
\hline & Home resource index & & .12 & .45 & .03 \\
\hline & Community resource index & & .52 & .33 & .18 \\
\hline \multirow[t]{5}{*}{2} & & .16 & & & \\
\hline & Job resource index & & .99 & .43 & $.25^{*}$ \\
\hline & Home resource index & & .13 & .44 & .03 \\
\hline & Community resource index & & .45 & .32 & .15 \\
\hline & Interaction job*home resource index & & -1.57 & .72 & $-.22 *$ \\
\hline
\end{tabular}

Note. $N=85$.

$* p<.05$

The simple slopes procedure charted fathers' positive work to family spillover at high home/high job, low home/low job, high home/low job, and low home/high job points and allowed for a better interpretation of the direction of the moderating relationship (see Figure 1).

Figure 1

Simple Slopes Interaction Job*Home on Positive Work to Family Spillover

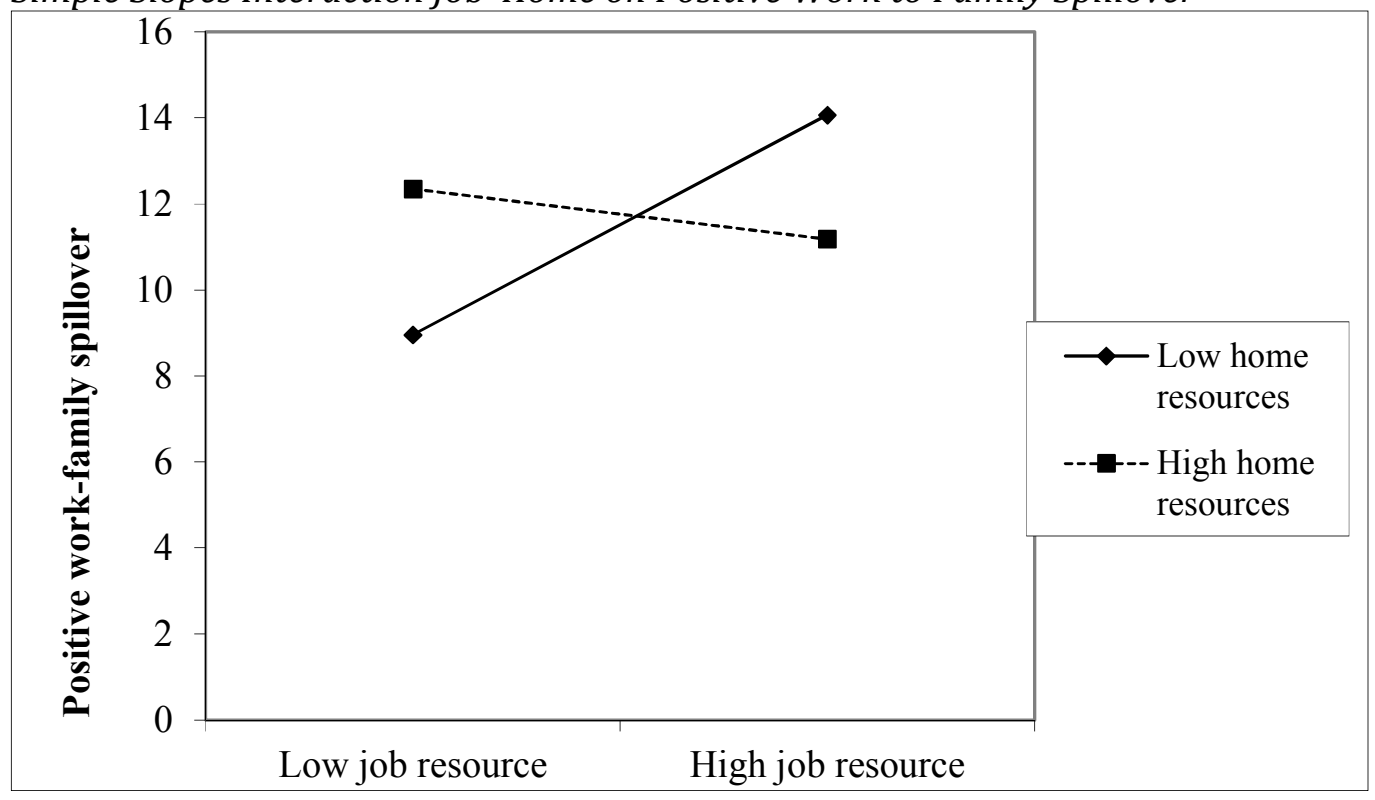


Fathers with low home and high job resources reported the highest level of positive work to family spillover, even higher than fathers with both high home and high job resources. Fathers with both low home and job resources reported the lowest levels of positive work to family spillover. Fathers in the high home and low job resource group showed moderate levels of positive work to family spillover and scored higher on positive work to family spillover than fathers in the high job and high home resource group. Greater job resources seem to compensate for a lack of home resources, more than greater home resources compensate for a lack of job resources.

Research question 6: Do community resources moderate the effects of home resources on difficulty combining work and family, and spillover for employed fathers of children with SHCN? The second set of regression analyses found one non-significant trend level effect for all five outcome variables. As can be seen in Table 25, the effect of the interaction of home and community resources on negative family to work spillover reached trend level significance of $p=.9$ when controlling for the simple effects of job, home, and community resources $(F=9.57, p=.00)$. Home, community, and the interaction of home and community resources were negatively and significantly related with negative family to work spillover when controlling for job resources. The model including the interaction term explained $32 \%$ of variance, which is a $3 \%$ increase compared to the main-effects-only model. 
Table 25

Regression of Job, Home, and Community Resources on Negative Family to Work Spillover including Home*Community Interaction

\begin{tabular}{|c|c|c|c|c|c|}
\hline Step & Predictor & $\mathrm{R}^{2}$ & $B$ & $S E B$ & $\beta$ \\
\hline \multirow[t]{4}{*}{1} & & .29 & & & \\
\hline & Job resource index & & .60 & .36 & .16 \\
\hline & Home resource index & & -1.05 & .37 & $-.26^{* *}$ \\
\hline & Community resource index & & -1.25 & .28 & $-.45^{* * *}$ \\
\hline \multicolumn{6}{|l|}{2} \\
\hline & & .32 & & & \\
\hline & Job resource index & & .64 & .36 & $.17^{\dagger}$ \\
\hline & Home resource index & & -1.10 & .37 & $-.27^{* *}$ \\
\hline & Community resource index & & -1.24 & .27 & $-.45^{* * *}$ \\
\hline & $\begin{array}{l}\text { Interaction home* community resource } \\
\text { index }\end{array}$ & & .71 & .41 & $.16^{\dagger}$ \\
\hline
\end{tabular}

The simple slopes (Dawson, 2014) presented in Figure 2 of negative family to work spillover at low and high home and community resource levels illustrated that fathers with low home and community resources reported the highest levels of negative family to work spillover and fathers with both high home and community resources the lowest levels of negative family to work spillover. Fathers with low community resources showed a greater reduction of negative family to work spillover when having high home resources than expected from the simple effect of community and home resources as represented by the non-parallel development of the two slopes. Fathers in the high community resource group did not report as great a reduction of negative family to work spillover when accessing high levels of home resources compared to low levels of home resources. This graph therefore pointed to a compensating effect of low community and high home resources. 
Figure 2

Simple Slopes Interaction Home*Community on Negative Family to Work Spillover

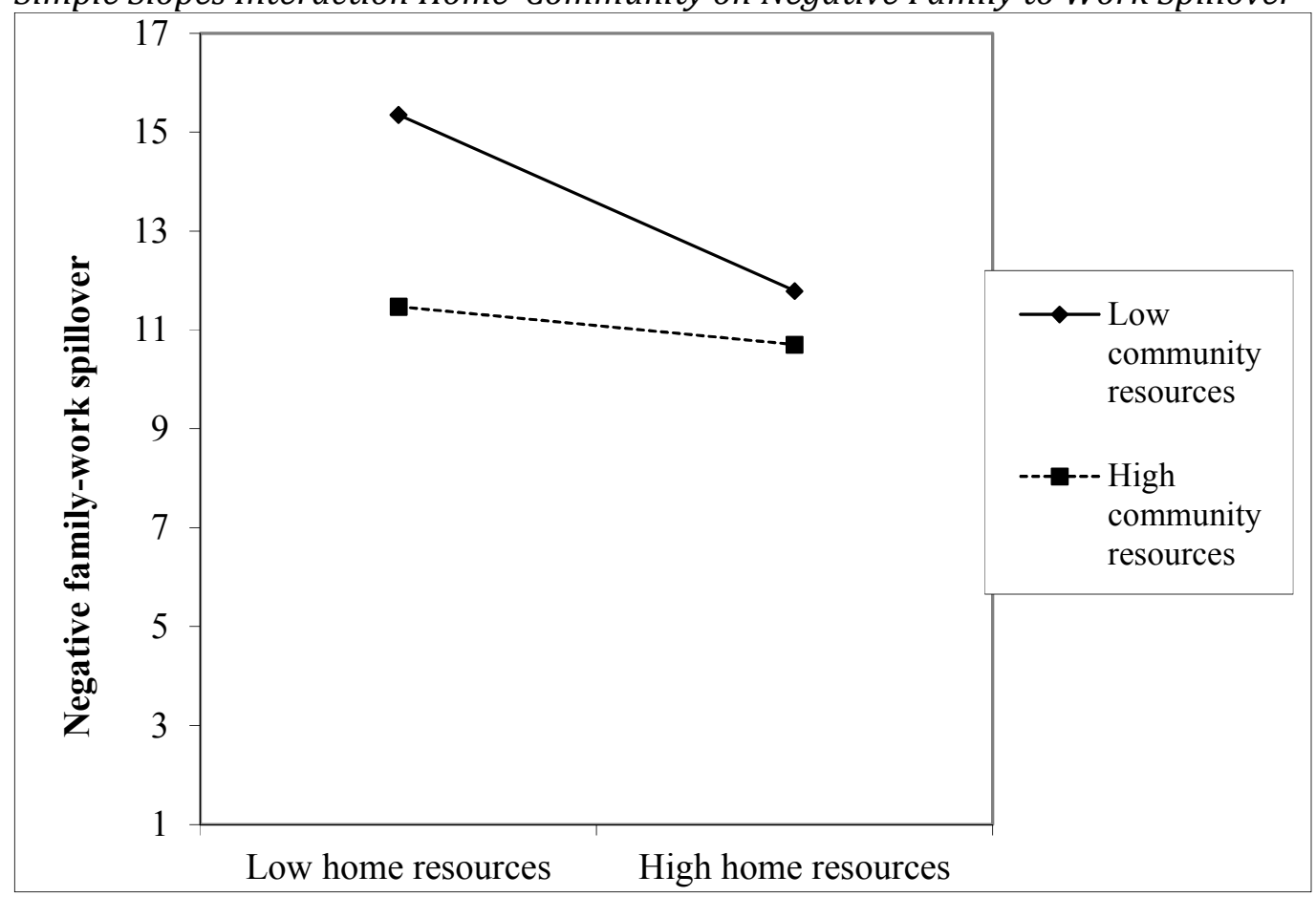

Research question 7: Do community resources moderate the effects of job resources on difficulty combining work and family, and spillover for employed fathers of children with SHCN? Considering the final research question, there was neither a significant nor a non-significant trend level effect for a potentially moderating relationship of community resources on job resources regarding difficulty combining work and family, and negative and positive spillover.

\section{Summary}

Fathers in this sample reported fairly high levels of job and home resources, but only moderate levels of community resources. The regression analyses demonstrated that some types of job, home, and community resources 
were significantly related to fathers' ability to integrate work and family demands. Greater access to workplace flexibility was significantly associated with decreased difficulty combining work and family, and negative family to work spillover when controlling for the other job resources. The flexibility in the family to take care of work issues was a significant predictor of positive family to work spillover, and reduced difficulty combining work and family, and negative family to work spillover. Support from friends and neighbors was associated with all five outcome variables, and access to supportive services was a significant predictor of negative family to work spillover.

The single items used to construct each of the three resource indices were correlated with each other supporting the theoretical consideration that these single items measured the same underlying concepts, for example, the two community resource items were correlated with each other supporting the assumption that they both measure community resources. The job, home, and community resource indices were therefore appropriate for use in regression analyses to better understand the complexity of resource patterns experienced by fathers caring for children with SHCN. Resources in all three ecologies were significant predictors of difficulty combining work and family, and spillover, with community resources being the strongest predictor for most dimensions. Age of the youngest child and the child's symptom levels were significant predictors for negative work to family spillover and positive family to work spillover.

The analyses also supported the possibility of moderating relationships between resource ecologies. Fathers reporting low home and low job resources indicated the lowest levels of positive work to family spillover; and fathers 
reporting low home resources and high job resources, indicated the highest levels of positive work to family spillover. High home resources were especially significant for low community resource ecologies in relation to negative family to work spillover. The analyses of the current study found a moderating relationship for home resources on job resources related to positive work to family spillover and for community resources on home resources related to negative family to work spillover. 


\section{Chapter V}

\section{Discussion}

Employed fathers of children with SHCN require the availability and accessibility of relevant resources within each of their job, home, and community ecologies in order to effectively combine the requirements of job and family. The current study is one of the few investigations to examine the work-life experiences of fathers with child-related exceptional caregiving responsibilities. The image of work-life integration as a puzzle (Emlen, 2010), uniquely configured by each father, is a useful metaphor for how resources and flexibilities are woven together by the respondents. Findings of this study suggest that there is a compensatory relationship between resources across the three ecologies, the level of resources in one ecology interacting with the level of resources in the other two. Similarly to studies of mothers or primary caregivers of children with SHCN (Brennan, Rosenzweig, Ogilvie et al., 2007; Brown, 2014; Stewart, 2013), fathers have significant difficulty combining work and family demands. Access to flexibility in the job ecology, a condition frequently identified in the literature as essential for work-life integration (Allen et al., 2013; Kelly et al., 2008; Kossek et al., 2006), does little to ease the difficulty of meeting workfamily demands for these fathers.

\section{Importance of resources across ecologies for combining work and family responsibilities}

Community resources. Resources within the community ecology, including social relationships and supportive services were especially relevant for this group of fathers. One survey item allowed fathers to rate the helpfulness 
of specific services including childcare, school, after-school care, public transportation, and health care on a scale of 0 (not at all helpful) to 10 (almost always helpful). School and health care services received the highest ratings for helpfulness to working and providing care for family needs followed by childcare and after-school care. Unfortunately, overall service availability for all services used by the families was rated low to moderate. A portion of the fathers did not provide a rating regarding the helpfulness of public transportation and afterschool care for combining work and family limiting possibility for interpretation. For example only $39 \%$ of fathers provided helpfulness ratings for public transportation and $49 \%$ of fathers provided ratings for after-school care. The absence of ratings may reflect a lack of availability or relevance of these services for children with SHCN (Brennan, Rosenzweig, Ogilvie et al., 2007). Public transportation services might not be accessible for these children because of their health care requirements or public transportation services might not be available because of more rural living conditions. Caregivers in previous studies were reported to be often the sole source of transportation for their children with emotional and behavioral issues (Rosenzweig et al., 2002). Similarly, children with emotional and behavioral issues were more likely to be cared for by a parent in their own home after school rather than outside the home by extended family or paid childcare staff (Rosenzweig, Brennan et al., 2008). School and health care services received more and higher ratings with regard to their helpfulness for combining work and family from fathers in this study. However, the levels of supportiveness of school and health care remained moderate. Findings from the 2009/2010 National Survey of Children with 
Special Health Care Needs indicated that $24 \%$ of caregivers of children with SHCN had at least one unmet need for health care services or equipment, and $23 \%$ had problems getting the necessary referrals. Children with SHCN were more likely than children with typical development to miss more than 11 days of school and to have repeated calls home related to problems in school (Bethell, Forrest, Stumbo, Gombojav, Carle, \& Irwin, 2012). These school disruptions affect parents' ability to maintain employment, especially if children could not be cared for by extended family members (Rosenzweig et al., 2002).

Findings from the current study align with results from prior investigations that address the importance of support from friends and neighbors for easing the difficulty of combining work and family (Stewart, 2013; Voydanoff, 2005). Previous research has indicated that caregivers of children with SHCN may face greater social isolation (Friesen, 1989; Friesen, Brennan, \& Penn, 2008) and that fathers may be less likely to seek social and emotional support (Darling et al., 2012; Heckmann, 2007; Kallenbach, 2002). Almost half of the fathers responding reported that they had limited support from friends and neighbors. Lack of social engagement expressed by the respondents could be an indicator of courtesy stigmatization experiences, which can lead to social exclusion. For example, Angermeyer et al. (2003) reported in their qualitative study that relatives of individuals with schizophrenia cited social exclusion and withdrawal as the second most relevant experience of stigmatization. Another study of caregivers of children with autism reported that friends withdrew contact and that they often lacked time or energy to engage in friendships due to exceptional caregiving responsibilities (Jungbauer \& Meye, 2008). Community 
engagement can therefore be another demand and source of stress (Voydanoff, 2005b) and fathers with less difficulty integrating work and family might be more likely to engage with friends and neighbors reporting greater friend and neighbor support.

Interestingly, fathers indicating higher levels of friend and neighbor support also reported higher levels of support from formal services, such as school and health care services. Friesen, Brennan, and Penn (2008) suggest that fathers of children with mental health disorders might turn to friends and neighbors with similar experiences for information about community-based services and use these informal networks to educate themselves about their rights, and how to advocate for their children with SHCN. Supportive informal networks may be an important factor in parents accessing quality formal services (Shilling et al., 2012).

Home resources. Home resources were the second most important source of support for fathers in this study to ease the difficulty of combining work and family and improve positive spillover between the ecologies of job and home. Fathers who indicated having more flexibility in their family schedule to handle work and childcare issues, faired better in combining work and family.

One area that warrants further investigation is the role of the partner/spouse in enhancing a father's experience of home resources and flexibility. Findings from the study suggest that fathers relied on their partners/spouses to engage more in child-related responsibilities and care needs, and possibly, less in the workplace. Fathers who reported more difficulty combining work and family were more likely to report that their spouse/partner 
FATHERS OF CHILDREN WITH SHCN 101

took on more responsibility for childcare. Fathers typically reported full-time employment while only half of them reported that their partners/spouses were employed outside the home. Fathers who indicated that their partners/spouses were not employed outside the home also reported being less involved in childcare and care coordination than their dual-earner counterparts. These findings suggest that a gendered division of work and family roles found in research on fathers in the general population (Harrington et al., 2011) is present among parents of children with SHCN. Most fathers in Harrington et al.'s study indicated that men and women should equally share in employment and childcare, however, offered that their spouses provided the greatest share of care-related work. Lewis, Kagan, and Heaton (2000a) found in their qualitative study that ideological factors related to the gendered division of labor influenced couples' family patterns of work and care. Mothers felt that the child's health care needs required maternal care and fathers were not considered competent to meet these needs. These traditional gender roles also seem to be perpetuated by helping professionals (Traustadottir, 1991).

The time, intensity, and unpredictability of exceptional caregiving responsibilities contribute to an understanding of how parents manage the division of tasks with the family. Findings from the 2009/2010 National Survey of Children with Special Health Care Needs show that in 15\% of households with a child having SHCN, one family member had to stop employment to provide care for the child. This finding is consistent with other studies. Brennan, Rosenzweig, Ogilvie et al. (2007), found that $63 \%$ of the participating parents reduced their paid work hours due to their child's mental health issues. Likewise, mothers of 
FATHERS OF CHILDREN WITH SHCN 102

children with disabilities were found to be at the greatest risk to reduce paid work hours, quit their jobs, or not seek employment because of care needs of their children (Porterfield, 2002; Powers, 2003).

Home resources may be more influential for fathers than job resources in effectively combining work and family. Considering traditional gender roles and ideal worker norms (Williams, 2010), employed fathers may experience adjustments in the workplace as less desirable then adjustments in the home related to family needs. Despite gender egalitarian ideals, males opt for the more traditional role of the breadwinner when faced with limited workplace supports for family responsibilities (Gerson, 2010; Pedulla \& Thébaud, 2015).

Job resources. Access to workplace flexibility was an important job resource for fathers, even more so than using the flexibility. Kossek et al. (2006) discuss how perceptions of workplace flexibility options, which may add to a sense of control, might trump the actual use of flexible work arrangements. To this point, fathers who report a higher likelihood of using flexibility options, indicate a higher level of negative influence from work to family. One explanation might be related to traditional perceptions of ideal worker norms. The use of flexible work options may be incompatible with the criteria for an ideal worker, thus increasing the perception of the negative influence of work on home life. Hammer et al. (2005) reported similar findings for employed women with both child and elder care responsibilities, who experienced more family-work conflict when using workplace flexibility options. Another explanation might be that fathers with more difficulty in integrating work and family also have to use more workplace flexibility than fathers with less difficulty integrating work and family. 
FATHERS OF CHILDREN WITH SHCN 103

Support from supervisors and coworkers may be an important influence for fathers of children with SHCN who are considering using available workplace flexibility (Allen, 2001). Fathers in the study reporting high supervisor and coworker support were more likely to report access to and use of flexibility options. These fathers might also experience less flexibility stigma and negative career repercussions exemplified in higher supervisor and coworker support.

Not surprisingly, income and education tend to enhance levels of job resources. As Williams (2010, p. 45) reports from Heymann's (2000) study: "Things are different for blue- and pink-collar workers... One study found that one-third of working-class employees -men as well as women - cannot decide when to take breaks, nearly $60 \%$ cannot choose starting or quitting times, and 53\% cannot take time off to care for sick children." This supports the assumption that working-class fathers tend to have less access to flexibility than white-collar workers. Further study is needed across job variables to understand the impact that these have on employed parents of children with SHCN.

\section{Interconnectedness of resource ecologies-the flexibility puzzle}

Findings of this research draw attention to the combined and interactive effects of the different ecologies on the difficulty fathers experience combining work and family. Emlen (2010) illustrated in his study that parents have to make choices to solve the flexibility puzzle. Parents who had high levels of workplace or family flexibility were able to choose less flexible childcare arrangements. Parents who lacked workplace flexibility needed to increase flexibility through family or childcare adjustments. Fathers of children with SHCN access resources in their workplaces, their families, and their communities. All three ecologies are 
FATHERS OF CHILDREN WITH SHCN 104

relevant for the successful combination of work and family demands. Fathers adapt resources within these ecologies in order to improve fit across all three ecologies. As Emlen (2010) wrote: "How parents solve their flexibility puzzle isn't always painless. But their solutions make sense" (p. 107). Fathers of children with SHCN use resources within the job, home, or community ecology to solve this puzzle.

They also try to compensate for a lack of resources in one of the ecologies by increasing resources in others. As Lewis et al. (2000a) summarize in their qualitative study of parents caring for children with disabilities: "Parents worked out arrangements to manage work and care, weighing the specific constraints of their situations and the supports available" (p. 1037). Improving community resources could be of critical importance to decrease negative spillover and reduce the pressure on families to adjust home resources. For example, fathers with low home and low community resources reported very high levels of negative family to work spillover. Fathers had to compensate for low community resources by increasing home resources for flexibility. Fathers with high community resources reported fairly low levels of negative family to work spillover even when reporting low home resources.

Fathers experience demands and resources within and across different ecologies that influence their perception of positive or negative spillover (Voydanoff, 2005d). For example, fathers with low job and home resources did not experience their jobs as very enriching for their family lives. Fathers reported very high levels of positive work to family spillover when they experienced their workplace as more flexible and supportive and their family life 
FATHERS OF CHILDREN WITH SHCN 105

as less demanding. It is therefore critical to take a closer look at the intersections of different resource ecologies and how resources within different ecologies respond to demands across ecologies.

\section{Intensity of exceptional caregiving responsibilities}

All fathers in this study cared for a child with SHCN limiting the ability to isolate the impact of exceptional caregiving responsibilities on difficulty combining work and family, and spillover. However, fathers who reported that their children's activities were more often affected by their health issues reported lower levels of positive family to work spillover. The intensity of exceptional caregiving responsibilities might therefore influence how supportive or challenging fathers experience their family life as they attempt to meet work demands (Brown, 2014; Stewart, 2013). Exceptional caregiving responsibilities seem to extend beyond gender boundaries even when the fathers' spouses/partners provide the majority of childcare and care management. The work-family interface: Positive and negative spillover

Resources within job, home, and community ecologies did not only reduce fathers' perceptions of conflict between work and family but also improved their sense of enrichment between work and family. Fathers in this study reported higher mean scores on negative work to family and family to work spillover and lower mean scores on positive family to work spillover but higher mean scores on positive work to family spillover than employed men in the National Survey of Midlife Development in the United States (MIDUS) for which these spillover scales were developed (Grzywacz \& Marks, 2000). Fathers of children with SHCN might experience more demands in the family related to their exceptional 
FATHERS OF CHILDREN WITH SHCN 106

caregiving responsibilities resulting in lower positive family to work and higher negative family to work scores. The workplace could also serve as a place of respite from family demands as indicated by higher levels of positive work to family spillover. Lewis et al. (1999) reported on the psychological benefits of employment for mothers. One mother for example described the benefits as follows: "I work and I call it my sanity time. I went back in desperation to get out. I don' t come out with a great deal, no no I don' t, but it saves my sanity" (p. 565). A similar psychological benefit of employment might be true for fathers.

Fathers of children with SHCN in this study reported significantly more negative than positive work to family spillover and more positive than negative family to work spillover. The psychological and economic benefits of employment therefore have to be interpreted within a complex arrangement of work and family demands and resources. These findings also show that fathers of children with SHCN experience their family life as rejuvenating and enriching for their work lives despite their exceptional caregiving responsibilities (Heiman, 2002).

\section{Study limitations}

Given the exploratory design of the current study, limitations affect the generalizability of the findings. First, the sample was a convenience sample mostly recruiting fathers who are part of support groups or looking for support on the internet. This means that they might be fairly engaged in caring for their children with SHCN and interested in learning more about how to best support them. The responses might therefore be biased towards a specific group of fairly engaged fathers. Second, the use of an online survey accesses fathers, who most 
likely own technology such as a computer and have to feel comfortable using technology. The Qualtrics ${ }^{\circledR}$ tracking tool indicated that many surveys were completed during the lunch hour. This again likely indicates fathers employed in workplaces with easy access to computers, possibly leaving out fathers employed in other sectors such as manufacturing or the service industries. The demographic data on the fathers in this survey indicated fairly high educational attainments and income levels. Both sampling strategies and data collection procedures limit generalizability of the study beyond the characteristics of a White, middle-class sample with most fathers living in marriages or partnerships. The overall small sample size also impairs generalizability of the study's results.

Third, collecting data through an online survey affected the nature of the data. It is recommended to keep online surveys between 10 and 15 minutes limiting the number of questions. It was therefore not possible to ask in detail about the workplaces, family life, and the communities in which fathers were engaged. Questions for example had to be focused on an overall assessment of supervisor support or service availability without expanding details. All the questions are self-report data, which seems adequate for most variables because of the focus on individual experiences of work-life fit. Most questions were retrieved from existing surveys and have been tested for their usefulness in this field of study, but because of the lack of research on fathers caring for children with SHCN there was no existing set of questions for this specific group of employees and caregivers. The rating scale to assess the helpfulness of services such as childcare, school, or health care services was developed specifically for 
this study based on previous studies about community resources for fathers or caregivers of children with SHCN (Gareis \& Barnett, 2008; Rosenzweig et al., 2002). This scale offered the option for fathers to choose "n/a", which was later found to be difficult to interpret. Does it mean that they did not use the service or was the service not available to them? Many participating fathers did not answer the rating questions ( $n_{\text {public transportation }}=34, n_{\text {after-school care }}=40, n_{\text {childcare }}=55, n_{\text {school }}=$ 78 , and $n_{\text {healthcare }}=78$ ). This lack of responses rendered the scales difficult to use in the analysis stage. Future research with fathers will need to develop more appropriate questions.

Fourth, the dissertation was designed as a cross-sectional study. This means that the direction of effects cannot be established. The findings of this study are therefore correlational not causal in nature. The findings of this exploratory study remain meaningful despite these limitations and provide a starting point for future explorations.

\section{Implications for theory and organizational policy-practice}

Results from this study illustrate that participation in different roles cannot be solely viewed as conflictual. Fathers experienced negative spillover from both the family and work roles but they also reported positive spillover from participation in these ecologies. Employment, for example, can provide economic and psychological benefits that enhance participation in family life instead of hindering it. Spending time with children with typical development or SHCN can help re-charge the employed father for the next work day and can give greater meaning to employment. The theory of positive and negative spillover therefore seems appropriate when conceptualizing the work-life interface. 
Theories based on ecological frameworks (Barnett, 1998; Moen, 2011; Voydanoff, 2005) are also being supported by the research results. Resources within the job, home, and community ecologies were relevant predictors of fathers' difficulty combining work and family, and spillover. Community resources proved especially salient for fathers of children with SHCN. This study therefore supports a broader conceptualization of participation in micro-, meso-, and macro-systems.

This study did not use a comparative research design and did not include mothers' perceptions or perceptions of fathers without exceptional caregiving responsibilities. Some of the study's findings do identify differences based on gender roles, and caregiving responsibilities, strengthening the theoretical concept of exceptional caregiving responsibilities (Roundtree \& Lynch, 2001). For example, fathers in this sample reported higher negative spillover scores than a sample of fathers drawn from the 1995/1996 MIDUS study. Fathers of children with SHCN might experience certain types of workplace flexibility differently than fathers without exceptional caregiving responsibilities. Employment might offer certain psychological benefits not relevant for other types of employees. Individual and person-centered factors therefore need to be considered in work-life theory-building and empirical research (Barnett, 1998; Moen, 2011).

Conceptualizations of work-life fit or life-course fit assume that overall patterns and appraisals of resources in different ecologies are crucial (Hill et al. 2008; Moen et al., 2008a), which is in line with the findings of this study. Indices of job, home, and community resources, which assessed these overall patterns 
FATHERS OF CHILDREN WITH SHCN 110

and clusters of resources, significantly predicted difficulty combining work and family, and spillover. Findings even supported theoretical statements on the complex interplay and interactive effects of these resource clusters. This illustrates that resources within job, home, and community ecologies directly influence work-life fit and that certain combinations of job and home resources, and home and community resources have compensatory effects.

Notions of flexibility stigma and courtesy stigmatization can be supported as well. Fathers reported perceptions of negative career impact related to both using flexibility and caring for a child with SHCN. Flexibility stigma is considered to be especially salient for fathers. Traditional gender norms expect mothers to respond to family needs but fathers diverge from traditional gender expectations when they show a commitment to family demands. For example, in one experimental study of 371 college students, participants rated male leave takers who requested leave for family reasons as more feminine than male leave takers who requested leave for work reasons, and female leave takers who requested leave for family reasons (Rudman \& Mecher, 2013). The authors conclude that fathers might experience femininity stigma in addition to flexibility stigma, if they request leave for reasons that diverge from traditional gender expectations. Fathers of children with SHCN might deal with stigmatization in the workplace related to both their use of flexibility and their exceptional caregiving responsibilities.

There is also some support for the relevance of ideal worker norms and the traditional breadwinner role for fathers of children with SHCN, which is in line with previous research (Lewis et al., 2000a). Spouses/partners tended to 
FATHERS OF CHILDREN WITH SHCN 111

take more responsibility for childcare and care coordination and tended to work fewer hours if working outside the home at all.

Organizational practice. Job resources were associated with fathers' difficulty combining work and family, as well as spillover, especially access to flexibility. Unfortunately, fathers still felt that making use of flexibility options and caring for a child with SHCN negatively impacted their career development. Fathers will feel reluctant to use flexibility options and may even experience career punishments for using flexibility as long as ideal worker norms persist. The role of fathers is shifting, with fathers spending more time doing housework and caring for children (Bianchi \& Milkie, 2010). Workplaces need to adapt and support male workers in their role as fathers. Workplace flexibility will only be a real option if it comes without flexibility stigma and negative career consequences. Supervisors can be crucial for modeling family-supportive behaviors so that employees feel comfortable making use of flexibility policies (Allen, 2001; Hammer et al., 2011).

Fathers of children with SHCN might be reluctant to disclose their child's health condition out of fear of courtesy stigmatization (Rosenzweig, Brennan, \& Malsch, 2009). The fear of courtesy stigmatization and flexibility stigma (Butler \& Skattebo, 2004; Coltrane et al., 2013; Williams, Blair-Loy, \& Berdahl, 2013) might keep these working fathers from making use of flexibility policies available at their workplaces. Fathers feel that they need to show absolute commitment to their jobs and that providing care for their child with SHCN runs counter to this commitment. Workplace adaptive strategies therefore can affect career 
FATHERS OF CHILDREN WITH SHCN 112

development for fathers and the fear of negative consequences in the workplace can reduce fathers' active role in caring for their children and families.

Fathers might remain in dead-end jobs or forgo career and job changes because they fear a loss of flexibility. Caring for a child with SHCN increases fathers' need for flexible workplaces, health insurance, and supportive supervisors and coworkers. Once they found these supportive arrangements, they might be reluctant to change jobs. The National Survey of Children with Special Health Care Needs 2009/2010 found that 18\% of caregivers of children with SHCN avoided changing jobs out of concerns for health insurance.

Human resource personnel that are aware of the specific challenges fathers of children with SHCN might face can be a valuable resource to support fathers in the process of disclosure and can help mitigate negative repercussions within the workplace (Lewis et al, 2000b; Rosenzweig et al., 2009). Campaigns acknowledging the diversity of care responsibilities can enhance acceptance of diversity and reduce stigmatization.

Certain implications for organizational practice need to be supported by policy frameworks. For example, providing every employee with access to paid leave for dependent care would be one policy implication especially as research indicates that access to paid leave might reduce the risk of income loss (Earle \& Heymann, 2012).

\section{Implications for social work practice}

This study most importantly provides valuable insights for social work practice. Community resources were the most important predictors for difficulty combining work and family, and spillover for fathers of children with SHCN. 
FATHERS OF CHILDREN WITH SHCN 113

Community resources in this study included both social support from neighbors and friends and community services, including school and after-school care, childcare, and health care services. Services that were experienced as more helpful alleviated negative family to work spillover and improved positive work to family spillover. Unfortunately, too many fathers did not experience services as especially helpful, leaving room for improvement. Existing research on common shortcomings of service delivery can provide some insights into how to better support caregivers (Anderson-Butcher \& Ashton, 2004; Brennan, Evans, \& Spencer, 2008; Heckmann, 2007; NS-CSHCN, 2009/2010; Weist, Lowie, Flaherty, \& Pruitt, 2001). Caregivers report that they always have to be strong advocates for their children to secure access to services and the quality of services. They have to educate themselves to learn about the child's condition, what support would be best, and where to find these supports. Even if they are able to locate services they often encounter waiting lists and lengthy processes to gain access (Jungbauer \& Meye, 2008). The out-of-pocket costs of services put additional financial strain on families (NS-CSHCN, 2009/2010). Caregivers are also dealing with age cut-offs and their children aging out of specific support systems, which results in the need to find new quality services (Davis, Green, \& Hoffman, 2009; Jinnah \& Stoneman, 2007). Finally, the lack of communication between services and the siloing of services complicates access greatly, especially if service providers are not aware of, or do not provide referrals to, existing resources in the community. Access to services can also vary depending on the location, with rural areas being underserved for specialty services often needed when caring for a child with SHCN (Jungbauer \& Meye, 2008). 
FATHERS OF CHILDREN WITH SHCN 114

Social connectedness with friends and neighbors was another important predictor of positive and negative spillover and service providers could use this knowledge to foster networking opportunities for these fathers. Families caring for a child with SHCN often report social isolation and encounter an environment that is stigmatizing or fearful. The use of more formal face-to-face or online support groups could be one source of positive social and emotional support (O'Connor, 2008). Social work could create opportunities for fathers to connect and share experiences through family support groups. It could be useful to consider gender-specific support to enable safe spaces for sharing not only parenting but also marital issues. Family support either informally or formally through support groups can provide emotional and social support, but also valuable information on how to best navigate service systems (Rosenzweig, Roundtree et al., 2008; Brennan, Bradley et al., 2008).

Several recommendations can be developed from these considerations including the improvement of the quality of services in general, providing access to services especially in less urban areas, making access easier, and funding more services to reduce wait-listing children, providing financial supports for families to better afford services, creating integrated services and cross-service collaboration for better service delivery, helping parents to find appropriate services and refer accordingly, as well as improving service providers' knowledge of resources available in local communities. Case management within schools, for example, can be one strategy to improve school outcomes for children with SHCN (Bethell et al., 2012). Wrap-around services for children with serious emotional and behavioral issues are another strategy developed to 
improve service outcomes specifically for children with mental health issues (Furman \& Jackson, 2002). Parents of children with autism commented that access to one case manager who coordinates not only therapeutic care but also provides support for social and legal needs would be critical (Jungbauer \& Meye, 2008). As this research shows, quality services are not only important for supporting the child but influence the whole family and can be resources or barriers to a father's work-life fit. Social work needs to consider work-life fit to improve service quality and better support service users (Krivelyova \& Stephens, 2005; Prinz \& Miller, 1994).

The political system is also asked to expand funding for community services. Service providers dealing with large case numbers cannot provide individualized and cross-system services. Learning about local resources, connecting with other agencies, getting to know families' needs and connecting them with helpful services requires time. Funding also needs to be appropriate for agencies to hire enough staff to reduce waitlists and for agencies to serve more remote and rural areas. Political and legal solutions for assuring quality of services need to be expanded, especially inclusive childcare and after-school care. Access to health insurance that is affordable and provides reasonable coverage is another area that can be improved through policy support.

\section{Future research}

This study used an exploratory, cross-sectional design and further research is called for to see if these initial findings can be generalized to the wider group of fathers with exceptional caregiving responsibilities. It is especially crucial to include interactions to clarify the moderating relationships 
FATHERS OF CHILDREN WITH SHCN 116

between resource ecologies. An analysis of the qualitative interview data collected from some of the participating fathers will be critical for a more detailed understanding of the resources accessed and the challenges faced by employed fathers of children with SHCN.

This study only included fathers of children with SHCN and conclusions about the gendered distribution of work and family care are based on fathers' reports. Comparative research is therefore indicated to shed more light on issues of gender equality and gender divisions for caregivers with exceptional caregiving responsibilities. It would be especially beneficial to conduct research on couple dyads to look at reports from both mother and father in the same family constellation. In addition, comparative research needs to look at difficulty combining work and family as well as spillover for fathers with and without exceptional caregiving responsibilities.

Most fathers were also married or partnered sharing care responsibilities within the family system. Seeing in this sample that sharing care responsibilities is a significant factor for reducing difficulty combining work and family it is important to conduct research specifically on single fathers caring for children with SHCN. Previous research also found that single caregivers accessed fewer family support resources (Brennan, Rosenzweig, Ogilvie et al., 2007). The moderating relationship of community resources and home resources would support the assertion that community resources could compensate for a lack of home resources but further studies are warranted.

Fathers in this study were generally very well educated and most of them reported middle class incomes but findings indicate that income adequacy 
FATHERS OF CHILDREN WITH SHCN 117

influences negative work to family spillover and that income and education are positively correlated with job resources. It is therefore important to investigate work-life issues for fathers with fewer socio-economic resources to learn more about their challenges and barriers. Previous research stresses the importance of social supports and community for low-wage workers (Griggs et al., 2013) leaving room for research to explore the connection of income and social support with work-life fit and exceptional caregiving responsibilities. The sample in this study was not very racially/ethnically diverse and future research should investigate racial/ethnical differences for fathers of children with SHCN.

Despite only including fathers with exceptional caregiving responsibilities in this study, it must be reiterated that these responsibilities need to be considered in work-life research. Fathers caring for children that exhibited higher symptom levels experienced less positive family to work spillover. Exceptional caregiving responsibilities affect caregivers across gender binaries and further research is warranted to compare fathers with and without exceptional caregiving responsibilities and fathers with different kinds of exceptional caregiving responsibilities such as caring for a spouse with a disability or an aging parent. It would also be important to learn more about fathers who care for children with SHCN who are older than 18 years of age. This might pose specific challenges because the social environment may be even less understanding of care responsibilities for a young adult and even fewer community resources might be in place to support working fathers. This research is a start to broaden the view by including job, home, and community 
FATHERS OF CHILDREN WITH SHCN 118

resources. More studies should be conducted to further clarify which resources and barriers are relevant for fathers with exceptional caregiving responsibilities.

\section{Conclusions}

This research focused on fathers' difficulty combining work and family, and spillover when caring for children with SHCN and it showed that resources in the job, home, and community ecologies were critical for addressing work-life issues. Community resources were highly relevant for fathers of children with SHCN and they were often not adequate to meet the family's needs. Support from friends and neighbors beyond formal services were part of fathers' resource packages to better integrate work and family demands. Additionally, home and job resources remained relevant for the work-life puzzle. Attaining satisfactory resource levels in these three ecologies can be an active process that requires advocacy skills, foregoing career advances, or moving across states to find more supportive employment. The solution to the flexibility puzzle might include limited or no employment for spouses and partners leaving families and especially women economically vulnerable. Whatever the specific steps are that families have to take, exceptional caregiving responsibilities influence fathers' choices in all three ecologies, even if they are not considered primary caregivers. These processes can be especially difficult for fathers with lower incomes or less education who struggle with limited job resources. Organizations, policymakers, and social workers are called upon to better support fathers caring for children with SHCN. 


\section{References}

Acker, J. (2006). Inequality regimes, gender, class, and race in organizations. Gender \& Society, 20(4), 441-464.

Ainbinder, J. G., Blanchard, L. W., Singer, G. H., Sullivan, M. E., Powers, L. K., Marquis, J. G., . . . Consortium to Evaluate Parent to Parent. (1998). A qualitative study of parent to parent support for parents of children with special needs. Journal of Pediatric Psychology, 23(2), 99-109.

Ali, A., Hassiotis, A., Strydom, A., \& King, M. (2012). Self stigma in people with intellectual disabilities and courtesy stigma in family carers: A systematic review. Research in Developmental Disabilities, 33, 2122-2140.

Allen, T. D. (2001). Family-supportive work environments: The role of organizational perceptions. Journal of Vocational Behavior, 58, 414-435.

Allen, T. D., Herst, D. E. L., Bruck, C. S., \& Sutton, M. (2000). Consequences associated with work-to-family conflict: A review and agenda for future research. Journal of Occupational Health Psychology, 5(2), 278-308.

Allen, T. D., Johnson, R. C., Kiburz, K. M., \& Shockley, K. M. (2013). Work-family conflict and flexible work arrangements: Deconstructing flexibility. Personnel Psychology, 66, 345-376.

Allen, T. D., \& Russell, J. E. A. (1999). Parental leave of absence: Some not so family-friendly implications. Journal of Applied Social Psychology, 29(2), $166-191$

Al-Yogan, M., \& Cinamon, R. G. (2008). Work-family relations among mothers of children with learning disorders. European Journal of Special Needs Education, 23(2), 91-107. 
Americans with Disability Act (ADA) of 1990, PL 101-336, 42 U.S.C. §12102.

Anderson-Butcher, D. \& Ashton, D. (2004). Innovative models of collaboration to serve children, youth, families, and communities. Children \& Schools, 26, 39-53.

Angermeyer, M. C., Schulze, B., \& Dietrich, S. (2003). Courtesy stigma. A focus group study of relatives of schizophrenia patients. Social Psychiatry and Psychiatric Epidemiology, 38, 593-602.

Aumann, K, Galinsky, E., \& Matos, K. (2011). The new male mystique. New York, NY: Families \& Work Institute.

Baker, D. L., \& Drapela, L. A. (2010). Mostly the mother: Concentration of adverse employment effects on mothers of children with autism. The Social Science Journal, 47, 578-592.

Barnett, R. C. (1998). Toward a review and reconceptualization of the work/family literature. Genetic, Social \& General Psychology Monographs, 124(2), $125-182$.

Barnett, R. C., \& Gareis, K. C. (2009). Does community resource fit matter to fathers? A study of employed fathers, school and school activity schedules, and well-being. Journal of Family Issues, 30(7), 1001-1016.

Barnett, R. C., Gareis, K. C., \& Brennan, R. T. (1999). Fit as a mediator of the relationship between work hours and burnout. Journal of Occupational Health Psychology, 4(4), 307-317.

Becker, I. (2006). Ein Leben so normal wie möglich führen... “Lebenslagen und 
FATHERS OF CHILDREN WITH SHCN 121

Lebensbewältigung von Familien mit behinderten Kindern und

Jugendlichen. Eröffnungsvortrag Fachtagung Stiftung Liebenau. Retrieved from: http://www.epb.uni-hamburg.de/files/u14/Liebenau2006.pdf.

Benzies, K. M., Harrison, M. J., \& Magill-Evans, J. (2004). Parenting and childhood behavior problems: Mothers' and fathers' voices. Issues in Mental Health Nursing, 25(1), 9-24.

Berdahl, J. L., \& Moon, S. H. (2013). Workplace mistreatment of middle class workers based on sex, parenthood, and caregiving. Journal of Social Issues, 69 (2), 341-366.

Berry, J. G., Bloom, S., Foley, S., \& Palfrey, J. S. (2010). Health inequity in children and youth with chronic health conditions. Pediatrics, 126, 111-118

Bethell, C. D., Forrest, C. B., Stumbo, S., Gombojav, N., Carle, A., \& Irwin, C. E. (2012). Factors promoting or potentially impeding school success: Disparities and state variations for children with special health care needs. Maternal and Child Health Journal, 16, S35-S43.

Bethell, C. D., Newacheck, P. W., Fine, A., Strickland, B. B., Antonelli, R. C., Wilhelm, C. L., ... Wells, N. (2013). Optimizing health and health care systems for children with special health care needs using the life course perspective. Maternal and Child Health Journal, 18(2), 467-477.

Bianchi, S. M., \& Milkie, M. A. (2010). Work and family research in the first decade of the 21st century. Journal of Marriage and Family, 72(3), 705725.

Blair-Loy, M. (2001). Cultural constructions of family schemas: The case of women finance executives. Gender \& Society, 15, 687-709. 
FATHERS OF CHILDREN WITH SHCN 122

Blair-Loy, M., \& Dehart, G. (2003). Family and career trajectories among African American female attorneys. Journal of Family Issues, 24(7), 908-933.

Bookman, A. (2004). Starting in our own backyards: How working families can build community and survive the new economy. New York, NY: Routledge.

Booth-LaForce, C., \& Kelly, J. F. (2004). Childcare patterns and issues for families of preschool children with disabilities. Infants and Young Children, 17(1), $5-16$.

Bourque, L.B. (2004). Cross-sectional designs. In M.S. Lewis-Beck, A. Bryman, \& T. Futing Liao, Encyclopedia of social science research methods, (pp. 230231). Thousand Oaks, CA: Sage.

Brannan, A., \& Heflinger, C. A. (2001). Distinguishing caregiver strain from psychological distress: Modeling the relationships among child, family, and caregiver variables. Journal of Child and Family Studies, 10, 405-418.

Brannan, A. M., Heflinger, C. A., \& Bickman, L. (1997). The caregiver strain questionnaire: Measuring the impact on the family of living with a child with serious emotional disturbance. Journal of Emotional and Behavioral Disorders, 5, 212-222.

Brennan, E. M., Bradley, J. R., \& Ackerson Lieberman, L. (2008). Child care: An essential support for working families. In J. M. Rosenzweig \& E. M. Brennan, Work, life, and the mental health system of care, (pp. 175-200). Baltimore, MD: Paul H. Brookes.

Brennan, E. M., \& Brannan, A. M. (2005). Participation in the paid labor force by caregivers of children with emotional and behavioral disorders. Journal of Emotional and Behavioral Disorders, 13, 237-246. 
Brennan, E. M., Evans, M. E., \& Spencer, S. A. (2008). Mental health services and supports for children and families. In J. M. Rosenzweig \& E. M. Brennan, Work, life, and the mental health system of care, (pp. 119-142). Baltimore, MD: Paul H. Brookes.

Brennan, E. M., \& Rosenzweig, J. (2008). Parents of children with disabilities and work-life challenges: Presentation summary. Alfred P. Sloan Work and Family Research Network Panel Meeting. Portland, OR: Research and Training Center on Family Support and Children's Mental Health, Portland State University.

Brennan, E. M., Rosenzweig, J., Malsch, A. M., Stewart, L. M., \& Conley, J. (2007). Taking it on: Disclosure, stigmatization, and self-esteem. In S. Swart, B. J. Friesen, A. Holman, \& N. Aue (Eds.), Building on family strengths: Research and services in support of children and their families. 2007 conference proceedings (pp. 137-142). Portland, OR: Portland State University, Research and Training Center on Family Support and Children's Mental Health.

Brennan, E. M., Rosenzweig, J., Malsch, A. M., Stewart, L. M., Kjellstrand, J., \& Coleman, D. (2013). Supports for working parents of children with disabilities: A cross-national comparison of inclusive policies. In V. Dujon, J. Dillard, \& E. M. Brennan (Eds.), Social sustainability: A multilevel approach to social inclusion, (pp. 183-211). New York, NY: Routledge.

Brennan, E. M., Rosenzweig, J. M., Ogilvie, A. M., Wuest, L., \& Shindo, A. A. (2007). 
FATHERS OF CHILDREN WITH SHCN 124

Employed parents of children with mental health disorders: Achieving work-family fit, flexibility, and role quality. Families in Society: The Journal of Contemporary Social Services, 88(1), 115-123.

Brennan, E. M., Rosenzweig, J. M., Ogilvie, A. M., Zimmerman, P. A., \& Ward, A. A. (1999). Support for working caregivers interview schedule. Portland, OR: Portland State University, Research and Training Center on Family Support and Children's Mental Health and the Center for the Study of Mental Health Policy and Services.

Brohan, E., et al. (2012). Systematic review of beliefs, behaviours and influencing factors associated with disclosure of a mental health problem in the workplace. BioMed Central Psychology, 12(11), 1-14.

Bronfenbrenner, U. (1977). Toward an experimental ecology of human development. American Psychologist, 32(7), 513-531.

Bronfenbrenner, U. (1986). Ecology of the family as a context for human development: Research perspectives. Developmental Psychology, 22(6), 723-742.

Bronfenbrenner, U. (1994). Ecological models of human development. International Encyclopedia of Education, 3(2), 37-43.

Brown, T. J. (2014). Work family conflict among parents of atypically developing children: Exploring the impact of worker, work, and child factors. Journal of Child and Family Studies, 23(5), 854-862.

Busse-Widmann, P. (2005). Alltagsbelastungen und Folgen für die berufliche 
Entwicklung von Eltern chronisch kranker Kinder am Beispiel Diabetes mellitus. Dissertation, LMU München: Medizinische Fakultät. Retrieved from: http://edoc.ub.uni-muenchen.de/3888/.

Butler, A. B., \& Skattebo, A. (2004). What is acceptable for women may not be for men: The effects of family conflicts with work on job-performance ratings. Journal of Occupational and Organizational Psychology, 77, 553-564.

Cairns-Nagi, J. M., \& Bambra, C. (2013). Defying the odds: A mixed-methods study of health resilience in deprived areas of England. Social Science \& Medicine, 91, 229-237.

Carmines E. G., \& Woods, J. (2004). Index. In M.S. Lewis-Beck, A. Bryman, \& T. Futing Liao, Encyclopedia of social science research methods, (pp. 486487). Thousand Oaks, CA: Sage.

Cech, E. A., \& Blair-Loy, M. (2014). Consequences of flexibility stigma among academic scientists and engineers. Work and Occupations, 41(1), 86-110.

Ceglowski, D. A., Logue, M. E., Ullrich, A., \& Gilbert, J. (2009). Parents' perceptions of child care for children with disabilities. Early Childhood Education Journal, 36, 497-504.

Cohen, J., Cohen, P., West, S., G., \& Aiken, L. S. (2003). Applied multiple regression/correlation analysis for the behavioral sciences. Mahwah, NJ: Lawrence Erlbaum.

Coleman, D. (Spring, 2012). Preliminary analyses and assumption checking for correlation and regression. Unpublished lecture notes.

Coltrane, S., Miller, E. C., DeHaan, T., \& Stewart, L. (2013). Fathers and the flexibility stigma. Journal of Social Issues, 69(2), 279-302. 
FATHERS OF CHILDREN WITH SHCN 126

Corrigan, P. W., \& Miller, F. E. (2004). Shame, blame and contamination: A review of the impact of mental illness on family members. Journal of Mental Health, 13, 537-548.

Current Population Survey. (2013). Labor force characteristics. Retrieved from: http://www.bls.gov/cps/lfcharacteristics.htm\#fullpart

Darling, C. A., Senatore, N., \& Strachan, J. (2012). Fathers of children with disabilities: Stress and life satisfaction. Stress and Health, 28, $269-278$.

Davis, M., Green, M., \& Hoffman, C. (2009). The service system obstacle course for transition-age youth and young adults. In H. B. Clark \& D. K. Unruh (Eds.). Transition of youth and young adults with emotional or behavioral disorders: An evidence-supported handbook, (pp. 25-46). Baltimore, MD: Paul H. Brookes.

Dawson, J. F. (2014). Moderation in management research: What, why, when, and how. Journal of Business Psychology, 24, 1-19.

Earle, A., \& Heymann, J. (2011). Protecting the health of employees caring for family members with special health care needs. Social Science and Medicine, 73, 68-78.

Earle, A., \& Heymann, J. (2012). The cost of caregiving: Wage loss among caregivers of elderly and disabled adults and children with special needs. Community, Work, and Family, 15(3), 357-375.

Eaton, S. C. (2003). If you can use them: Flexibility policies, organizational commitment, and perceived performance. Industrial Relations, 42(2), 145167.

Emlen, A. C. (2010). Solving the childcare and flexibility puzzle: How working 
parents make the best feasible choices and what that means for public policy. Boca Raton, FL: Universal-Publishers.

Edwards, J. R., \& Rothbard, N. P. (1999). Work and family stress and well-being: An examination of person-environment fit in the work and family domains. Organizational Behavior and Human Decision Processes, 77, 85129.

Family and Medical Leave Act (FMLA) of 1993, PL 103-3, 5 U.S.C. §§ 6381 et seq., 29 U.S.C. $\S \S 2601$ et seq.

Fowler, F. J. (2009). Survey research methods. Thousand Oaks, CA: Sage.

Friesen, B. J. (1989). Survey of parents whose children have serious emotional disorders: Report of a national study. Portland, OR: Research and Training Center on Family Support and Children's Mental Health, Portland State University.

Friesen, B. J., Brennan, E. M., \& Penn, M. (2008). Family supports needed by working parents. In J. M. Rosenzweig \& E. M. Brennan, Work, life, and the mental health system of care, (pp. 27-56). Baltimore, MD: Paul H. Brookes.

Frone, M. R. (2003). Work-family balance. In J. C. Quick \& L. E. Tetrick (Eds.), Handbook of occupational health psychology, (pp. 143-162). Washington, DC: American Psychological Association.

Furman, R., \& Jackson, R. (2002). Wrap-around services: An analysis of community-based mental health services for children. Journal of Child and Adolescent Psychiatric Nursing, 15(3), 124-131.

Gareis, K. C., \& Barnett, R. C. (2008). The development of a new measure for 
work-family research: Community resource fit. Community, Work \& Family, 11(3), 273-282.

Gareis, K. C., Barnett, R. C., Ertel, K. A., \& Berkman, L. F. (2009). Work-family enrichment and conflict: Additive effects, buffering, or balance? Journal of Marriage and Family, 71, 696-707.

George, A., Vickers, M. H., Wilkes, L., \& Barron, B. (2008). Working and caring for a child with chronic illness: Challenges in maintaining employment. Employee Responsibilities and Rights Journal, 20, 165-176.

Gerson, K. (2010). The unfinished revolution: How a new generation is reshaping family, work, and gender in America. Oxford, UK: Oxford University Press.

Goffman, E. (1963). Stigma: Notes on the management of spoiled identity. New York, NY: Simon and Schuster.

Gopalan, G., Burton, G., McKay, M. M., \& Rosenzweig, J. (2008). Achieving schoolfamily collaboration for children with emotional or behavioral disorders. In J. M. Rosenzweig \& E. M. Brennan, Work, life, and the mental health system of care, (pp. 201-237). Baltimore, MD: Paul H. Brookes.

Gopalan, G., Goldstein, L., Klingenstein, K., Sicher, C., Blake, C., \& McKay, M. M. (2010). Engaging families into child mental health treatment: Updates and special considerations. Journal of the Canadian Academy of Child and Adolescent Psychiatry, 19(3), 182-196.

Gornick, J. C., \& Meyers, M. K. (2009). Institutions that support gender equality in parenthood and employment In J. C. Gornick, \& M. K. Meyers, (Eds.) Gender equality: Transforming family divisions of labor, (pp. 3-66). Brooklyn, NY: Verso. 
Greenhaus, J. H., \& Beutell, N. J. (1985). Sources of conflict between work and family roles. Academy of Management Review, 10(1), 76-88.

Griggs, T. L., Casper, W. J., \& Eby, L. T. (2013). Work, family and community support as predictors of work-family conflict: A study of low-income workers. Journal of Vocational Behavior, 82, 59-68.

Grisham-Brown, J., Cox, M., Gravil, M., \& Missall, K. (2010). Differences in child care quality for children with and without disabilities. Early Education and Development, 21(1), 21-37.

Grzywacz, J. G. (2000). Work-family spillover and health during midlife: Is managing conflict everything?. American Journal of Health Promotion, 14, 236-243.

Grzywacz, J. G., \& Bass, B. L. (2003). Work, family, and mental health: Testing different models of work-family fit. Journal of Marriage and Family, 65, 248-262.

Grzywacz, J. G., \& Marks, N. F. (2000). Reconceptualizing the work family interface: An ecological perspective on the correlates of positive and negative spillover between work and family. Journal of Occupational Health Psychology, 5(1), 111-126.

Guerra, N. G., Williams, K. R., \& Sadek, S. (2011). Understanding bullying and victimization during childhood and adolescence: A mixed methods study. Child Development, 82(1), 295-310.

Ha, J. H., Greenberg, J. S., \& Mailick Seltzer, M. (2011). Parenting a child with a disability: The role of social support for African American parents. Families in Society, 92(4), 405-411. 
FATHERS OF CHILDREN WITH SHCN 130

Hammer, L. B., Kossek, E. E., Anger, W. K., Bodner, T., \& Zimmerman, K. (2011). Clarifying work-family intervention processes: The roles of work-family conflict and family supportive supervisor behaviors. Journal of Applied Psychology, 96, 134-150.

Hammer, L. B., Neal, M. B., Newsom, J. T., Brockwood, K .J., \& Colton, C. L. (2005). A longitudinal study of the effects of dual-earner couples' utilization of family-friendly workplace supports on work and family outcomes. Journal of Applied Psychology, 90(4), 799-810.

Harden, J. (2005). Parenting a young person with mental health problems: Temporal disruption and reconstruction. Sociology of Health and Illness, $27(3), 351-371$.

Harrington, B., Van Deusen, F., \& Humberd, B. (2011). The new dad: Caring, committed and conflicted. Boston College Center for Work \& Family. Retrieved from: http://www.bc.edu/content/dam/files/centers/cwf/pdf/FH-Study-Web2.pdf

Heckmann, C. (2007). Familien stärken - Lebenssituation und Hilfebedarf von Familien mit Menschen mit Behinderungen. Presseinformationen, Hokamp http://www.caritas-warendorf.de/presse-informationen/familienstaerken.html

Heiman, T. (2002). Parents of children with disabilities: Resilience, coping, and future expectations. Journal of Developmental and Physical Disabilities, 14(2), $159-171$.

Heiman, T., \& Berger, O. (2007). Parents of children with Asperger syndrome or 
with learning disabilities: Family environment and social support. Research in Developmental Disabilities, 29, 289-300.

Heinrich, F. (2007). Väter behinderter Kinder: Situation, Beratungs- und Hilfsangebote. Norderstedt, Germany: GRIN Verlag.

Hennessy, J. (2009). Morality and work-family conflict in the lives of poor and low-income women. The Sociological Quarterly, 50, 557-580.

Heymann, J. (2000). The widening gap: Why America's working families are in jeopardy and what can be done about it. New York, NY: Basic Books.

Hill, E. J. (2005). Work-family facilitation and conflict, working fathers and mothers, work-family stressors and support. Journal of Family Issues, 26, 793-819.

Hill, E. J., Grzywacz, J. G., Allen, S. J., Blanchard, V. L., Matz-Costa, C., Shulkin, S., \& Pitt-Catsouphes, M. (2008). Defining and conceptualizing workplace flexibility. Community, Work \& Family, 11, 149-163.

Hill, R., Tranby, E., Kelly, E. L., \& Moen, P. (2013). Relieving the time squeeze? Effects of a white-collar workplace change on parents. Journal of Marriage and Family, 75, 1014-1029.

Hoagwood, K. E. (2005). Family-based services in children's mental health: A research review and synthesis. Journal of Child Psychology and Psychiatry, 46(7), 690-713.

Hochschild, A. R. (1989). The second shift: Working parents and the revolution at home. New York, NY: Viking, Penguin.

Individuals with Disabilities Education Act (IDEA). 20 USC 1401, §602 3a.

Jinnah, H.A., \& Stoneman, Z. (2007). Parents' experiences in seeking child care for 
FATHERS OF CHILDREN WITH SHCN 132

school age children with disabilities-Where does the system break down? Children and Youth Services Review, 30, 967-977.

Jungbauer, J., \& Meye, N. (2008). Belastungen und Unterstützungsbedarf von Eltern mit autistischen Kindern. Praxis für Kinderpsychologie und Kinderpsychiatrie, 57, 521-535.

Kagan, C., Lewis, S., \& Brennan, E. M. (2008). Building community supports for work life integration. In J. M. Rosenzweig \& E. M. Brennan (Eds.), Work, life, and the mental health system of care: A guide for professionals supporting children with emotional and behavioral disorders (pp. 325349). Baltimore, MD: Paul H. Brookes.

Kallenbach, K. (2002). Vater eines behinderten Kindes. Das Familienhandbuch des Staatsinstituts für Frühpädagogik. Retrieved from: https://www.familienhandbuch.de/behinderung/behindertekinder/vater-eines-behinderten-kindes.

Kelly, E. L., Kossek, E. E., Hammer, L. B., Durham, M., Bray, J., Chermack, K., . . Kaskubar, D. (2008). Getting there from here: Research on the effects of work-family initiatives on work-family conflict and business outcomes. The Academy of Management Annals, 2(1), 305-349.

Kendall, J. (1998). Outlasting disruption: The process of reinvestment in families with ADHD children. Qualitative Health Research, 8(6), 839-857.

Kerr, S. M., \& McIntosh, J. B. (2000). Coping when a child has a disability: Exploring the impact of parent-to-parent support. Childcare, Health and Development, 26(4), 309-322.

Knoche, L., Peterson, C. A., Pope Edwards, C., \& Jeon, H. J. (2006). Child care for 
FATHERS OF CHILDREN WITH SHCN 133

children with and without disabilities: The provider, observer, and parent perspectives. Early Childhood Research Quarterly, 21, 93-109.

Kossek, E. E. \& Lautsch, B. (2008). CEO of me: Creating a life that works in the flexible job age. Philadelphia, PA: Pearson/Wharton School Publishing.

Kossek, E. E., Lautsch, B. A., \& Eaton, S. C. (2006). Telecommuting, control, and boundary management: Correlates of policy use and practice, job control, and work-family effectiveness. Journal of Vocational Behavior, 68, 347367.

Kuhltau, K., Smith Hill, K., Yucel, R., \& Perrin, J. M. (2005). Financial burden for families of children with special health care needs. Maternal and Child Health Journal, 9(2), 207-218.

Krivelyova, A., \& Stephens, R. (2005). Caregivers of children in systems of care: Economic outcomes. 17th Annual Conference Proceedings - A System of Care for Children's Mental Health: Expanding the Research Base, (pp. 271276). Tampa, FL: University of South Florida.

Lapierre, L. M., \& Allen, T. A. (2006). Work-supportive family, family-supportive supervision, use of organizational benefits, and problem-focused coping: Implications for work-family conflict and employee well-being. Journal of Occupational Health Psychology, 11(2), 169-181.

Larson, J. E., \& Corrigan, P. (2008). The stigma of families with mental illness. Academic Psychiatry, 32, 87-91.

Laughlin, L. (2013). Who's minding the kids? Child care arrangements: Spring 2011. Current Population Reports, (pp. 70-135). Washington, DC: U. S. Census Bureau. 
Lewis, S., Kagan, C., \& Heaton, P. (2000a). Dual-earner parents with disabled children: Family patterns for working and caring. Journal of Family Issues, 20(8), 1031-1060.

Lewis, S, Kagan, C., \& Heaton, P. (2000b). Managing work-family diversity for parents of disabled children. Personnel Review, 29(3), 417- 430.

Lewis, S., Kagan, C., Heaton, P., \& Cranshaw, M. (1999). Economic and psychological benefits from employment: The experiences and perspectives of mothers of disabled children. Disability \& Society, 14(4), $561-575$

Lewis, S., Rapoport, R., \& Gambles, R. (2003). Reflections on the integration of paid work and the rest of life. Journal of Managerial Psychology, 18(8), 824-841.

Lukemeyer, A., Meyers, M., \& Smeeding, T. (2000). Expensive children in poor families: Out-of-pocket expenditures for the care of disabled and chronically ill children in welfare families. Journal of Marriage and the Family, 62, 399-415.

Lynch, F., \& Dickerson, J. (2012). PS2-21: Validity and reliability of the family economic impact interview: A new instrument to measure costs related to child mental health conditions. Clinical Medical Research, 10(3), 1-81.

MacCallum, R. C., Zhang, S., Preacher, K. J., \& Rucker, D. D. (2002). On the practice of dichotomization of quantitative variables. Psychological Methods, 7(1), $19-40$.

Margolis, M. L. (1984). Mothers and such: Views of American women and why they changed. Berkeley and Los Angeles, CA: University of California Press. 
McCabe, K., Yeh, M., Lau, A., Garland, A., \& Hough, R. (2005). Racial/ethnic differences in caregiver strain and perceived social support among parents of youth with emotional and behavioral disorders. Mental Health Services Research, 5, 137-148.

McLennan, C. J., Moyle, B. D., Ruhanen, L. M., \& Ritchie, B. W. (2013). Developing and testing a suite of institutional indices to underpin the measurement and management of tourism destination transformation. Tourism Analysis, $18,157-171$.

McPherson, M. et al. (1998). A new definition of children with special health care needs. Pediatrics, 102(1), 137-140

Michel, S. (2011). The history of child care in the U.S. Retrieved from: http://www.socialwelfarehistory.com/programs/child-care-theamerican-history/

Moen, P. (2011). From 'work-family' to the 'gendered life course' and 'fit': Five challenges to the field. Community, Work, \& Family, 14 (1), 81-96.

Moen, P., Kelley, E. L., \& Huang, R. (2008a). "Fit" inside the work-family black box: An ecology of the life course, cycles of control reframing. Journal of Occupational and Organizational Psychology, 81, 411-433.

Moen, P., Kelly, E .L., \& Huang, Q. (2008b). Work, family, and life-course fit: Does control over work time matter? Journal of Vocational Behavior, 7, 414425.

Moodie-Dyer, A. (2011). A policy analysis of child care subsidies: Increasing quality, access and affordability. Children and Schools 33(1), 37-45. Retrieved from: http://www.socialworkers.org/ 
Mooi, E., \& Sarstedt, M. (2011). Cluster analysis. In E. Mooi \& M. Sarstedt, $A$ concise guide to market research, (pp. 237-284). Berlin, Heidelberg, Germany: Springer Verlag.

Morell, L., \& Tan, R. J. B. (2009). Validating for use and interpretation: A mixed methods contribution illustrated. Journal of Mixed Methods Research, 3(3), $242-264$.

Munir, F. Leka, S., \& Griffiths, A. (2005). Dealing with self-management of chronic illness at work: Predictors for self-disclosure. Social Science \& Medicine, 60, 1397-1407.

National Survey of Children with Special Health Care Needs. (2009/2010). Retrieved from: http://www.childhealthdata.org

National Survey of Midlife Development in the United States (MIDUS). (19951996). Retrieved from: http://www.midus.wisc.edu

Neal, M. B., Chapman, N. J., Ingersoll-Dayton, B., \& Emlen, A. C. (1993). Balancing work and caregiving for children, adults, and elders. Newbury Park, CA: Sage.

Nomaguchi, K. M. (2012). Marital status, gender, and home-to-job conflict among employed parents. Journal of Family Issues, 33(3), 271-294.

O’Connor, D. L. (2008). Toward empowerment. Revisioning family support groups. Social Work with Groups, 25(4), 37-56.

Pallant, J. (2010). SPSS survival manual: A step by step guide to data analysis using SPSS (4th ed.). Berkshire, England: Mc Graw-Hill.

Palley, E., \& Shdaimah, C. S. (2014). In our hands: The struggle for U.S. child care policy. New York, NY: New York University Press. 
FATHERS OF CHILDREN WITH SHCN 137

Pedulla, D. S., \& Thébaud, S. (2015). Can we finish the revolution? Gender, workfamily ideals, and institutional constraints. American Sociological Review, 80(1), 116-139.

Peduzzi, P., Concato, J., Kemper, E., Holford, T. R., \& Feinstein, A. R. (1996). A simulation study of the number of events per variable in logistic regression analysis. Journal of Clinical Epidemiology, 49(12), 1373-1379.

Perry-Jenkins, M., Repetti, R. L., \& Crouter, A. C. (2000). Work and family in the 1990s. Journal of Marriage and the Family, 62(4), 981-998.

PEW Research Center (2013). The rise of single fathers: A ninefold increase since 1960. Retrieved from: http://www.pewsocialtrends.org/2013/07/02/the-rise-of-singlefathers/

Pitt-Catsouphes, M., MacDermid, S. M., Schwarz, R., \& Matz, C. (2006). Community contexts: The perspectives and adaptations of working parents. American Behavioral Scientist, 49, 1-22.

Porterfield, S. L. (2002). Work choices of mothers in families with children with disabilities. Journal of Marriage and Family, 64, 972 - 981.

Power, A. (2008). Caring for independent lives: Geographies of caring for young adults with intellectual disabilities. Social Science \& Medicine, 67, 834-843.

Powers, E. T. (2003). Children's health and maternal work activity: Estimates under alternative disability definitions. The Journal of Human Resources, 38(3), 523-556.

Prinz, R., \& Miller, G. E. (1994). Family-based treatment for childhood antisocial 
FATHERS OF CHILDREN WITH SHCN 138

behavior: Experimental influences on dropout and engagement. Journal of Consulting and Clinical Psychology, 62(3), 645-650.

Rosenzweig, J. M., Barnett, R. C., Huffstutter, K. J ., \& Stewart, L. M. (2008). Worklife integration: History, theory, and strategy. In J. M. Rosenzweig \& E. M. Brennan, Work, life, and the mental health system of care, (pp. 89-115). Baltimore, MD: Paul H. Brookes.

Rosenzweig, J. M., Brennan, E. M., Huffstutter, K. J., \& Bradley, J. R. (2008). Child care and employed parents of children with emotional or behavioral disorders. Journal of Emotional and Behavioral Disorders, 16 (2), 78-89.

Rosenzweig, J. M., Brennan, E. M., \& Malsch, A. M. (2009). Breaking the silence: Parents' experiences of courtesy stigmatization in the workplace. Focal Point, 23(1), 29-31.

Rosenzweig, J. M., Brennan, E. M., \& Ogilvie, A. M. (2002). Work-family fit: Voices of parents of children with emotional and behavioral disorders. Social Work, 47(4), 415-424.

Rosenzweig, J. M., Roundtree, L. T., \& Huffstutter, K. J. (2008). Work-life integration barriers and supports. In J. M. Rosenzweig \& E. M. Brennan, Work, life, and the mental health system of care, (pp. 143-174). Baltimore, MD: Paul H. Brookes.

Roundtree, L., \& Lynch, K. (2006). Exploring the complexities of exceptional caregiving: Executive briefing series. Boston, MA: Boston College, Center for Work \& Family. Retrieved from: http://www.bc.edu/content/dam/files/centers/cwf/research/publicatio ns/pdf/exceptional_caregiving_ebs.pdf. 
FATHERS OF CHILDREN WITH SHCN 139

Rudman, L. A, \& Mescher, K. (2013). Penalizing men who request a family leave: Is flexibility stigma a femininity stigma? Journal of Social Issues, 69(2), $322-340$.

Ryan, S. (2005). 'Busy behaviour' in the 'land of the golden M': Going out with learning disabled children in public places. Journal of Applied Research in Intellectual Disabilities, 18, 65-74.

Sax, L. J., Gilmartin, S. K., \& Bryant, A. N. (2003). Assessing response rates and nonresponse bias in web and paper surveys. Research in Higher Education, 44(4), 409-432.

Shilling, V., Morris, C. Thompson-Coon, J. , Ukoumunne, O., Rogers, M., \& Logan, S. (2013). Peer support for parents of children with chronic disabling conditions: A systematic review of quantitative and qualitative studies. Developmental Medicine and Child Neurology, 55, 602-609.

Schilling, V., Petermann, F., \& Hampel, P. (2006). Psychosoziale Situation bei Familien von Kindern mit ADHS. Zeitschrift für Psychologie und Psychotherapie, 54(4), 293 - 301.

Schoeder, C. E., \& Remer, R. (2007). Perceived social support and caregiver strain in caregivers of children with Tourette's Disorder. Journal of Child and Family Studies, 16, 888-901.

Schuh, D. (2008). Kohärenzgefühl, Stresserleben und Partnerschaftsqualität der Eltern chronisch kranker und psychisch auffälliger Kinder. Diplomarbeit, Universität Wien. Retrieved from: http://othes.univie.ac.at/3102/1/2008-12-01_0101284.pdf.

Siegrist, J., Starke, D., Chandola, T., Godin, T., Marmot, M., Niedhammer, I., Peter, 
FATHERS OF CHILDREN WITH SHCN 140

R. (2004). The measurement of effort-reward imbalance at work:

European comparisons. Social Science \& Medicine, 58, 1483-1499.

Skok, A., Harvey, D., \& Reddihough, D. (2006). Perceived stress, perceived social support, and wellbeing among mothers of school-aged children with cerebral palsy. Journal of Intellectual \& Developmental Disability, 31(1), $53-57$.

Singleton, R. C., \& Straits, B. C. (2010). Research ethics. In R. C. Singleton \& B. C. Straits, Approaches to social research, (pp. 47-76). New York, NY: Oxford University Press.

Steinfels, M. (1973). Who's minding the kids? The history and politics of day care in America. New York, NY: Simon and Schuster

Stewart, L. M. (2013). Family care responsibilities and employment: Exploring the impact of type of family care on work-family and family-work conflict. Journal of Family Issues, 34(1), 113-138.

Sweet, S., Swisher, R., \& Moen, P. (2005). Selecting and assessing the familyfriendly community: Adaptive strategies of middle-class, dual-earner couples. Family Relations, 54, 596 - 606.

Towers, C. (2009). Recognising fathers. A national survey of fathers who have children with leaning disabilities. London, United Kingdom: Mental Health Foundation.

Traustadottir, R. (1991). Mothers who care: Gender, disability, and family life. Journal of Family Issues, 12(2), 211-228.

Underwood, D., Kim, H., \& Matier, M. (2000). To mail or to web: Comparisons of 
FATHERS OF CHILDREN WITH SHCN 141

survey response rates and respondent characteristics. Cincinnati, $\mathrm{OH}$ :

Annual Forum of the Association for Institutional Research.

Van Horn, M. L., Bellis, J. M., \& Snyder, S. W. (2001). Family resource scale-

revised: Psychometrics and validation of a measure of family resources in a sample of low-income families. Journal of Psychoeducational Assessment, $19,54-68$.

Vespa, J., Lewis, J. M., \& Kreider, R. M. (2013). America's families and living arrangements: 2012. Washington, DC: U. S. Census Bureau.

Voydanoff, P. (2002). Linkages between the work-family interface and work, family, and individual outcomes. Journal of Family Issues, 23(1), 138-164.

Voydanoff, P. (2005a). Social integration, work-family conflict and facilitation, and job and marital quality. Journal of Marriage and Family, 67(3), 666679.

Voydanoff, P. (2005b). The differential salience of family and community demands and resources for family-to-work conflict and facilitation. Journal of Family and Economic Issues, 26(3), 395-417.

Voydanoff, P. (2005c). The effects of community demands, resources, and strategies on the nature and consequences of the work-family interface: An agenda for future research. Family Relations, 54, 583-595.

Voydanoff, P. (2005d). Toward a conceptualization of perceived work-family fit and balance: A demands and resources approach. Journal of Marriage and Family, 67, 822-836.

Voydanoff, P. (2005e). Work demands and work-to-family and family-to-work 
FATHERS OF CHILDREN WITH SHCN 142

conflict: Direct and indirect relationships. Journal of Family Issues, 26(6), 707-726.

Voydanoff, P. (2007). Work, family, and community: Exploring interconnections. Mahwah, NJ: Lawrence Erlbaum.

Weist, M. D., Lowie, J. A., Flaherty, L. T., \& Pruitt, D. (2001). Collaboration among the education, mental health, and public health systems to promote youth mental health. Psychiatric Services, 52(10), 1348-1351.

Williams, J. C. (2000). Unbending gender: Why family and work conflict and what to do about it. New York, NY: Oxford University Press.

Williams, J. C. (2010). Reshaping the work-family debate: Why men and class matter. Cambridge, MA: Harvard University Press.

Williams, J. C., Blair-Loy, M., \& Berdahl, J. L. (2013). Cultural schemas, social class, and the flexibility stigma. Journal of Social Issues, 69(2), 209-234. 


\section{Appendix A: Survey}

\section{Portland State University \\ Informed Consent Cover Letter for Anonymous Surveys:}

\section{Fathers caring for children with special health care needs: Experiences of work-life fit}

This study is being conducted by Claudia Sellmaier, who is a doctoral student at Portland State University. The purpose of the study is to learn more about how employed fathers of children with special health care needs combine work and parenting responsibilities. As an employed father caring for one or more children with special health care needs, you are invited to participate in this study. Your participation will include completing an online survey that asks about the resources and challenges you might be experiencing in your work, family, and community. The survey will take about 15 minutes to complete. Your participation in the study is completely voluntary, and you may choose not to participate. Please be assured that your name or any other identifying information is not associated with the survey. All data will be kept for 3 years in a locked file in the researcher's office and in a password-secured file and then destroyed. One example of survey item includes indicating your level of agreement with a statement such as: "I have the schedule flexibility I need to manage work and family life". You can refuse to answer any of the questions at any time. There are no known risks in this study, but some individuals may experience minor emotional discomfort when answering some of the questions. You may enter to win a $\$ 25$ gift certificate. The findings from this study are intended to provide important information about how employed fathers experience the challenges of meeting work responsibilities while caring for children with special health care needs, as well as the necessary resources in the workplace and community to support work-life fit. This knowledge can better inform service delivery and workplace policies and practices. Any publications or presentations will use results in summary form only. 
If you have any questions about this research project, please feel free to call or e-mail. If you have questions regarding your legal rights as a research subject, you may call the PSU Office of Research Integrity at (503) 725-2227. Thank you for your consideration.

Sincerely, Claudia Sellmaier

Doctoral student

1. I have read and understand the above consent form and desire of my own free will to participate in this study.

○ Yes

○ No

\section{Welcome to the Employed Fathers' Work-Life Fit and Exceptional Care}

Study! The first few questions will be screening questions to make sure that you are eligible to participate in this survey. For clarification:

A child with special health care needs is a child that has a chronic physical, developmental, behavioral, or emotional condition who needs health and other services that go beyond what children generally need.

2. Are you a father or male caregiver of a child or children under the age 18 with special health care needs?
○ Yes
○ No

3. Do you live in the home full-time with the child or children with special health care needs?
○ Yes
○ No

3.1. Do you live in the home part-time with the child with special health care needs?

○ Yes

○ No 
4. Check which employment status best describes your situation?

○ Self-employed

- Employed full-time (at least 30 hours)

○ Employed part-time (between 15 and 30 hours)

○ Not employed

The following questions will ask about your workplace, your family situation, your community and how well these pieces work together in your life.

5. How many hours of paid employment did you work in your last full work week? Please enter the number below.

6. How long does it take you on average to get from your home to your workplace? Please enter the number of minutes below.

7. Which type of work schedule best describes your work situation?

- Standard full-time

○ Flexible work hours

- Compressed work week (such as four 10 hour days or three 12 hour days)

○ Job sharing (part-time)

○ Other part-time

8. Do you have the flexibility to make short-notice schedule changes?
○ Yes
○ No

9. Do you have the flexibility to work from some other place than your workplace, for example your home?
○ Yes
○ No 
10. How difficult is it for you to take time off during workday for personal/family matters?
- Not at all difficult
○ Not too difficult
○ Somewhat Difficult
○ Very difficult

11. Do you have access to at least five paid days off per year to care for sick child(ren)?
○ Yes
○ No

12. Do you believe that employees in your organization are less likely to advance if they are using flexible work options such as telecommuting or compressed work week?
○ Strongly agree
- Somewhat agree
○ Somewhat disagree
○ Strongly disagree

13. How would you rate your overall access to workplace flexibility?
$\circ$ High
○ Moderate
○ Low

14. How would you rate your overall use of workplace flexibility?
○ High
○ Moderate
○ Low

15. Do you think that caring for your child or children with special health care needs has negatively impacted your career?
○ Definitely
○ Somewhat
○ A little
○ Not at all 
16. How would you rate your overall supervisor support for family/personal matters?
$\circ$ High
○ Moderate
○ Low

17. How would you rate your overall coworker support?
$\circ$ High
○ Moderate
○ Low

The following questions will ask about your family situation.

18. Which of the following best describes your situation?
- Married
- Partners and living together
○ Partners and NOT living together
○ Single
○ Widowed
○ Divorced
○ Legal separation

19. If you are married or partnered, is your spouse or partner employed?
○ Yes
○ No

19.1. How many hours a week does your spouse or partner spend in paid employment on average? Please enter the number below.

20. Do you have someone with whom you can share home and care responsibilities?
○ Yes
○ No 
21. In your family who takes responsibility for childcare?
○ I do completely
○ Mostly I do
$\circ$ Equally shared
- Mostly spouse/partner or other
- Spouse/Partner or other does completely

22. In your family who takes responsibility for care coordination for the child or children with special health care needs?
○ I do completely
○ Mostly I do
- Equally shared
○ Mostly spouse/partner or other
- Spouse/Partner or other does completely

23. How much flexibility do you have in your family schedule to handle work responsibilities?
- A lot of flexibility
○ Some flexibility
○ Hardly any flexibility
○ No flexibility at all

24. How much flexibility do you have in your family schedule to handle childcare responsibilities?
- A lot of flexibility
○ Some flexibility
○ Hardly any flexibility
○ No flexibility at all 
The following questions will ask about resources in your community.

25. On a scale of 0 (not at all helpful) - 10 (almost always helpful) how well do the following resources help you to work and take care of your family? Childcare

0-------1-------2--------3-------4--------5------6-------7--------8--------9-------10 N/A

School

0-------1-------2-------3-------4--------5------6-------7--------8--------9-------10 N/A

After-school care

0-------1-------2-------3-------4--------5------6-------7--------8--------9-------10 N/A

Public transportation

0-------1-------2-------3-------4--------5------6-------7--------8--------9-------10 N/A

Health services including primary care, mental health services, or specialized health services

0-------1-------2--------3-------4-------5------6-------7--------8--------9-------10 N/A

26. How would you rate the availability of services and resources in your community to better integrate your work and family life?

○ High

○ Moderate

○ Low

27. How much do you agree with the following statement: I have the support I need from friends and neighbors when I have a personal problem.

○ Strongly agree

- Agree

- Disagree

- Strongly Disagree 
28. In general, how easy or difficult is it for you to combine work demands with family responsibilities?
○ Very Difficult
○ Difficult
○ Somewhat Difficult
○ Somewhat Easy
○ Easy
○ Very Easy

29. Has your home life helped you relax and feel ready for the next day's work?
○ Never
○ Rarely
○ Sometimes
○ Most of the time
- All of the time

30. Have the love and respect you get at home made you feel confident about yourself at work?

- Never

○ Rarely

○ Sometimes

○ Most of the time

- All of the time

31. Has talking with someone at home helped you deal with problems at work?
○ Never
○ Rarely
○ Sometimes
- Most of the time
- All of the time 
32. Have responsibilities at home reduced the effort you can devote to your job?
○ Never
○ Rarely
○ Sometimes
- Most of the time
- All of the time

33. Have personal or family worries and problems distracted you when you were at work?
○ Never
○ Rarely
○ Sometimes
○ Most of the time
- All of the time

34. Have activities and chores at home prevented you from getting the amount of sleep you needed to do your job well?
○ Never
○ Rarely
- Sometimes
- Most of the time
- All of the time

35. Has stress at home made you irritable at work?
○ Never
- Rarely
- Sometimes
- Most of the time
- All of the time 
36. Have the skills you use on your job been useful for things you have to do at home?
○ Never
○ Rarely
○ Sometimes
- Most of the time
- All of the time

37. Have the things you do at work helped you deal with personal and practical issues at home?
○ Never
○ Rarely
○ Sometimes
- Most of the time
- All of the time

38. Have the things you do at work made you a more interesting person at home?
○ Never
○ Rarely
- Sometimes
- Most of the time
- All of the time

39. Has having a good day at your job made you a better companion when you get home?
○ Never
○ Rarely
○ Sometimes
○ Most of the time
- All of the time 
40. Has your job reduced the effort you can give to activities at home?
- Never
○ Rarely
○ Sometimes
- Most of the time
- All of the time

41. Has stress at work made you irritable at home?
○ Never
○ Rarely
○ Sometimes
- Most of the time
- All of the time

42. Has your job made you feel too tired to do the things that need attention at home?
○ Never
○ Rarely
- Sometimes
○ Most of the time
- All of the time

43. Have job worries or problems distracted you when you are at home?
○ Never
○ Rarely
- Sometimes
○ Most of the time
- All of the time

44. I have experienced or I expect to experience an undesirable change in my work situation.
○ Very likely
○ Somewhat likely
○ Not very likely
○ Not likely at all 
FATHERS OF CHILDREN WITH SHCN 154

45. How well does your current household income meet your financial needs? Use the following scale of $0-10: 0$ is very inadequate, 5 sometimes adequate and 10 is more than adequate.

Household income

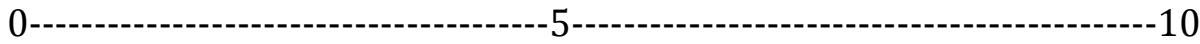

A child with special health care needs is a child that has a chronic physical, developmental, behavioral, or emotional condition who needs health and other services that go beyond what children generally need.

46. Please list the age, gender, ethnicity, relationship to you, and special health care status, and diagnosis of all children who live in your home full-time or part-time. List the oldest child first.

Age Gender Race/Ethnicity Relationship Special health care needs (Yes/No)

1.

2.

3.

4.

If you care for more than one child with special health care needs, please select the child with the more chronic condition to answer the next two questions. If all children have similar conditions, please select the youngest.

47. How often have your child's medical, behavioral, emotional, developmental or other health conditions affected his/her ability to do things other children the same age would do?
○ Never
○ Sometimes
○ Usually
○ Always 
48. How much do your child's medical, behavioral, emotional, developmental or other health conditions affect his/her ability to do things?
- A great deal
○ Some
○ Very little

The following questions help us understand who is completing the survey.

49. What is the highest grade/degree in school that you completed?
- Grade school or less
○ Some high school
○ Graduated from high school
○ Some college
- Graduated from college
○ Some graduate study
- Graduate degree

50 . What is your age in years?

51. How would you identify your race/ethnicity? 
FATHERS OF CHILDREN WITH SHCN 156

52. Which of the categories best approximates your annual household income?
○ Under $\$ 30,000$
○ $\$ 30,000-\$ 39,000$
○ $\$ 40,000-\$ 49,000$
○ $\$ 50,000-\$ 59,000$
○ $\$ 60,000-\$ 69,000$
○ $\$ 70,000-\$ 79,000$
○ $\$ 80,000-\$ 89,000$
○ $\$ 90,000-\$ 99,000$
○ $\$ 100,000-\$ 109,000$
○ $\$ 110,000-\$ 119,000$
○ $\$ 120,000-\$ 129,000$
○ $\$ 130,000-\$ 139,000$
○ $\$ 140,000-\$ 149,000$
○ More than $\$ 150,000$

53. What is your zip code?

54. How did you hear about this survey?

Thank you very much for your time and support! Please forward this survey to anyone you think would be interested in sharing his experience.

If you are willing to be interviewed about your experiences raising a child with special health care needs, please enter your e-mail address or phone number below. I will contact you to schedule the interview. Your e-mail address or phone number will be recorded as a survey item. If you have any questions please feel free to get in touch with me.

Please enter your e-mail address below if you would like to participate in a \$25 Target gift certificate drawing. Your e-mail address will not be connected with your survey information. Thank you so much for your support! 


\section{Appendix B: Codebook}

\begin{tabular}{|c|c|}
\hline Informed consent & $1=$ yes, $2=$ no \\
\hline Screen1_father & $1=$ yes, $2=$ no \\
\hline Screen2_livingfull & $1=$ yes, $2=$ no \\
\hline Screen3_livepart & $1=$ yes, $2=$ no \\
\hline Screen4_employment & $\begin{array}{l}1=\text { s elf-employed, } 2 \text { = full-time, } 3=\text { part-time, } \\
4=\text { not employed }\end{array}$ \\
\hline Weekly_workh & Number \\
\hline Commute & Number \\
\hline Workschedule & $\begin{array}{l}1 \text { = standard full-time, } 2 \text { = flexible work hours, } \\
3 \text { = compressed work week, } 4=\text { job sharing, } 5 \\
=\text { other part-time }\end{array}$ \\
\hline Flextime & $1=$ no, $2=$ yes \\
\hline Flexplace & $1=$ no, $2=$ yes \\
\hline Diff_timeoff & $\begin{array}{l}1=\text { not at all difficult, } 2=\text { not too difficult, } 3= \\
\text { somewhat difficult, } 4=\text { very difficult }\end{array}$ \\
\hline Sickday & $1=$ no, $2=$ yes \\
\hline Careerimpact_flex & $\begin{array}{l}1=\text { strongly agree, } 2=\text { somewhat agree, } 3= \\
\text { somewhat disagree, } 4=\text { strongly disagree }\end{array}$ \\
\hline Access_flex & $1=$ low, $2=$ moderate, $3=$ high \\
\hline Use_flex & $1=$ low, $2=$ moderate, $3=$ high \\
\hline Careerimpact_care & $\begin{array}{l}1=\text { not at all, } 2=\text { a little, } 3=\text { somewhat, } 4= \\
\text { definitely }\end{array}$ \\
\hline Supervisorsupport & $1=$ low, $2=$ moderate, $3=$ high \\
\hline Coworkersupport & $1=$ low, $2=$ moderate, $3=$ high \\
\hline Maritalstatus & $\begin{array}{l}1=\text { married, } 2=\text { partners living together, } 3= \\
\text { partners not living together, } 4=\text { single, } 5= \\
\text { widowed, } 6=\text { divorced, } 7=\text { legal separation }\end{array}$ \\
\hline Employment_partner & $1=$ yes, $2=$ no \\
\hline Whours_partner & Number \\
\hline Schared_homeresp & $1=$ yes, $2=$ no \\
\hline Resp_childcare & $\begin{array}{l}1=\text { I do completely, } 2=\text { mostly I do, } 3=\text { equally } \\
\text { shared, } 4=\text { mostly spouse/partner or other } \\
\text { does, } 5=\text { spouse/partner or other does } \\
\text { completely }\end{array}$ \\
\hline Resp_carecoord & $\begin{array}{l}1=\text { I do completely, } 2=\text { mostly I do, } 3=\text { equally } \\
\text { shared, } 4=\text { mostly spouse/partner or other } \\
\text { does, } 5=\text { spouse/partner or other does } \\
\text { completely }\end{array}$ \\
\hline Familyflex_work & $\begin{array}{l}1=\text { No flexibility at all, } 2 \text { = hardly any } \\
\text { flexibility, } 3=\text { some flexibility, } 4=\text { a lot of } \\
\text { flexibility }\end{array}$ \\
\hline Familyflex_childcare & $\begin{array}{l}1 \text { = No flexibility at all, } 2 \text { = hardly any } \\
\text { flexibility, } 3=\text { some flexibility, } 4=\text { a lot of } \\
\text { flexibility }\end{array}$ \\
\hline
\end{tabular}


FATHERS OF CHILDREN WITH SHCN

\begin{tabular}{|c|c|}
\hline Childcare & Number 0-10 \\
\hline School & Number 0-10 \\
\hline Afterschool & Number $0-10$ \\
\hline Pubtrans & Number $0-10$ \\
\hline Healthcare & Number 0-10 \\
\hline Service_avail & $1=$ low, $2=$ moderate, $3=$ high \\
\hline Friend_sup & $\begin{array}{l}1=\text { I strongly disagree, } 2=\text { disagree, } 3=\text { agree }, \\
4=\text { strongly agree }\end{array}$ \\
\hline Diffcomb & $\begin{array}{l}1=\text { very easy, } 2=\text { easy, } 3=\text { somewhat easy, } 4= \\
\text { somewhat difficult, } 5=\text { difficult, } 6=\text { very } \\
\text { difficult }\end{array}$ \\
\hline P_F_W1 & $\begin{array}{l}1=\text { never, } 2=\text { rarely, } 3=\text { sometimes, } 4=\text { most } \\
\text { of the time, } 5=\text { all of the time }\end{array}$ \\
\hline P_F_W2 & $\begin{array}{l}1=\text { never, } 2=\text { rarely, } 3=\text { sometimes, } 4=\text { most } \\
\text { of the time, } 5=\text { all of the time }\end{array}$ \\
\hline P_F_W3 & $\begin{array}{l}1=\text { never, } 2=\text { rarely, } 3=\text { sometimes, } 4=\text { most } \\
\text { of the time, } 5=\text { all of the time }\end{array}$ \\
\hline N_F_W1 & $\begin{array}{l}1=\text { never, } 2=\text { rarely, } 3=\text { sometimes, } 4=\text { most } \\
\text { of the time, } 5=\text { all of the time }\end{array}$ \\
\hline N_F_W2 & $\begin{array}{l}1=\text { never, } 2=\text { rarely, } 3=\text { sometimes, } 4=\text { most } \\
\text { of the time, } 5=\text { all of the time }\end{array}$ \\
\hline N_F_W3 & $\begin{array}{l}1=\text { never, } 2=\text { rarely, } 3=\text { sometimes, } 4=\text { most } \\
\text { of the time, } 5=\text { all of the time }\end{array}$ \\
\hline N_F_W4 & $\begin{array}{l}1=\text { never, } 2=\text { rarely, } 3=\text { sometimes, } 4=\text { most } \\
\text { of the time, } 5=\text { all of the time }\end{array}$ \\
\hline P_W_F1 & $\begin{array}{l}1=\text { never, } 2=\text { rarely, } 3=\text { sometimes, } 4=\text { most } \\
\text { of the time, } 5=\text { all of the time }\end{array}$ \\
\hline P_W_F2 & $\begin{array}{l}1=\text { never, } 2=\text { rarely, } 3=\text { sometimes, } 4=\text { most } \\
\text { of the time, } 5=\text { all of the time }\end{array}$ \\
\hline P_W_F3 & $\begin{array}{l}1=\text { never, } 2=\text { rarely, } 3=\text { sometimes, } 4=\text { most } \\
\text { of the time, } 5=\text { all of the time }\end{array}$ \\
\hline P_W_F4 & $\begin{array}{l}1=\text { never, } 2=\text { rarely, } 3=\text { sometimes, } 4=\text { most } \\
\text { of the time, } 5=\text { all of the time }\end{array}$ \\
\hline N_W_F1 & $\begin{array}{l}1=\text { never, } 2=\text { rarely, } 3=\text { sometimes, } 4=\text { most } \\
\text { of the time, } 5=\text { all of the time }\end{array}$ \\
\hline N_W_F2 & $\begin{array}{l}1=\text { never, } 2=\text { rarely, } 3=\text { sometimes, } 4=\text { most } \\
\text { of the time, } 5=\text { all of the time }\end{array}$ \\
\hline N_W_F3 & $\begin{array}{l}1=\text { never, } 2=\text { rarely, } 3=\text { sometimes, } 4=\text { most } \\
\text { of the time, } 5=\text { all of the time }\end{array}$ \\
\hline N_W_F4 & $\begin{array}{l}1=\text { never, } 2=\text { rarely, } 3=\text { sometimes, } 4=\text { most } \\
\text { of the time, } 5=\text { all of the time }\end{array}$ \\
\hline Negjobchange & $\begin{array}{l}1=\text { very likely, } 2=\text { somewhat likely, } 3=\text { not } \\
\text { very likely, } 4=\text { not likely at all }\end{array}$ \\
\hline Incomemeetsneeds & $\begin{array}{l}0=\text { very inadequate } 5=\text { sometimes adequate } \\
10=\text { more than adequate }\end{array}$ \\
\hline Childage_1 & Number \\
\hline
\end{tabular}




\begin{tabular}{|c|c|}
\hline Childgender_1 & $1=$ female, $2=$ male \\
\hline Childethnicity_1 & $\begin{array}{l}1=\text { Non-Hispanic White, } 2=\text { Hispanic/Latino, } \\
3=\text { African/American/Black, } 4=\text { Asian/Pacific } \\
\text { Islander, } 5 \text { = Biracial/mixed race }\end{array}$ \\
\hline Childspecialneed_1 & $1=$ yes, $2=$ no \\
\hline Childdiagnosis_1 & $\begin{array}{l}1=\text { ASD primary diagnosis, } 2=\text { CP primary } \\
\text { diagnosis, } 3=\text { mental health, } 4= \\
\text { developmental disability, } 5=\text { chronic physical } \\
\text { disease, } 6=\text { Other }\end{array}$ \\
\hline Childage_2 & Number \\
\hline Childgender_2 & $1=$ female, $2=$ male \\
\hline Childethnicity_2 & $\begin{array}{l}1=\text { Non-Hispanic White, } 2=\text { Hispanic/Latino, } \\
3=\text { African/American/Black, } 4=\text { Asian/Pacific } \\
\text { Islander, } 5=\text { Biracial/mixed race }\end{array}$ \\
\hline Childspecialneed_2 & $1=$ yes, $2=$ no \\
\hline Childdiagnosis_2 & $\begin{array}{l}1=\text { ASD primary diagnosis, } 2=\text { CP primary } \\
\text { diagnosis, } 3=\text { mental health, } 4= \\
\text { developmental disability, } 5=\text { chronic physical } \\
\text { disease, } 6=0 \text { ther }\end{array}$ \\
\hline Childage_3 & Number \\
\hline Childgender_3 & $1=$ female, $2=$ male \\
\hline Childethnicity_3 & $\begin{array}{l}\text { 1 = Non-Hispanic White, } 2=\text { Hispanic/Latino, } \\
3=\text { African/American/Black, } 4=\text { Asian/Pacific } \\
\text { Islander, } 5 \text { = Biracial/mixed race }\end{array}$ \\
\hline Childspecialneed_3 & $1=$ yes, $2=$ no \\
\hline Childdiagnosis_3 & $\begin{array}{l}1=\text { ASD primary diagnosis, } 2=\text { CP primary } \\
\text { diagnosis, } 3=\text { mental health, } 4= \\
\text { developmental disability, } 5=\text { chronic physical } \\
\text { disease, } 6=\text { Other }\end{array}$ \\
\hline Childage_4 & Number \\
\hline Childgender_4 & $1=$ female, $2=$ male \\
\hline Childethnicity_4 & $\begin{array}{l}1=\text { Non-Hispanic White, } 2=\text { Hispanic/Latino, } \\
3=\text { African/American/Black, } 4=\text { Asian/Pacific } \\
\text { Islander, } 5=\text { Biracial } / \text { mixed race }\end{array}$ \\
\hline Childspecialneeds_4 & $1=$ yes, $2=$ no \\
\hline Childdiagnosis_4 & $\begin{array}{l}1=\text { ASD primary diagnosis, } 2=\text { CP primary } \\
\text { diagnosis, } 3=\text { mental health, } 4= \\
\text { developmental disability, } 5=\text { chronic physical } \\
\text { disease, } 6=\text { Other }\end{array}$ \\
\hline Childage_5 & Number \\
\hline Childgender_5 & $1=$ female, $2=$ male \\
\hline Childethnicity_5 & $\begin{array}{l}1 \text { = Non-Hispanic White, } 2=\text { Hispanic/Latino, } \\
3=\text { African/American/Black, } 4=\text { Asian/Pacific } \\
\text { Islander, } 5=\text { Biracial/mixed race }\end{array}$ \\
\hline Childspecialneeds_5 & $1=$ yes, $2=$ no \\
\hline Childdiagnosis_5 & $1=$ ASD primary diagnosis, $2=\mathrm{CP}$ primary \\
\hline
\end{tabular}




\begin{tabular}{|c|c|}
\hline & $\begin{array}{l}\text { diagnosis, } 3=\text { mental health, } 4= \\
\text { developmental disability, } 5=\text { chronic physical } \\
\text { disease, } 6=0 \text { ther }\end{array}$ \\
\hline Childage_6 & Number \\
\hline Childgender_6 & $1=$ female, $2=$ male \\
\hline Childethnicity_6 & $\begin{array}{l}\text { 1 = Non-Hispanic White, } 2=\text { Hispanic/Latino, } \\
3=\text { African/American/Black, } 4=\text { Asian/Pacific } \\
\text { Islander, } 5=\text { Biracial/mixed race }\end{array}$ \\
\hline Childspecialneeds_6 & $1=$ yes, $2=$ no \\
\hline Childdiagnosis_6 & $\begin{array}{l}1=\text { ASD primary diagnosis, } 2=\text { CP primary } \\
\text { diagnosis, } 3=\text { mental health, } 4= \\
\text { developmental disability, } 5=\text { chronic physical } \\
\text { disease, } 6=\text { Other }\end{array}$ \\
\hline $\begin{array}{l}\text { How often child symptoms } \\
\text { affect activities }\end{array}$ & $\begin{array}{l}1=\text { never, } 2=\text { sometimes, } 3=\text { usually, } 4= \\
\text { always }\end{array}$ \\
\hline $\begin{array}{l}\text { How much child symptoms } \\
\text { affect activities }\end{array}$ & $1=$ very little, $2=$ some, $3=$ a great deal \\
\hline Education & $\begin{array}{l}1=\text { grade school or less, } 2=\text { some high school, } \\
3=\text { graduated from high school, } 4=\text { some } \\
\text { college, } 5=\text { graduated from college, } 6=\text { some } \\
\text { graduate study, } 7=\text { graduate degree }\end{array}$ \\
\hline Age_father & Number \\
\hline Race_father & $\begin{array}{l}\text { 1 = Non-Hispanic White, } 2=\text { Hispanic/Latino, } \\
3=\text { African/American/Black, } 4=\text { Asian/Pacific } \\
\text { Islander, } 5=\text { Biracial/mixed race }\end{array}$ \\
\hline Race_twogroup & $\begin{array}{l}0=\text { Non-Hispanic White, } 1=\text { not Non-Hispanic } \\
\text { White }\end{array}$ \\
\hline Income & $\begin{array}{l}1=\text { under } \$ 30,000,2=\$ 30,000-\$ 39,000,3= \\
\$ 40,000-\$ 49,000,4=\$ 50,000-\$ 59,000,5= \\
\$ 60,000-\$ 69,000,6=\$ 70,000-\$ 79,000,7= \\
\$ 80,000-\$ 89,000,8=\$ 90,000-\$ 89,000,9= \\
\$ 100,000-\$ 109,000,10=\$ 110,000-\$ 119,000 \\
11=\$ 120,000-\$ 129,000,12=\$ 130,000- \\
\$ 139,000,13=\$ 140,000-\$ 149,000,14=\text { More } \\
\text { than } \$ 150,000\end{array}$ \\
\hline Zipcode & Number \\
\hline Surveyaccess & Text \\
\hline Interview & $1=$ yes \\
\hline $\begin{array}{l}\text { Jobresources_stand=Flextime+F } \\
\text { lexplace+Access_flex + Use_flex } \\
+ \text { Supervisorsupport + } \\
\text { Coworkersupport + Sickday }\end{array}$ & Number \\
\hline $\begin{array}{l}\text { Homeresources_stand=Employ } \\
\text { ment_partner + Resp_childcare } \\
\text { + Resp_carecoord + } \\
\text { Familyflex_work + }\end{array}$ & Number \\
\hline
\end{tabular}


FATHERS OF CHILDREN WITH SHCN 161

\begin{tabular}{|l|l|}
\hline Familyflex_childcare & \\
\hline $\begin{array}{l}\text { Communityresources_stand= } \\
\text { Service_avail + Friend_sup. }\end{array}$ & Number \\
\hline Interaction_job_home & Number \\
\hline Interaction_job_com & Number \\
\hline Interaction_home_com & Number \\
\hline
\end{tabular}


Appendix C: Recruitment letter

\section{PARTICIPANTS NEEDED FOR RESEARCH}

\section{STUDY:}

\section{EMPLOYED FATHERS RAISING CHILDREN}

\section{WITH SPECIAL HEALTH CARE NEEDS}

You are invited to participate in a study about how fathers of children with special health care needs combine employment and parenting responsibilities. If you are a father or male caregiver of a child with special health care needs and employed at least part-time consider taking a short survey. Help us learn about your unique experiences, challenges, and strategies.

Please click on the link below and share 15 minutes of your time to complete the online survey:

https://portlandstate.qualtrics.com//SE/?SID=SV eP7Qzeu0bZkpmhT

Participation in the survey is confidential and anonymous.

The research is conducted by Claudia Sellmaier, a doctoral student at Portland State University in Portland, OR. Please feel free to contact me if you would like more information. 